\title{
TREASURY RICHNESS
}

Matthias Fleckenstein

Francis A. Longstaff

Working Paper 29081

http://www.nber.org/papers/w29081

\author{
NATIONAL BUREAU OF ECONOMIC RESEARCH \\ 1050 Massachusetts Avenue \\ Cambridge, MA 02138 \\ July 2021
}

Matthias Fleckenstein is with the University of Delaware. Francis A. Longstaff is with the UCLA Anderson School and the NBER. We are grateful for helpful discussions with Steven Wang. All errors are our responsibility. The views expressed herein are those of the authors and do not necessarily reflect the views of the National Bureau of Economic Research.

NBER working papers are circulated for discussion and comment purposes. They have not been peer-reviewed or been subject to the review by the NBER Board of Directors that accompanies official NBER publications.

(C) 2021 by Matthias Fleckenstein and Francis A. Longstaff. All rights reserved. Short sections of text, not to exceed two paragraphs, may be quoted without explicit permission provided that full credit, including $\odot$ notice, is given to the source. 
Treasury Richness

Matthias Fleckenstein and Francis A. Longstaff

NBER Working Paper No. 29081

July 2021

JEL No. G12

\begin{abstract}
$\underline{\text { ABSTRACT }}$
It is widely believed that Treasuries trade at premium prices because of their safety and moneylike properties. In reality, this is only true on a relative basis when compared to other bonds, but is often not true on an absolute basis. Many Treasuries have repeatedly traded at substantial discounts to their intrinsic fair values for extended periods during the past 25 years. Since 2015, Treasuries have consistently been priced at an aggregate discount of $\$ 100$ to $\$ 300$ billion below their fair values. Treasuries often actually become cheaper following crises. These results provide new perspectives on safe-asset theories.
\end{abstract}

Matthias Fleckenstein

University of Delaware

Lerner College of Business and Economics

310 Purnell Hall

Newark, DE 19716

mflecken@udel.edu

Francis A. Longstaff

UCLA

Anderson Graduate School of Management

110 Westwood Plaza, Box 951481

Los Angeles, CA 90095-1481

and NBER

francis.longstaff@anderson.ucla.edu 


\section{INTRODUCTION}

One of the best-known and widely-accepted propositions in asset pricing is that Treasury securities trade at a premium to their actual fair values because of their safety and money-like characteristics. This premium is often termed the convenience yield or near-money premium in the literature, and is also widely known as Treasury "richness" by market participants. Important examples of this literature include Krishnamurthy and Vissing-Jørgensen (2012), Gorton and Ordoñez (2013), Dang, Gorton, and Holmström (2015), Greenwood, Hanson, and Stein (2015), Nagel (2016), He, Krishnamurthy, and Milbradt (2016, 2019), Duffie (2020), Infante (2020), and Brunnermeier, Merkel, and Sannikov (2020).

As it turns out, however, this popular view of the Treasury market is often not true. Many Treasury bills, notes, and bonds have repeatedly traded at significant discounts to their fair values for extended periods during the past 25 years. This may seem surprising in light of the extensive evidence that Treasuries trade at a premium relative to other fixed income securities. ${ }^{1}$ But this is clearly not the same as finding that Treasuries trade at prices greater than their intrinsic fair values. This is because the difference in relative values could simply be due to these other fixed income securities being priced at a discount because of their illiquidity. To test the proposition, we need a way of determining whether Treasury securities are actually priced at a premium on an absolute basis.

This paper presents a new methodology for measuring the richness/cheapness of Treasury securities. The key innovation that allows us to identify the noarbitrage fair value of a Treasury security is the use of the riskfree discounting curve implied from the term structure of swaps tied to the overnight repo rate. Intuitively, this approach can be viewed as a straightforward term-structure extension of Nagel (2016) who uses the three-month repo rate as the riskfree benchmark in estimating the premium in three-month Treasury bills. ${ }^{2}$ An important advantage of this approach is that it allows us to estimate the actual - rather than relative - premia/discounts in Treasury security prices across the entire maturity

\footnotetext{
${ }^{1}$ For example, see Longstaff (2004), Krishnamurthy and Vissing-Jørgensen (2012), Nagel (2016), van Binsbergen, Diamond, and Grotteria (2019), Du, Im, and Schreger (2018), Christensen and Mirkov (2019), Lewis, Longstaff, and Petrasek (2020), and Joslin, Li, and Song (2020).

${ }^{2} \mathrm{He}$, Nagel, and Song (2020) and Klingler and Sundaresan (2020) use an approach similar to Nagel (2016).
} 


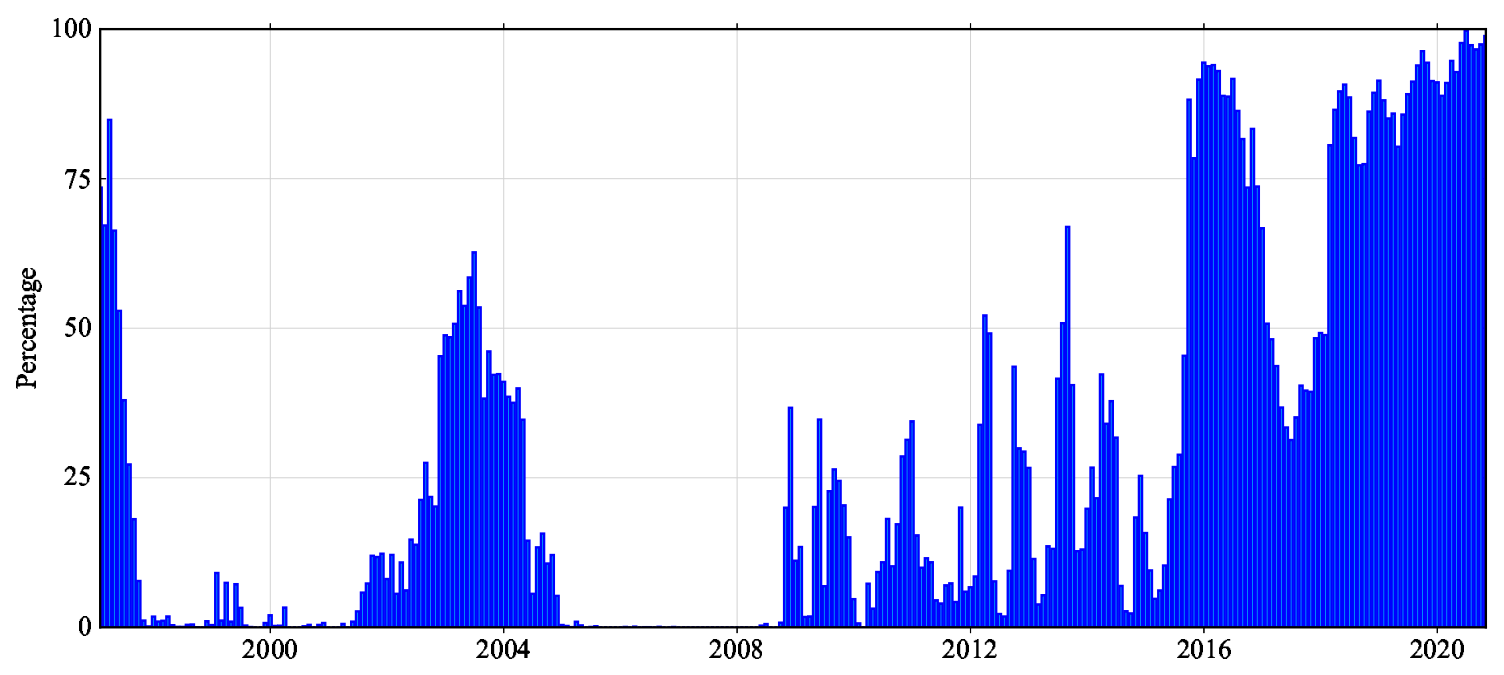

Figure 1. Percentage of Treasury Notes and Bonds Priced Below Their Intrinsic Fair Value.

spectrum.

To illustrate the point that Treasury securities often trade at a discount to their fair values, Figure 1 (reproduced above) plots the percentage of Treasury notes and bonds priced below fair value during the sample period. As shown, there are frequently times when a large fraction of these securities are priced below their intrinsic value, such as the Asian crisis of 1997, the Treasury buybacks of the early 2000s, and virtually the entire 2015-2020 period. Furthermore, the size of these discounts can be very large with some Treasuries trading more than ten percent below their intrinsic value. To put this into perspective, Figure 2 (reproduced below) plots the total dollar richness/cheapness taken over all Treasury securities. As shown, the Treasury market has become consistently cheap since 2015 with an aggregate discount on the order of $\$ 200$ to $\$ 300$ billion. Figure 2 also shows that Treasury securities often become cheaper following crisis events such as the September 2001 attacks, the Lehman bankruptcy of 2008, and the initial stages of the COVID-19 pandemic.

These results pose challenges to popular views about the pricing of Treasury securities. An important advantage of the new perspective provided by this methodology, however, is that it allows us to test directly the implications of a number of recent theoretical models in the literature. One major stream of this literature focuses on the near-money role that Treasury securities play in financial markets. Important examples of this literature imply that Treasury richness may be related to the supply of Treasury debt (Krishnamurthy and Vissing-Jørgensen (2012), Greenwood, Hanson, and Stein (2010, 2015)), international demand (He, Krishnamurthy, and Milbradt (2016, 2019)), or the opportunity cost of holding 


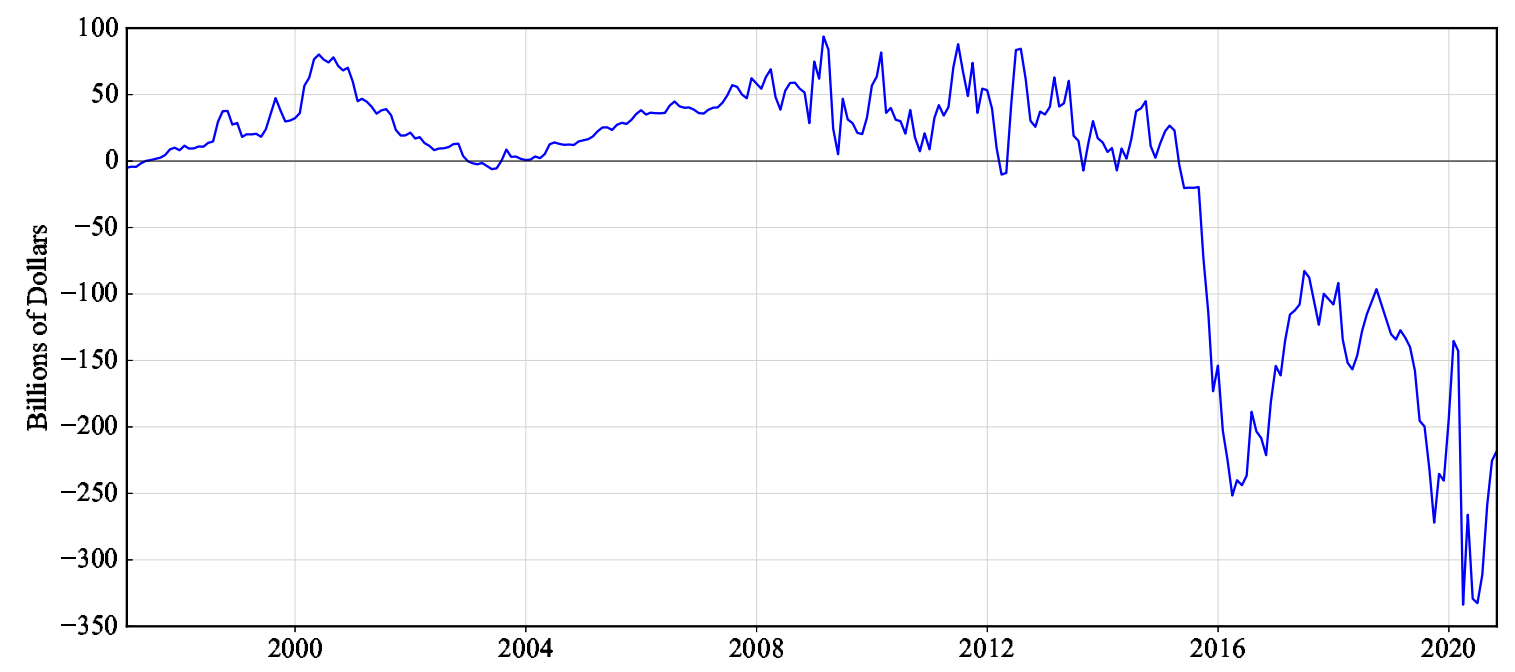

Figure 2. Total Dollar Richness/Cheapness of the Treasury Market.

money (Nagel (2016)). A second stream focuses on the liquidity-of-last-resort role that Treasury securities may play by remaining tradable even during extreme market scenarios when liquidity in other asset markets may dry up. Examples of this flight-to-liquidity literature include Longstaff (2004), Vayanos (2004), Beber, Brandt, and Kavajecz (2009), Krishnamurthy (2010a, 2010b), Musto, Nini, and Schwarz (2018), and Adrian, Crump, and Vogt (2019). We note, however, that neither of these two streams is likely to fully explain the nature of Treasury richness/cheapness since they typically imply exclusively positive premia. In contrast, a third stream focuses on the effects of illiquidity on asset prices and can potentially help explain why some Treasuries may trade at a discount to their fair value when their liquidity is impaired.

We begin by testing the empirical implications of the near-money literature. The empirical tests indicate that Treasury richness is directly related to the opportunity cost of holding money. These results provide strong support for one of the key implications of the model presented in Nagel (2016). In contrast, we find little evidence that Treasury richness is related to the supply of Treasury debt or to foreign demand for Treasury securities. To test these implications at a more fundamental causal level, we make use of several natural experiments in which either the supply of Treasury debt or the money-like nature of Treasury securities varies for exogenous reasons. In particular, we consider the impact on Treasury richness from the increase in the outstanding notional amount of a previously-auctioned Treasury note or bond from a scheduled reopening of the issue, as well as the impact resulting from Treasury notes and bonds crossing the 397-day maturity threshold that allows them to be held by money market 
funds. Again, we find little evidence of supply or elasticity-of-substitution effects on Treasury richness. Finally, we explore whether Treasury richness is related to the demand for other types of near-money assets such as demand deposits, savings accounts, and money market funds. Surprisingly, Treasury richness is more related to the exogenous demand for assets that hedge against extreme shocks to fundamental factors such as inflation and taxes than to the demand for other money-like instruments.

We turn next to testing empirical implications of the liquidity-of-last-resort or flight-to-liquidity literature. If Treasury richness is due to the liquidity-oflast-resort role Treasuries may play, then premia should be related to the risk of extreme shocks. We find a strong relation between changes in the price of gold and subsequent changes in Treasury premia. ${ }^{3}$ We also find significant links between Treasury richness and the returns on assets such as commodities or real estate that are viewed as hedges against inflation. Furthermore, Treasury richness is also related to measures of marginal tax rates as well as fiscal and tax uncertainty. We explore these relations in more depth by using changes in the pattern of Roth IRA conversions as an exogenous instrument for investor concerns about future tax rates. We find a strong relation between Treasury richness and this tax-related instrument.

Finally, we examine some of the implications of the illiquidity literature for Treasury richness/cheapness. In doing this, however, it is important to avoid potential endogeneity issues since prices and trading activity/liquidity may be jointly determined in equilibrium. To address this concern, we use a maturityrelated instrument to capture exogenous changes in the effective float/liquidity of individual Treasury securities. In particular, we examine the impact on Treasury notes and bonds when their time to maturity crosses specific horizons such as two, five, seven, and ten years. Crossing one of these thresholds may impact the availability and liquidity of a Treasury note or bond in the market since many types of financial intermediaries only invest in Treasuries with maturities in a given range. For example, it is common for intermediate bond funds to follow policies such as only investing in bonds with maturities from two to seven years, or from five to ten years. The results provide strong evidence of a causal link between maturity-related liquidity effects and the premium/discount at which a Treasury security trades.

This paper contributes to the literature in several ways. First, we provide a new methodology for measuring the richness of Treasuries on an absolute basis

\footnotetext{
${ }^{3}$ Goldman Sachs has described gold as "the currency of last resort." See https:// www.cnbc.com/2020/03/24/goldman-says-buy-gold-now-time-to-buy-the-curre ncy-of-last-resort.html.
} 
that is applicable to individual securities across the entire maturity spectrum. Second, our results show that a number of widely-held beliefs about the pricing of Treasury securities are not supported by the data. Third, the results indicate that no single factor or current theoretical model is likely to fully explain the intricate time-series and cross-sectional patterns of Treasury richness/cheapness. In particular, we find that the opportunity cost of holding money, the potential to trade in extreme states of the world, and changes in the liquidity of individual securities all appear to be important drivers of Treasury premia/discounts.

This paper also complements and extends important related papers by $\mathrm{Du}$, Im, and Schreger (2018), He, Nagel, and Song (2020), and Klingler and Sundaresan (2020). Du, Im, and Schreger (2018) measure the convenience yield of Treasuries relative to other sovereign debt as deviations from covered interest rate parity and show that Treasuries have cheapened during the post-financial-crisis period. He, Nagel, and Song (2020) and Klingler and Sundaresan (2020) also find that short-term Treasury bills have cheapened relative to other short-term rates in recent years, and particularly during the early stages of the COVID-19 pandemic. We extend this literature significantly by studying the patterns of Treasury richness/cheapness on an absolute basis across the entire range of maturities for all types of Treasury securities over a period spanning nearly 25 years. Our results raise the stakes in this field of research in a major way by showing that deviations of Treasury prices from their fair value are far larger, and more frequent, pervasive, and puzzling in nature than previously documented.

These results have important asset-pricing and policy implications. The evidence that Treasury securities have cheapened dramatically since 2015 could suggest a major shift in the confidence market participants may place in Treasuries as a safe haven. Furthermore, the timing of this large decline in Treasury richness coincides with a number of significant regulatory changes such as the SEC Money Market Fund Reform or the introduction of the Supplementary Leverage Ratio (SLR). This timing raises fundamental questions about the effects of post-financial-crisis capital regulation on Treasury markets and provides indirect support for the theoretical predictions of important recent papers by He, Nagel, and Song (2020) and Klingler and Sundaresan (2020) that highlight the potential impact of intermediary balance-sheet constraints on Treasury convenience yields. On the other hand, the evidence we provide of frequent Treasury discounts occurring prior to the financial crisis suggests that post-crisis capital regulation by itself is unlikely to fully explain the observed patterns of Treasury richness/cheapness.

These results also have clear implications for Treasury debt management. Issuing Treasury securities at a premium to their intrinsic value can be viewed as a type of seigniorage that reduces the overall cost of government debt, while 
the opposite is true for Treasury securities issued at a discount to fair value. The evidence indicates that the yield on long-term Treasury debt has consistently been 30 to 50 basis points above fair value since 2015. This suggests that the Treasury may have significantly increased its effective borrowing costs by not strategically selecting the maturity of the debt securities being issued.

\section{RELATED LITERATURE}

This paper is related to at least three major streams in the literature. For clarity, we designate these as the near-money literature, the liquidity-of-lastresort literature, and the illiquidity literature.

\subsection{The Near-Money Literature}

This stream emphasizes the money-like role that Treasury securities play in financial markets because of their safe-asset, store-of-value, no-questions-asked characteristics. Important examples include Krishnamurthy and Vissing-Jørgensen (2012) who present a model in which agents derive utility directly from holding convenience assets such as Treasury securities. Gorton and Ordoñez (2013) develop a model in which the store-of-value role of safe assets facilitates borrowing, clearing, and settlement in financial markets since these assets represent highquality collateral. Guiband, Nosbusch, and Vayanos (2013) present a clientele model of the optimal maturity structure of government debt. Greenwood, Hanson, and Stein (2015) study optimal government debt maturity in a model where short-term riskless debt provides monetary services to agents. Dang, Gorton, and Holmström (2015) consider the role that the informational sensitivity of a security plays in its valuation. He, Krishnamurthy, and Milbradt (2016, 2019) model the tradeoff between asset safety and the rollover risk associated with short-term debt financing. Nagel (2016) presents a model in which the convenience yield associated with safe assets is a function of the opportunity cost of holding money. Infante (2020) presents a model in which an increase in the demand for safe assets reduces the term premia associated with longer-term Treasury securities. ${ }^{4}$

\subsection{The Liquidity-of-Last-Resort Literature}

This stream emphasizes that Treasuries may be priced at a premium because the highly-liquid nature of the Treasury market allows these securities to play a key

\footnotetext{
${ }^{4}$ Other important examples include Caballero, Farhi, and Gourinchas (2008), Caballero and Krishnamurthy (2009), Greenwood and Vayanos (2014), Cochrane (2015), Duffie (2015), Sunderam (2015), Kacperczyk, Perignon, and Vuillemey (2020), and Duffie (2020).
} 
medium-of-exchange role since they remain tradable even during extreme events in which other asset classes may become partially or completely illiquid. This stream can also be termed the flight-to-liquidity literature. Examples include Longstaff (2004), Beber, Brandt, and Kavajecz (2009), Nagel (2016), Musto, Nini, and Schwarz (2018), Adrian, Crump, and Vogt (2019), He, Nagel, and Song (2020), and Haddad, Moreira, and Muir (2020).

\subsection{The Illiquidity Literature}

Another stream focuses on how market frictions that reduce liquidity may impact the value of securities. A number of papers consider the role of frictions that delay trading as investors search for intermediation in opaque over-the-counter markets. For example, Vayanos and Weill (2008) use a search-based model to study the on-the-run liquidity premium in Treasury securities. Other examples include Wolinsky (1990), Duffie, Gârleanu, and Pedersen (2005, 2007), Vayanos and Wang (2007), Weill (2007), Vayanos and Weill (2008), Duffie and Strulovici (2012), and Duffie, Malamud, and Manso (2015). Other papers consider the impact of network structure on the ability to trade and the timing of execution as investors interact with financial intermediaries. These include Grossman and Miller (1988), Atkeson, Eisfeldt, and Weill (2015), Babus (2016), Di Maggio, Kermani, and Song (2017), Babus and Hu (2017), Farboodi (2017), Babus and Kondor (2018), Sambalaibat (2018), Afonso and Lagos (2019), Neklyudov (2019), and Üslü (2019). A rapidly-growing literature focuses on how balancesheet constraints and regulatory frictions affect the ability of financial intermediaries to make markets and provide liquidity. Examples include Xiong (2001), Kyle and Xiong (2001), Gromb and Vayanos (2002), Brunnermeier and Pedersen (2009), Gârleanu and Pedersen (2011), He and Krishnamurthy (2012, 2013), Brunnermeier and Sannikov (2014), Adrien, Etula, and Muir (2014), He, Kelly, and Manela (2017), Kondor and Vayanos (2019), He, Nagel, and Song (2020), Klingler and Sundaresan (2020), Fleckenstein and Longstaff (2020a), and many others. Finally, other papers focus on factors that potentially drive time variation in the impact of illiquidity on security values. These include Vayanos (1998), Vayanos and Vila (1999), Longstaff (2001, 2009, 2018), Pastor and Stambaugh (2003), Acharya and Pedersen (2005), Chacko, Jurek, and Stafford (2008), and Lewis, Longstaff, and Petrasek (2020). ${ }^{5}$

\footnotetext{
${ }^{5}$ Many papers document that less-liquid Treasury securities can be priced at a discount relative to more-liquid Treasury securities. These include Amihud and Mendelson (1991), Kamara (1994), Duffee (1996), Grinblatt and Longstaff (2000), Jordan, Jorgensen, and Kuipers (2000), Krishnamurthy (2002), Fleckenstein, Longstaff, and Lustig (2014), Musto, Nini, and Schwarz (2018), and Fleckenstein and Longstaff (2020b).
} 


\section{IDENTIFYING TREASURY RICHNESS}

In this section, we describe how Treasury richness/cheapness can be identified using a riskfree discounting curve in conjunction with Treasury credit default swap (CDS) data. The next section then shows how the riskfree discounting curve is inferred from the term structure of repo swaps. ${ }^{6}$

Consider the case of a Treasury note with a coupon rate of $c$ percent and a market price of $\$ 100$. If there were no possibility of default, we could measure its richness by comparing the par price of the note to the sum of the present values of its cash flows discounted using the riskfree discounting curve.

In reality, however, Treasury securities are not completely riskfree and the possibility of default needs to be taken into account. The key intuition behind our approach is that we can effectively convert the Treasury note into a fully riskfree security by buying default protection via a CDS contract. To illustrate this, Table 1 uses a simple replication strategy to show that a long position in a risky Treasury security paying a coupon of $c$ combined with the purchase of CDS protection at a cost of $s$ has the same cash flows as a riskfree bond with a coupon of $c-s$. Thus, we can directly measure the richness of a Treasury security with coupon $c$ by comparing its market price with the present value of the riskfree bond with coupon $c-s$.

One interesting feature of the replication strategy shown in Table 1 is that the maturity of the riskfree bond is actually stochastic. This is because the par amount of the bond is paid at the time of default of the Treasury security, or at its final maturity, whichever is earliest. While this may seem a little unintuitive at first, it is important to recognize that the same situation occurs with any defaultable bond. For example, the final cash flow received from a defaulted corporate bond often occurs at the resolution of the bankruptcy process which can be much earlier than the stated maturity date of the debt.

To show how the stochastic maturity of the riskfree bond is taken into account in calculating its present value, we assume a simple reduced-form Duffie and Singleton (1999) framework in which default is triggered by the first jump of a Poisson process with constant intensity $\lambda$. From the properties of the Poisson process, the probability of no default prior to time $T$ is simply $e^{-\lambda T}$. Further-

\footnotetext{
${ }^{6}$ The Online Appendix provides full details about all of the algorithms and methodology used in this paper to estimate Treasury richness/cheapness. Also see the Online Appendix for a complete description of the data and variables used in the empirical analysis throughout the paper, as well as a listing of all the underlying data sources.
} 
more, the density of the default time $\tau$ is $\lambda e^{-\lambda \tau}$. Conditional on default occurring at time $\tau<T$, the present value of the riskless bond is given by

$$
(c-s) \int_{0}^{\tau} D(t) d t+D(\tau)
$$

where $D(t)$ is the riskfree present value factor for one dollar to be paid at time $t$. Integrating over all default times gives the present value of the riskless bond,

$$
\begin{aligned}
& \int_{0}^{T} \lambda e^{-\lambda \tau}\left((c-s) \int_{0}^{\tau} D(t) d t+D(\tau)\right) d \tau \\
& +e^{-\lambda T}\left((c-s) \int_{0}^{T} D(t) d t+D(T)\right)
\end{aligned}
$$

Given the riskfree discount factors $D(t)$ and the default intensity $\lambda$ (which we bootstrap from the term structure of Treasury CDS spreads), this expression is readily evaluated to give the present value of the riskless bond. The richness of the Treasury security is then determined by comparing this present value to the market price of the Treasury security.

It is important to acknowledge that in using this approach to identify Treasury richness, we are adopting several assumptions. First, we assume that the cash flows associated with the CDS contract are unaffected in the event that the protection seller defaults. This assumption, however, is a minor one since standard industry practice is to require full bilateral collateralization of CDS liabilities. Second, we assume that the market CDS spread is unaffected by the potential default risk of protection sellers. As shown by Arora, Gandhi, and Longstaff (2012), however, this assumption is also a modest one since they show that counterparty credit risk has very little effect on market CDS spreads.

\section{THE RISKFREE DISCOUNTING CURVE}

We next describe how the riskfree discounting curve can be inferred from the term structure of fixed-for-floating interest rate swaps in which the floating leg of the swap is based on the overnight repo rate.

\subsection{The Overnight Repo Rate}

The key to this approach is the recognition that the overnight repo rate can be viewed as a riskfree interest rate in the most basic sense of that term. There 
are several reasons for this. First, overnight general collateral Treasury repo loans are fully secured by the safest and most-liquid collateral in the marketTreasury securities. Second, repo loans are not only fully secured, but are actually overcollateralized because repo borrowers face haircuts and cannot borrow the full value of the Treasuries they provide as collateral. This haircut or margin requirement provides an additional level of safety to the repo lender (Gorton and Metrick (2012), Krishnamurthy, Nagel, and Orlov (2014)). Third, since general collateral Treasury repo loans are purely financial contracts rather than securities, overnight repo rates should be less affected by the various liquidity and supply factors that may drive the specialness of cash market instrument such as Treasuries. Finally, the riskfree nature of collateralized repo contracts has long been recognized in the finance literature. Key examples include Longstaff (2000), Nagel (2016), Du, Im, and Schreger (2018), Klingler and Sundaresan (2020), Infante (2020), and He, Nagel, and Song (2020).

It is also important to observe that the overnight repo rate would continue to represent a riskless rate even if there was a Treasury default. ${ }^{7}$ For example, if the default reduced the value of a Treasury bill from 100 to 20, a repo borrower would likely still be able to borrow, say, 10. From the repo lender's perspective, the repo loan would be sufficiently overcollateralized to remain riskfree. This is consistent with the evidence in Gorton and Metrick (2012) that repo lenders tended to adjust the haircuts on repo collateral during the financial crisis of 2007-2008 while leaving repo rates largely unaffected.

\subsection{Repo Swaps}

As discussed, we identify the riskless discounting curve using the term structure of fixed-for-floating swap rates in which the floating rate is the short-term riskless rate, which we interpret as the overnight repo rate. Since repo swaps may be less familiar than conventional swaps, we begin with a brief introduction to this market and then describe how the data set of repo swap rates is constructed.

A repo swap is a specific case of the set of interest rate swaps commonly referred to as overnight index (OIS) swaps. In a standard fixed-for-floating OIS swap, the counterparties agree to exchange floating rate cash flows based on a geometrically compounded overnight index rate (such as the overnight fed funds rate) for fixed cash flows over the life of the swap. A repo swap is an OIS swap in which the floating index rate is the overnight repo rate.

For repo swaps with maturities of less than one year, both the fixed and

${ }_{7}$ This point is discussed in an important recent paper by Augustin, Chernov, Schmid, and Song (2021) in the context of the effects of defaults on benchmark indexes. 
floating legs have a single cash flow at maturity. For longer-dated swaps, both the fixed and floating legs have annual cash flows. The day-count convention for repo swaps is actual $/ 360$. To illustrate, consider a one-year repo swap with a notional amount of $\$ 100$ and a quoted swap rate of 1.200 percent. In one year (365 days), the fixed rate payer pays $1.200 \times 365 / 360=1.21667$ and receives the compounded repo rate for 365 days. $^{8}$

The current repo swap market is based primarily on a specific construction of the overnight repo rate known as the Secured Overnight Financing Rate (SOFR). SOFR measures the cost of borrowing cash in the repurchase agreement (repo) market via overnight loans collateralized by U.S. Treasury securities. Specifically, SOFR is calculated using a broad basket of transactions from three segments of the $\$ 800$ billion overnight U.S. Treasury repo market. First, Fixed Income Clearing Corporation (FICC) member banks trade general U.S. Treasury collateral repos which are cleared through the FICC's General Collateral Finance (GCF) repo service. Second, FICC members trade repos for specific Treasury securities in the FICC Delivery-versus-Payment (DvP) repo market. Third, in the tri-party repo market, security dealers trade repos with the Bank of New York Mellon acting as the third party. SOFR is calculated each day as the volumeweighted median of overnight repo rates on transactions in the GCF, FICC DvP, and tri-party repo markets. ${ }^{9}$ The Federal Reserve Bank of New York, in cooperation with the Office of Financial Research (OFR), provides SOFR rates going back to August 2014. The Alternative Reference Rates Committee (ARCC) has selected SOFR to become the new benchmark interest rate to replace U.S. Libor in 2022. ${ }^{10}$ SOFR swaps are actively traded in financial markets, either as basis swaps or fixed-for-floating swaps. As of the end of June 2020, the total notional amount of SOFR swaps was estimated to be $\$ 1.30$ trillion.

Because indicative and/or official SOFR rates have only been published since

\footnotetext{
${ }^{8}$ The repo rate for the last day of the compounding period is not known prior to the morning of the expiration day. Hence, the market convention is that repo swaps have a fixing lag of one day and the final payment occurs with a lag of two days. Note that fed funds OIS swaps use the same convention.

${ }^{9}$ The repo rates from all three segments of the repo market are used to calculate SOFR, with the exception of FICC DvP trades with rates falling below the 25th percentile of all FICC DvP data for a given day. The reason for this is that these repos are considered to be "special" and are hence excluded from the calculations.

${ }^{10}$ The Alternative Reference Rates Committee is group of private-market participants convened by the Federal Reserve Board and the New York Federal Reserve Bank to assist in the transition from U.S. Libor. See https://www.newyorkfed. org/arcc.
} 
2014, actual market SOFR swap rate data are only available for the latter part of the sample period. It is straightforward, however, to extend the repo swap data set backwards by making minor adjustments to the rates for OIS swaps based on the overnight fed funds rate. The difference between SOFR and fed funds OIS swap rates is only on the order of several basis points. Since OIS swap data are available from 1997, we can use the adjusted fed funds OIS swap rate data to proxy for repo swap rates over a significantly longer period. The Online Appendix provides full details on how the data set of repo swap rates is constructed from data on repo rates, SOFR, fed funds OIS and Libor swap rates, and Libor/OIS basis swap rates obtained from the Bloomberg system. The resulting data set consists of daily observations of repo swap rates for 1-, 3-, and 6-month, and 1-, 2-, 3-, 5-, 7-, 10-, 15-, 20-, and 30-year maturities for the period from January 23, 1997 to October 30, 2020. Table 2 provides summary statistics for the repo swap rates.

\subsection{Solving for the Riskfree Discount Curve}

To illustrate the intuition, consider the case of a one-year repo swap. Let $r_{t}$ denote the overnight repo rate, and $D(t)$ the present value of a riskfree cash flow of one dollar to be received at time $t$. Assuming continuous cash flows, the floating leg of the swap pays a single cash flow of

$$
\exp \left(\int_{0}^{1} r_{t} d t\right)
$$

in one year. Under the risk-neutral measure, the value of this cash flow is

$$
E\left[\exp \left(-\int_{0}^{1} r_{t} d t\right) \exp \left(\int_{0}^{1} r_{t} d t\right)\right]=1
$$

The fixed leg of the swap pays a single cash flow of $1+F_{1}$ in one year, where $F_{1}$ is the current one-year repo swap rate observed in the market. Since $F_{1}$ is fixed at time zero, the present value of the fixed leg is just $\left(1+F_{1}\right) D(1)$. Because the initial value of the swap is zero, the present value of the fixed leg of the swap equals the present value of the floating leg, which gives

$$
D(1)=\frac{1}{1+F_{1}}
$$

This approach is easily extended to longer maturities. The present value of the floating leg of a swap with cash flows based on $r_{t}$ is likewise one for any swap 
maturity. Setting the present value of the fixed leg of an $N$-year swap equal to one gives the relation,

$$
F_{N} \sum_{i=1}^{N} D(i)+D(N)=1 .
$$

Given the term structure of swap rates $F_{i}, i=2,3, \ldots, 30$, this expression can now readily be solved recursively for the riskfree discount factors $D(i), i=$ $2,3, \ldots, 30$. We then use a standard spline technique to interpolate the riskfree discount factors for any given maturity.

\section{TREASURY RICHNESS ESTIMATES}

Given the riskfree discounting curve, we can now estimate the richness/cheapness of individual Treasury bills, notes, and bonds. The empirical results we report are typically based on the premium which we define as the difference between the yield implied by the market price of the security and the yield implied by its intrinsic fair value which is simply the sum of the present value of its discounted cash flows. In some cases, we also present results based on the price premium which is the difference between the security's market price and its intrinsic fair value. For expositional purposes, it is useful to aggregate the estimates by maturity category and report the results based on the average premia within each category. Accordingly, we report results separately for Treasury bills and for Treasury notes and bonds with maturities of less than 1 year (we exclude maturities of less than 1 month), 1 to 5 years, 5 to 10 years, 10 to 20 years, and 20 to 30 years.

Figure 3 plots the monthly time series of the average premia for the individual categories. As shown, negative values for the premia occur frequently and can persist for extended periods of time. For example, the average premia for a number of the categories are negative at the beginning of the sample period in 1997, during the Treasury buyback period of 2000-2002, during the post-financial-crisis period, and throughout most of the $2015-2020$ period. ${ }^{11}$ Furthermore, the average premia for each of the six categories of Treasury securities take on negative values at some point during the sample period. Figure 4 also shows that Treasury securities do not always richen during financial crises when one might expect a

\footnotetext{
${ }^{11}$ Our results confirm and extend those of He, Nagel, and Song (2020) and Klingler and Sundaresan (2020) who report evidence of negative convenience yields in short-term Treasury bills during the post-financial-crisis period.
} 
flight-to-liquidity to occur. For example, the average premia for all six categories actually decrease significantly in the immediate aftermath of the Lehman default of September 2008. ${ }^{12}$ These results pose challenges to traditional views and beliefs about the nature and source of the premia in Treasury securities.

Table 3 reports summary statistics for the premia. As shown, the average value of the premia is positive across all of the maturity categories, indicating that Treasury securities are rich on average. The results show, however, that there is also wide variation in the average values across maturity categories. In particular, the average for Treasury bills is 25.00 basis points, which is roughly twice the average of 12.71 basis points for Treasury notes and bonds with less than one year to maturity, and is many times larger than the average of 1.75 basis points for Treasury bonds with maturities from 20 to 30 years. Table 3 also shows that the highest average for Treasury notes and bonds is for the 5-10 year category which has an average of 17.03 basis points.

Table 4 reports similar summary statistics for the price premia which are expressed as a percentage of the notional amount of the Treasury securities. As shown, Treasury notes and bonds with maturities from 5 to 10 years are the richest on average, with a mean price premium of 1.121 percent. Note that the average price premia for Treasury bonds with maturities from 20 to 30 years is actually negative. Table 4 also shows that there is wide variation in the price premia, and that longer-maturity Treasury securities can become surprisingly rich or cheap. In particular, the price premia for the longest-maturity category of Treasury bonds range from a low of -21.471 percent to a high of 12.666 percent. Figure 4 plots the time series of price premia/discounts for the $20-30$ year category.

Finally, Table 5 presents the correlation matrix of monthly changes in the average premia for the various maturity categories. In general, the correlations across different maturity categories are surprisingly low. For example, the correlation between changes in the premia of Treasury notes and bonds with less than 1 year to maturity and those for Treasury bonds with maturities from 5 to 30 years is 0.350 or lower. These results make a strong case that Treasury richness is unlikely to be fully explained by any single factor.

\section{TESTING NEAR-MONEY IMPLICATIONS}

An important advantage of having estimates of the absolute richness of Treasury

${ }^{12}$ Klingler and Sundaresan (2020) document a similar result for the convenience yield in short-term Treasury bills. 
securities is that it allows us to test the implications of current theoretical models. In this section, we focus on the implications of several key models in the nearmoney literature.

Krishnamurthy and Vissing-Jørgensen (2012) and Greenwood, Hanson, and Stein (2015) present models in which the safety and liquidity premia in Treasury security prices are directly related to the supply of Treasury debt. Krishnamurthy and Vissing-Jørgensen (2012) identify the ratio of Treasury debt to total GDP as a key determinant of these premia, while Greenwood, Hanson, and Stein (2015) focus on the supply of Treasury bills relative to total GDP. These models share the implication that Treasury richness is a decreasing function of the ratio of Treasury debt to GDP.

He, Krishnamurthy, and Milbradt (2016, 2019) present models in which the rollover risk of Treasury debt affects its potential richness. In these models, global investors coordinate their purchases of sovereign debt in a way that ensures that a specific sovereign borrower is able to roll over its maturing debt, thereby allowing its debt to serve as the safe asset in the market. In turn, this implies that the safety of Treasury debt is directly related to the international demand for Treasury securities. ${ }^{13}$

Finally, Nagel (2016) emphasizes the role that the opportunity cost of holding money may play in determining the demand for Treasury securities as safe assets. In particular, a higher short-term riskless rate increases the opportunity cost of holding money, thereby making interest-bearing Treasury securities relatively more attractive as safe alternatives to money. This implies that Treasury richness should be an increasing function of the level of riskless interest rates.

\subsection{Regression Results}

As a first step in testing the empirical implications of these models, we regress changes in Treasury richness on changes in the factors suggested by these models. Following Krishnamurthy and Vissing-Jørgensen (2012), Greenwood, Hanson, and Stein (2015), Nagel (2016), and others, we use the log ratios of total Treasury debt outstanding to GDP and total Treasury bills outstanding to GDP as measures of debt supply. Following Nagel (2016), we use the fractions of Treasury bills held by foreign investors and of Treasury notes and bonds held by foreign investors as measures of foreign demand. Finally, we again follow Nagel (2016) and use the short-term fed funds rate as the measure of the opportunity cost of holding money.

Table 6 reports the regression results for the individual maturity categories.

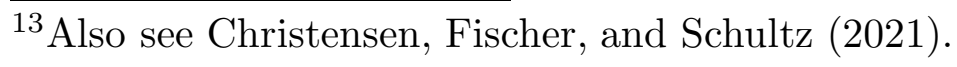


As shown, the results provide little support for the hypotheses that debt supply and foreign ownership are related to Treasury premia. In particular, changes in the supply of short-term and long-term Treasury debt are not significant for any of the maturity categories. Similarly, changes in foreign holdings of Treasury bills and Treasury notes and bonds are not significant for five of the maturity categories. These results parallel those of Nagel (2016) who finds that debt supply and foreign ownership variables are largely subsumed when the opportunity cost of holding money is included in a similar regression for the near-money premium in three-month Treasury bills.

In contrast, the regression results in Table 6 provide strong support for opportunity-cost-of-money hypothesis of Nagel (2016). Specifically, the change in the fed funds rate is significant at either the five- or ten-percent level for five of the six maturity categories. Furthermore, the sign of the coefficient is positive in all six regressions. These empirical results extend those in Nagel (2016) to the full spectrum of maturities from 1 month to 30 years and are all consistent with the opportunity-cost-related implications of his model.

\subsection{Treasury Reopenings}

As another testing approach, we make use of a natural experiment in which the supply of specific Treasury securities increases for purely exogenous reasons. In particular, we examine whether the premium for a Treasury security is affected when the Treasury reopens the issue and auctions an additional amount of that security. The Treasury follows a predictable set pattern in reopening issues. For example, the Treasury follows the pattern of issuing a 30-year bond every three months, and then reopening the issue during the next two subsequent months. Thus, the increases in the outstanding amount of a 30-year Treasury bond resulting from the two reopenings after the initial issuance are fully-anticipated exogenous events unrelated to the richness of the bond. ${ }^{14}$ This aspect provides us a valuable instrument with which we can directly test whether changes in Treasury richness are related to exogenous changes in the supply of debt at a more fundamental causal level.

Table 7 reports the results from panel regressions of the monthly change in the premia for individual Treasury securities on the change in the outstanding amount of that issue resulting from a reopening during the month. Specifically, we regress the change in the premium on the reopening ratio which is defined as the ratio of the change in the outstanding notional amount of a previouslyauctioned Treasury security during a month as a result of a reopening auction divided by the total outstanding notional amount of the security at the end of the

\footnotetext{
${ }^{14}$ The Online Appendix provides a detailed discussion of the Treasury reopening schedule.
} 
previous month. The panel regression also includes a number of control variables such as the coupon rate, the total outstanding amount of the issue, and several maturity-related measures. The regression also includes annual fixed effects.

The results in Table 7 show that there is a marginally significant effect on the premium associated with an increase in the supply of the Treasury security from a reopening. In particular, after controlling for the amount of outstanding debt prior to the reopening, the regression coefficient for the reopening ratio is significant at the ten-percent level. The sign of the coefficient, however, is positive which is not consistent with the existing theoretical models focusing on debt supply. Thus, these results provide little support for the specific debt-supply models presented in the literature. In contrast, since an increase in the outstanding amount of a Treasury security likely increases the availability and liquidity of the security in the market, these results can be interpreted as being consistent with liquidity/illiquidity types of models of Treasury richness/cheapness.

\subsection{The 397-Day Money Market Fund Inclusion Criterion}

An interesting additional implication of the Nagel (2016) model is that the nearmoney premium for an individual security is directly related to the elasticity of substitution between money and that security. To explore this, we make use of another natural experiment in which the elasticity of substitution of a Treasury security changes exogenously as it becomes eligible to be held by a money market fund (MMF).

SEC Rule 2a-7(c)(2) places a number of maturity-related constraints on MMF portfolios. For example, the dollar-weighted average maturity of the securities owned by a MMF may not exceed 60 days, and the dollar-weighted average life to maturity may not exceed 120 days. The SEC's MMF Reform of 2014 also introduced new requirements for daily and weekly liquid assets and concentration limits on portfolio holdings. ${ }^{15}$

In this section, we focus on a specific requirement of SEC Rule 2a-7(c)(2) that prohibits MMFs from acquiring any security with a remaining maturity greater than 397 days. Because of this requirement, a Treasury security that today has a maturity of 398 days is ineligible to be held by MMFs. The same Treasury security, however, would be fully eligible to held by a MMF tomorrow when its maturity becomes 397 days. We would expect, however, that Treasury securities that are eligible for inclusion in a MMF would have higher elasticities of substitution with respect to money than ineligible Treasury securities. ${ }^{16}$ In turn,

\footnotetext{
${ }^{15}$ The Online Appendix provides a detailed discussion of MMFs, their regulation, and the SEC's MMF Reform.

${ }^{16}$ For example, recall that MMFs are specifically included in the definition of the
} 
this means that the simple mechanical event of a Treasury security crossing the 397-day threshold for inclusion in a MMF portfolio allows us to identify an exogenous change in the elasticity of substitution for individual Treasury securities.

To test the elasticity-of-substitution implications of Nagel (2016), we conduct a difference-in-differences analysis in which we use the event of crossing the 397-day threshold as the instrument. Specifically, we examine how the premium/discount of a Treasury note or bond changes (first difference) as the maturity of the security crosses the 397-day threshold (second difference). In doing this, we use an event study approach in which we control for market effects in measuring the change in the premium as the Treasury note or bond becomes eligible for inclusion. This is done by first computing the daily change in the average premium for all Treasury notes and bonds with maturities between 10 and 18 months (excluding securities with maturities within the event window), and then subtracting this change from the daily change in the premium of the Treasury note or bond defining the event. Thus, the difference-in-differences analysis focuses on the market-adjusted change in the premium of a security as it becomes eligible to be held by money market funds. Note that eligibility is determined solely by the exogenous maturity of the security and is independent of the richness of the security.

Table 8 reports the results for the individual and cumulative changes in the premia over an event window spanning the ten days before and after the Treasury note or bond first satisfies the money market fund 397-day inclusion criterion. There are 840 events in which the maturity of a Treasury note or bond crosses the 397-day threshold for money market fund eligibility. As shown, the change on the event date is not statistically significant. Similarly, the cumulative change over the event window is -0.329 basis points and is not significant. Furthermore, the signs of the event-date change and the cumulative change are both negative. In contrast, we would expect that the elasticity of substitution for a Treasury note or bond should increase as it becomes eligible for inclusion. In turn, the results in Nagel (2016) imply that the premium should then increase as the Treasury security crosses the 397-day threshold. Thus, these empirical results again pose a challenge to the hypothesis that the premia are a reflection of the money-like characteristics of Treasury securities.

\subsection{The Demand for Near-Money Assets}

In light of the puzzling results of the previous section, it is worthwhile to take a closer look at the underlying premise that the premia in Treasury securities are related to the demand for the near-money characteristics of these securities.

M2 money supply measure. 
As one way of doing this, we explore whether the richness of Treasury securities is related to the observed demand for other types of money-like investments. If the premia in Treasury securities are due to the value investors place on their near-money aspects, we would anticipate that these premia would increase during periods in which the demand for other types of money-like investment vehicles increases.

To pursue this line of inquiry, we follow a similar approach as before and regress changes in the average premia on changes in the aggregate amounts of money-like instruments held by investors including demand deposits, time deposits, savings deposits, money market funds, and fixed income mutual funds. Table 9 reports the results from the regressions for individual maturity categories.

The results in Table 9 are surprising in that there is little evidence that changes in Treasury premia are related to the demand for the most money-like of the other types of assets. In particular, few of the regression coefficients for changes in demand deposits, time deposits, saving deposits, or for any of the four categories of money market funds are significant. If the premia in Treasury securities were directly related to their money-like role, we would expect that the strongest relation would occur for short-term close-to-money assets such as demand, time, and saving deposits and money market funds since these are all components of the money supply measure M2. In actuality, the situation is almost the opposite.

Specifically, Table 9 shows that there is a strong relation between changes in Treasury premia and changes in the amount of assets held by inflation-related mutual funds. In particular, the coefficient for the change in inflation-related mutual funds is positive and significant for five of the maturity categories. Flows into inflation-related mutual funds can be viewed as an exogenous instrument for investor concerns about future inflation rates.

Similarly, there is also a strong relation between changes in Treasury premia and changes in the amount of assets held by mutual funds that invest in municipal bonds issued by a specific state. Note that interest income received from these funds would typically be exempt from income taxation at the Federal level and by the state in which the municipal bonds are issued. ${ }^{17}$ Thus, these types of funds are targeted towards investors who are more concerned about minimizing taxes by holding only municipal bonds issued within a specific state than they are about holding a more diversified portfolio of municipal bonds. Table 9 shows that the coefficient for changes in the amount of assets held by state municipal bond mutual funds is significant for all but the two shortest maturity categories. Flows into these state municipal bond mutual funds can also be viewed as an

${ }^{17}$ The Online Appendix describes the taxation of municipal bonds in more depth. 
exogenous instrument for investor concerns about future tax rates.

In summary, these empirical results parallel those in the previous section that raise questions about whether Treasury richness is directly related to the money-like properties of these securities. On the other hand, the mutual fund results hint at the possibility of a relation between Treasury richness and concerns about obtaining liquidity during extreme events that might also be associated with major shocks to inflation, tax rates, etc. We explore this possibility in the next section.

\section{TESTING LIQUIDITY-OF-LAST-RESORT IMPLICATIONS}

We turn next to examining the implications of the liquidity-of-last-resort or flightto-liquidity literature. Recall that this literature suggests that Treasury richness may reflect the premium investors are willing to pay for a safe asset that continues to be tradable even during extreme events in which the liquidity in other asset markets might disappear. In turn, this suggests that Treasury richness could be related to the risk of these types of extreme events occurring.

\subsection{Regression Results}

To explore these empirical implications, we use a framework in which we regress changes in Treasury premia on changes in variables proxying for the risk of a number of macroeconomic and market factors. Motivated by the results in the previous section, we include the returns of a number of asset classes that are widely viewed as potential hedges against extreme inflation scenarios. Specifically, we include returns on gold, commodities, housing, Treasury Inflation Protected Securities (TIPS), and the S\&P 500. We also include measures of expected short-term and long-term inflation. ${ }^{18}$

Motivated by the tax-related results in the previous section, we include changes in the U.S. Implied Tax Rate which is a time series computed using the inverse of the SIFMA Municipal Swap Index/Libor ratio. The SIFMA Municipal Swap Index is an index of rates on high-quality short-term municipal debt obligations. The U.S. Implied Tax Rate is computed by Bloomberg as the calculation agent for SIFMA. We also include changes in the Baker, Bloom, and Davis (2016) indexes of fiscal and tax uncertainty. Finally, we also include several macroeconomic measures such as the change in the Michigan Consumer Sentiment Index, the change in the unemployment rate, and the change in the Chicago Federal Reserve NFI index.

${ }^{18}$ Gold returns are lagged by one month. 
Table 10 reports the regression results. As shown, changes in the premia for Treasury notes and bonds with maturities of five years or more are all positively and significantly related to the returns on gold, commodities, and housing. Changes in the premia for Treasuries with a maturity of less than one year are also significantly related to TIPS returns. These results are broadly consistent with the hypothesis that Treasury premia are a reflection of the benefit of preserving liquidity in states of the world in which these types of assets may serve as hedging vehicles.

Table 10 also provides evidence that Treasury richness for some of the shorter-maturity categories is related to the implied tax rate. In particular, the change in the premium is positively and significantly related to the change in the implied tax rate for Treasury bills, and for Treasury notes and bonds with a maturity of less than one year, and with maturities between five and ten years. The premium for long-term Treasury bonds is also significantly related to changes in both the fiscal and tax uncertainty measures.

Finally, Table 10 also shows that Treasury richness is strongly related to all three of the macroeconomic measures included in the regression. These results are again consistent with the possibility that changes in premia reflect changes in investor perceptions of the risk and severity of extreme economic events that may impact liquidity throughout many financial markets.

\subsection{Tax Effects and Roth IRA Conversions}

To explore the relation between Treasury richness and investor concerns about future tax rates at a more fundamental causal level, we make use of an exogenous instrument for these concerns. Specifically, we use the number of conversions from a traditional IRA to a Roth IRA as a measure of the perceived risk of higher future tax rates.

Individual Retirement Accounts (IRAs) and Roth IRAs are designed to provide retirement income on a tax-advantaged basis. With a traditional IRA, the individual receives the benefit up-front with a tax deduction for the contribution, accumulates income tax-free, and then pays taxes on the distributions taken at retirement. In contrast, with a Roth IRA, the individual does not receive a tax deduction when the contribution is made, but still accumulates tax-free income, and does not pay taxes when distributions are taken. In addition, Roth IRAs allow participants to withdraw funds without incurring fees and penalty charges. A traditional IRA accumulates greater wealth if the tax rate applied to current contributions is higher than the withdrawal tax rate. In contrast, a Roth IRA is relatively more attractive if the current contribution tax rate is lower than the withdrawal tax rate. Thus, when participants expect tax rates to increase in the future, they have incentives to convert traditional IRAs into Roth IRAs. Hence, 
the number of conversions from traditional IRAs to Roth IRAs can be viewed as an exogenous measure of the perceived risk of higher tax rates in the future. ${ }^{19}$

We again use a panel regression framework to examine the relation between premia and the instrument for investor concerns about future tax rates. All things being equal, the incentive to convert a traditional IRA to a Roth IRA should be stronger the higher the coupon rate on a Treasury security. Thus, we use an interaction term between coupon rates and the annual percentage changes in the number of Roth IRA conversions as the primary explanatory variable in the panel regression. As additional controls, we again include several maturityrelated measures, the coupon rate of the bond, and annual fixed effects in the regression.

The results reported in Table 11 provide support for the hypothesis that Treasury richness is related to investor concerns about future tax rates. In particular, even after controlling for the coupon rate of the Treasury securities, the coefficient for the interaction term is highly significant with a $t$-statistic of -4.93 . The negative sign of the coefficient suggests that investors may view Treasury securities as being a less effective vehicle for protecting against uture increases in tax rates than perhaps other types of investments such as municipal bonds.

\section{TESTING ILLIQUIDITY IMPLICATIONS}

In this section, we focus on testing implications of the illiquidity literature for the properties of Treasury premia. As discussed earlier, there are many branches of this literature, each emphasizing a different type of friction or mechanism as the underlying source of illiquidity. These branches, however, all share the common implication that frictions or constraints that reduce the ability to trade securities may also have negative effects on their prices. Thus, rather than taking a stand on what causes illiquidity in Treasury markets (search costs, intermediary capital constraints, etc.), we adopt the reduced-form approach of testing whether changes in liquidity are related to changes in Treasury richness/cheapness.

In studying the relation between illiquidity and Treasury premia, however, we need to be careful to avoid endogeneity issues in the analysis since both prices and trading activity/liquidity are likely to be jointly determined in equilibrium. In light of this, we use a reduced-form maturity-related instrument to capture exogenous changes in the effective float/liquidity of individual Treasury securities. In particular, we examine the impact on Treasury note and bond premia when

${ }^{19}$ The Online Appendix provides further details on Roth IRAs, Roth IRA conversions, and the data used in this analysis. 
their maturity crosses specific horizons such as two, five, seven, and ten years.

The intuition behind the use of this type of maturity-related instrument is that many types of financial intermediaries face either explicit or implicit restrictions on the range of maturities that they are allowed to hold in their portfolios. To illustrate this, we manually collect data on the investment policies of 75 of the largest Treasury-related fixed income mutual funds and identify the range of maturities that these investment policies allow the funds to hold in their portfolios. Table A3 in the Online Appendix shows that the eligible range of maturities is almost always expressed in terms of an integer number of years. As examples, the Vanguard Short-Term Treasury Index Fund has a maturity range of 1-3 years, the T. Rowe Price U.S. Treasury Intermediate Index Fund has a maturity range of 4-10 years, and the Fidelity Long-Term Treasury Bond Index Fund has a maturity range of 10-30 years. Typical maturity ranges for short-term bond funds are 1-3 years or 1-5 years. Common maturity ranges for intermediate-term bond funds include 3-5 years, 3-7 years, 5-7 years, 5-10 years, and $7-10$ years. $^{20}$

Crossing a maturity threshold such as five years is clearly just an arbitrary mechanical event and, in theory, should have no direct impact on the valuation of its underlying economic cash flows. On the other hand, however, if crossing a threshold affects the number and types of investors that can hold the security, then the crossing could be accompanied by an exogenous change in the liquidity/illiquidity of that security. In particular, many intermediate-term fixed income funds may be required by their investment policies to sell a Treasury note or bond simply because its remaining maturity is now less than three, four, or five years. In turn, the change in the set of clienteles available to own the security could potentially reduce its liquidity in the market. Furthermore, this would be true irrespective of the underlying source of illiquidity in Treasury markets. Thus, finding evidence that crossing an integer-year-maturity threshold is associated with a significant change in the premium would support the hypothesis that liquidity/illiquidity is a fundamental determinant of Treasury richness/cheapness. Note that this would imply that significant declines in Treasury market liquidity could provide at least a partial explanation for recently observed patterns of Treasuries being priced far below their fair value.

\footnotetext{
${ }^{20} \mathrm{SEC}$ regulations impose additional restrictions on the maturity of investment portfolios held by fixed income mutual funds. Specifically, the SEC requires that a fixed income fund that includes the words "short-term," "intermediateterm,", or "long-term," in its name have a dollar-weighted average maturity of, respectively, no more than three years, more three years but less than ten years, or more than ten years. See Rule 35-d (17 CFR 270.35d-1) under the Investment Company Act of 1940 (15 U.S.C. 80a-1 et seq.).
} 
To test these empirical implications, we again use a difference-in-differences event-study approach. As before, we control for market effects in measuring the change in the premium as a Treasury note or bond crosses a maturity threshold. Specifically, we first compute the daily change in the average premium for all Treasury notes and bonds that straddle the maturity we are examining (excluding securities within the event window), and then subtract this change from the daily change in the premium of the Treasury note or bond defining the event.

Table 12 reports the results where the events are defined as crossing the two-, three-, four-, five-, seven-, and ten-year maturities. The table shows the cumulative market-adjusted change in the premium for the Treasury notes and bonds crossing the maturity threshold along with their associated $t$-statistics. The event window covers the period from 20 days prior to the event to 20 days after the event. Note that we only include a Treasury note or bond in the analysis if it is available throughout the entire event window. Figure 6 plots the cumulative market-adjusted changes.

As shown, there is a significant decline in the market-adjusted premium prior to crossing the maturity threshold for each of the different maturities. For example, the premium decreases by nearly three basis points during the 20 days before Treasury notes and bonds cross the five-year threshold. This decrease is highly significant with a $t$-statistic of -16.34 . Figure 6 also shows that the decrease in the premium occurs primarily before crossing the maturity threshold and that there is little further decline after the crossing occurs.

As another way of illustrating the threshold crossing effect, the upper panel of Figure 7 shows the average premium for five-year Treasury notes (notes issued with an initial maturity of five years) throughout the sample period, where the premia are stratified by months to maturity. The lower panel shows the average premium for ten-year Treasury notes, where the premia are stratified by quarters to maturity. As shown, there are a number of clearly visible discontinuities in the average premia at integer-year maturities.

Taken together, these results strongly support the hypothesis that changes in liquidity may be an important driver of changes in Treasury richness/cheapness. If the event of crossing a specific maturity threshold such as five years results in a large change in premia, then it is clearly plausible that more fundamental changes in the liquidity/illiquidity of specific sectors of the Treasury curve could account for the wide variation between positive and negative premia observed in the data.

Finally, it is important to acknowledge that the reduced-form approach we use does not allow us to draw specific conclusions about the underlying trends and causes of illiquidity in Treasury markets. Recall from earlier results, how- 
ever, that Treasuries have become significantly and persistently cheap since 2015, coinciding with the introduction of a number of major post-financial-crisis regulatory reforms such as the SLR. Thus, these results appear to be at least consistent with mechanisms similar to those discussed by He, Nagel, and Song (2020) and Klingler and Sundaresan (2020) in which intermediary capital constraints lead to illiquidity which, in turn, results in Treasury securities trading at prices below their intrinsic fair values. Clearly, further research would be needed to establish a definitive causal relation between post-financial-crisis intermediary capital regulation and Treasury richness. Furthermore, the fact that Treasury discounts existed long before the financial crisis indicates that post-crisis capital regulation cannot fully account for the patterns of Treasury richness/cheapness.

\section{CONCLUSION}

This paper introduces a new methodology for examining whether Treasury securities are priced at a premium/discount to their intrinsic values. The key to this approach is the use of the riskfree discounting curve obtained from the term structure of repo swap rates.

We find that Treasury securities have often traded at a discount to their fair values, and many longer-term Treasury notes and bonds have been persistently cheap since 2015. This recent trend raises important questions about the ongoing safe-asset status of Treasury securities as well as the future of the dollar as a reserve currency.

Having a measure of the richness/cheapness of Treasury securities allows us to test directly the implications of a number of important theoretical models of the valuation of money-like safe assets. The empirical results provide strong support for the opportunity-cost-of-capital model of Nagel (2016). In contrast, models that focus on the supply of debt or the international demand for Treasuries receive less support from the data. The results also support liquidity-oflast-resort models that imply that Treasuries serve as safe havens that provide continuing liquidity during extreme market events in which trading may dry up in other asset markets. It is important to observe, however, that while these types of models may help explain positive premia or convenience yields, the evidence of significant persistent discounts in Treasury security prices suggests that other factors such as illiquidity may also play a central role.

Finally, the analysis conducted in this paper barely scratches the surface of what we can potentially learn about the pricing of Treasury securities using an absolute measure of their no-arbitrage intrinsic values. In particular, the rich time-series and cross-section patterns of Treasury premia/discounts we find 
in the market call for extensive additional empirical research and exploration. Furthermore, the negative premia observed in the markets, as well as the evidence that Treasuries often cheapen during times of crisis, pose major challenges to current models in the literature and point to the need for additional theoretical research. Many puzzles remain to be addressed. 


\section{REFERENCES}

Acharya, Viral V., and Lasse H. Pedersen, 2005, Asset Pricing with Liquidity Risk, Journal of Financial Economics 77, 375-410.

Adrian, Tobias, R. K. Crump, and E. Vogt, 2019, Nonlinearity and Flight-toSafety in the Risk-Return Trade-Off for Stocks and Bonds, Journal of Finance 74, 1931-1973.

Adrien, Tobias, Etula, E., and Tyler Muir, 2014, Financial Intermediaries and the Cross-Section of Asset Returns, Journal of Finance 69, 2557-2596.

Afonso, Gara, and Ricardo Lagos, 2019, Trade Dynamics in the Market for Federal Funds, Econometrica 83, 263-313.

Amihud, Yakov, and Haim Mendelson, 1991, Liquidity, Maturity, and the Yields on U.S. Treasury Securities, Journal of Finance 46, 1411-1425.

Arora, Navneet, Priyank Gandhi, and Francis A. Longstaff, 2012, Counterparty Credit Risk and the Valuation of Credit Default Swaps, Journal of Financial Economics 103, 280-293.

Atkeson, Andrew, Andrea Eisfeldt, and Pierre-Olivier Weill, 2015, Entry and Exit in OTC Derivatives Markets, Econometrica 83, 2231-2292.

Augustin, Patrick, Mikhail Chernov, Lukas Schmid, and Dongho Song, 2021, Benchmark Interest Rates when the Government is Risky, Journal of Financial Economics 140, 74-100.

Babus, Ana, 2016. The Formation of Financial Networks, RAND Journal of Economics 47, 239-272.

Babus, Ana, and Tai-Wei Hu, 2017. Endogenous Intermediation in Over-theCounter Markets, Journal of Financial Economics 125, 200-215.

Babus, Ana, and Peter Kondor, 2018, Trading and Information Diffusion in Over-the-Counter Markets, Econometrica 86, 1727-1769.

Baker, Scott, Nicholas Bloom, and Steven Davis, 2016, Measuring Economic Policy Uncertainty, Quarterly Journal of Economics 131, 1593-1636.

Beber, Alessandro, Michael W. Brandt, and Kenneth A. Kavajecz, 2009, Flightto-Quality or Flight-to-Liquidity? Evidence from the Euro-Area Bond Market, Review of Financial Studies 22, 925-957.

van Binsbergen, Jules H., William Diamond, and Marco Grotteria, 2019, Risk 
Free Interest Rates, Working paper, National Bureau of Economic Research.

Brunnermeier, Markus, Sebastian Merkel, and Yuliy Sannikov, 2020, Debt as Safe Asset: Mining the Bubble, Working paper, Princeton University.

Brunnermeier, Markus, Lasse H. Pedersen, 2009, Market Liquidity and Funding Liquidity, Review of Financial Studies 22, 2201-2238.

Brunnermeier, Markus, and Yuliy Sannikov, 2014, A Macroeconomic Model with a Financial Sector, American Economic Review 104, 379-421.

Caballero, Ricardo J., Emmanuel Farhi, and Pierre-Olivier Gourinchas, 2008, An Equilibrium Model of Global Imbalances and Low Interest Rates, American Economic Review 98, 358-393.

Caballero, Ricardo J., and Arvind Krishnamurthy, 2009, Global Imbalances and Financial Fragility, American Economic Review 99, 584-588.

Chacko, George C., Jakub W. Jurek, and Erik Stafford, 2008, The Price of Immediacy, Journal of Finance 63, 1253-1290.

Christensen, Jens H. E., Eric Fischer, and Patrick J. Schultz, 2021, Bond Flows and Liquidity: Do Foreigners Matter?, Journal of International Money and Finance 117, 1-20.

Christensen, Jens H. E., and Nikola Mirkov, 2021, The Safety Premium of Safe Assets, FRB San Francisco Working Paper 2019-028.

Cochrane, John H., 2015, A New Structure for U.S. Federal Debt, Hoover Institution, Economics Working Paper 15108.

Dang, Vi Tri, Gary Gorton, and Bengt Holmström, 2015, Ignorance, Debt and Financial Crises, Columbia University Working Paper.

Di Maggio, Marco, Amir Kermani, Zhaogang Song, 2017, The Value of Trading Relations in Turbulent Times, Journal of Financial Economics 124, 266-284.

Du, Wenxin, Joanne Im, and Jesse Schreger, 2018, The U.S. Treasury Premium, Journal of International Economics 112, 167-181.

Duffee, Gregory R., 1996, Idiosyncratic Variation of Treasury Bill Yields, Journal of Finance 51, 527-551.

Duffie, Darrell, 2015, Discussion of 'A New Structure for U.S. Federal Debt' by John H. Cochrane, Brookings Institution Press.

Duffie, Darrell, 2020, Still the World's Safe Haven? Redesigning the US Treasury 
Market After the COVID-19 Crisis, Hutchins Center Working Paper (62).

Duffie, Darrell, Nicolae Gârleanu, and Lasse H. Pedersen, 2005, Over-the-Counter Narkets, Econometrica 73, 1815-1847.

Duffie, Darrell, Nicolae Gârleanu, and Lasse H. Pedersen, 2007, Valuation in Over-the-Counter Markets, Review of Financial Studies 20, 1865-1900.

Duffie, Darrell, Semyon Malamud, and Gustavo Manso, 2015, Information Percolation in Segmented Markets, Journal of Economic Theory 157, 1130-1158.

Duffie, Darrell, and Kenneth J. Singleton, 1999, Modeling Term Structure of Defaultable Bonds, Review of Financial Studies 14, 687-720.

Duffie, Darrell, and Bruno Strulovici, 2012, Capital Mobility and Asset Pricing, Econometrica 80, 2469-2509.

Farboodi, Maryam, 2017, Intermediation and Voluntary Exposure to Counterparty Risk, Working paper, MIT.

Fleckenstein, Matthias, and Francis A. Longstaff, 2020a, Renting Balance Sheet Space: Intermediary Balance Sheet Rental Costs and the Valuation of Derivatives, Review of Financial Studies 33, 5051-5091.

Fleckenstein, Matthias, and Francis A. Longstaff, 2020b, The U.S. Treasury Floating Rate Note Puzzle: Is there a Premium for Mark-to-Market Stability?, Journal of Financial Economics 137, 637-658.

Fleckenstein, Matthias, Francis A. Longstaff, and Hanno Lustig, 2014, The TIPSTreasury Puzzle, Journal of Finance 69, 2151-2197.

Gârleanu, Nicolae, and Lasse H. Pedersen, 2011, Margin-Based Asset Pricing and Deviations from the Law of One Price, Review of Financial Studies 22, 4259-4299.

Gorton, Gary, and Andrew Metrick, 2012, Securitized Banking and the Run on Repo, Journal of Financial Economics 104, 425-451.

Gorton, Gary, and Guillermo L. Ordoñez, 2013, The Supply and Demand for Safe Assets, NBER Working Paper No. 18732.

Greenwood, Robin, Samuel G. Hanson, and Jeremy C. Stein, 2010, A Gap-Filling Theory of Corporate Debt Maturity Choice, Journal of Finance 65, 993-1028.

Greenwood, Robin, Samuel G. Hanson, and Jeremy C. Stein, 2015, A Compara tive-Advantage Approach to Government Debt Maturity, Journal of Finance 70, $1683-1722$. 
Greenwood, Robin, and Dimitri Vayanos, 2014, Bond Supply and Excess Bond Returns, Review of Financial Studies 27, 663-713.

Grinblatt, Mark, and Francis A. Longstaff, 2000, Financial Innovation and the Role of Derivative Securities: An Empirical Analysis of Treasury STRIPS Program, Journal of Finance 60, 1415-1436.

Grossman, Sanford J., and Merton H. Miller, 1988, Liquidity and Market Structure, Journal of Finance 43, 617-633.

Gromb, Denis, and Dimitri Vayanos, 2002, Equilibrium and Welfare in Markets with Financial Constrained Arbitrageurs, Journal of Financial Economics 66, $361-407$.

Guibaud, Stephane, Yves Nosbusch, and Dimitri Vayanos, 2013, Bond Market Clienteles, the Yield Curve, and the Optimal Maturity Structure of Government Debt, Review of Financial Studies 26, 1914-1961.

Haddad, Valentin, Alan Moreira, and Tyler Muir, 2020, When Selling Becomes Viral: Disruptions in Debt Markets in the COVID-19 Crisis and the Fed's Response, Journal of Finance, forthcoming.

He, Zhiguo, Bryan Kelly, and Asef Manela, 2017, Intermediary Asset Pricing: New Evidence from Many Asset Classes, Journal of Financial Economics 126, $1-35$.

He, Zhiguo, and Arvind Krishnamurthy, 2012, A Model of Capital and Crises, Review of Economic Studies 79, 735-777.

He, Zhiguo, and Arvind Krishnamurthy, 2013, Intermediary Asset Pricing, American Economic Review 103, 732-770.

He, Zhiguo, Arvind Krishnamurthy, and Konstantin Milbradt, 2016, What Makes US Government Bonds Safe Assets?, American Economic Review 106, 519-523.

He, Zhiguo, Arvind Krishnamurthy, and Konstantin Milbradt, 2019, A Model of Safe Asset Determination, American Economic Review 109, 1230-1262.

He, Zhiguo, Stefan Nagel, and Zhaogang Song, 2020, Treasury Inconvenience Yields During the Covid-19 Crisis, Working paper, National Bureau of Economic Research.

Infante, Sebastian, 2020, Private Money Creation with Safe Assets and Term Premia, Journal of Financial Economics 136, 828-856.

Jordan, Bradford D., Randy D. Jorgensen, and David R. Kuipers, 2000, The Relative Pricing of Treasury STRIPS: Empirical Evidence, Journal of Financial 
Economics 56, 89-123.

Joslin, Scott, Wenhao Li, and Yang Song, 2020, The Term Structure of Liquidity Premium, Working paper, USC Marshall School.

Kamara, Avraham, 1994, Liquidity, Taxes, and Short-Term Treasury Yields, Journal of Financial and Quantitative Analysis 29, 403-417.

Kacperczyk, Marcin T., Christophe Perignon, and Guillaume Vuillemey, 2020, The Private Production of Safe Assets, Journal of Finance, forthcoming.

Klingler, Sven, and Suresh Sundaresan, 2020, Diminishing Treasury Convenience Premiums: Effects of Dealers' Excess Demand in Auctions, Working paper, Columbia University.

Kondor, Peter, and Dimitri Vayanos, 2019, Liquidity Risk and the Dynamics of Arbitrage Capital, Journal of Finance 74, 1139-1173.

Krishnamurthy, Arvind, 2002, The Bond/Old Bond Spread, Journal of Financial Economics 66, 463-506.

Krishnamurthy, Arvind, 2010a, How Debt Markets have Malfunctioned in the Crisis, Journal of Economic Perspectives 24, 3-28.

Krishnamurthy, Arvind, 2010b, Amplification Mechanisms in Liquidity Crises, American Economic Journal - Macroeconomics 2, 1-30.

Krishnamurthy, Arvind, Stefan Nagel, and Dmitry Orlov, 2014, Sizing up Repo, Journal of Finance 69, 2381-2417.

Krishnamurthy, Arvind, and Annette Vissing-Jørgensen, 2012, The Aggregate Demand for Treasury Debt, Journal of Political Economy 120, 233-267.

Kyle, A. S., Xiong, W., 2001. Contagion as a wealth effect. Journal of Finance $56,1401-1440$.

Lewis, Kurt, Francis A. Longstaff, and Lubomir Petrasek, 2020, Asset Mispricing, Journal of Financial Economics, forthcoming.

Longstaff, Francis A., 2000, The Term Structure of Very Short-Term Rates: New Evidence for the Expectations Hypothesis, Journal of Financial Economics 58, $397-415$.

Longstaff, Francis A., 2001, Optimal Portfolio Choice and the Valuation of Illiquid Securities, Review of Financial Studies 14, 407-431.

Longstaff, Francis A., 2004, The Flight-to-Liquidity Premium in U.S. Treasury 
Bond Prices, Journal of Business 77, 511-526.

Longstaff, Francis A., 2009, Portfolio Claustrophobia: Asset Pricing in Markets with Illiquid Assets, American Economic Review 99, 1119-1144.

Longstaff, Francis A., 2018, Valuing Thinly-Traded Assets, Management Science 64, 3868-3878.

Musto, David, Greg Nini, and Krista Schwarz, 2018, Notes on Bonds: Liquidity at all Costs During the Great Recession, Review of Financial Studies 31, 29833018.

Nagel, Stefan, 2016, The Liquidity Premium of Near-Money Assets, Quarterly Journal of Economics 131, 1927-1971.

Neklyudov, Artem, 2019, Bid-Ask Spreads and the Over-the-Counter Interdealer Markets: Core and Peripheral Dealers, Review of Economic Dynamics 33, 57-84.

Newey, Whitney K., and Kenneth D. West, 1987, A Simple, Positive SemiDefinite Heteroskedasticity and Autocorrelation Consistent Covariance Matrix, Econometrica 55, 703-708.

Pastor, Lubos, and Robert Stambaugh, 2003, Liquidity Risk and Expected Stock Returns, Journal of Political Economy 111, 642-685.

Sambalaibat, Batchimeg, 2018, Endogenous Specialization and Dealer Networks, Working paper, Indiana University.

Sunderam, Adi, 2015, Money Creation and the Shadow Banking System, Review of Financial Studies 28, 939-977.

Üslü, Semih, 2019. Pricing and Liquidity in Decentralized Asset Markets, Econometrica 87, 2079-2140.

Vayanos, Dimitri, 1998, Transaction Costs and Asset Prices: A Dynamic Equilibrium Model, Review of Financial Studies 11, 1-58.

Vayanos, Dimitri, 2004, Flight to Quality, Flight to Liquidity, and the Pricing of Risk, NBER Working Paper 10327.

Vayanos, Dimitri, and Jean-Luc Vila, 1999, Equilibrium Interest Rate and Liquidity Premium with Transaction Costs, Economic Theory 13, 509-539.

Vayanos, Dimitri, and Tang Wang, 2007, Search and Endogenous Concentration of Liquidity in Asset Markets, Journal of Economic Theory 136, 66-104.

Vayanos, Dimitri, and Pierre-Olivier Weill, 2008, A Search-Based Theory of the 
On-the-Run Phenomenon, Journal of Finance 63, 1361-1398.

Xiong, Wei, 2001, Convergence Trading with Wealth Effects: An Amplification Mechanism in Financial Markets, Journal of Financial Economics 62, 247-292.

Weill, Pierre-Olivier, 2007, Leaning Against the Wind, Review of Economic Studies 74, 1329-1354.

Wolinsky, Asher, 1990, Information Revelation in a Market with Pairwise Meetings, Econometrica 58, 1-23. 


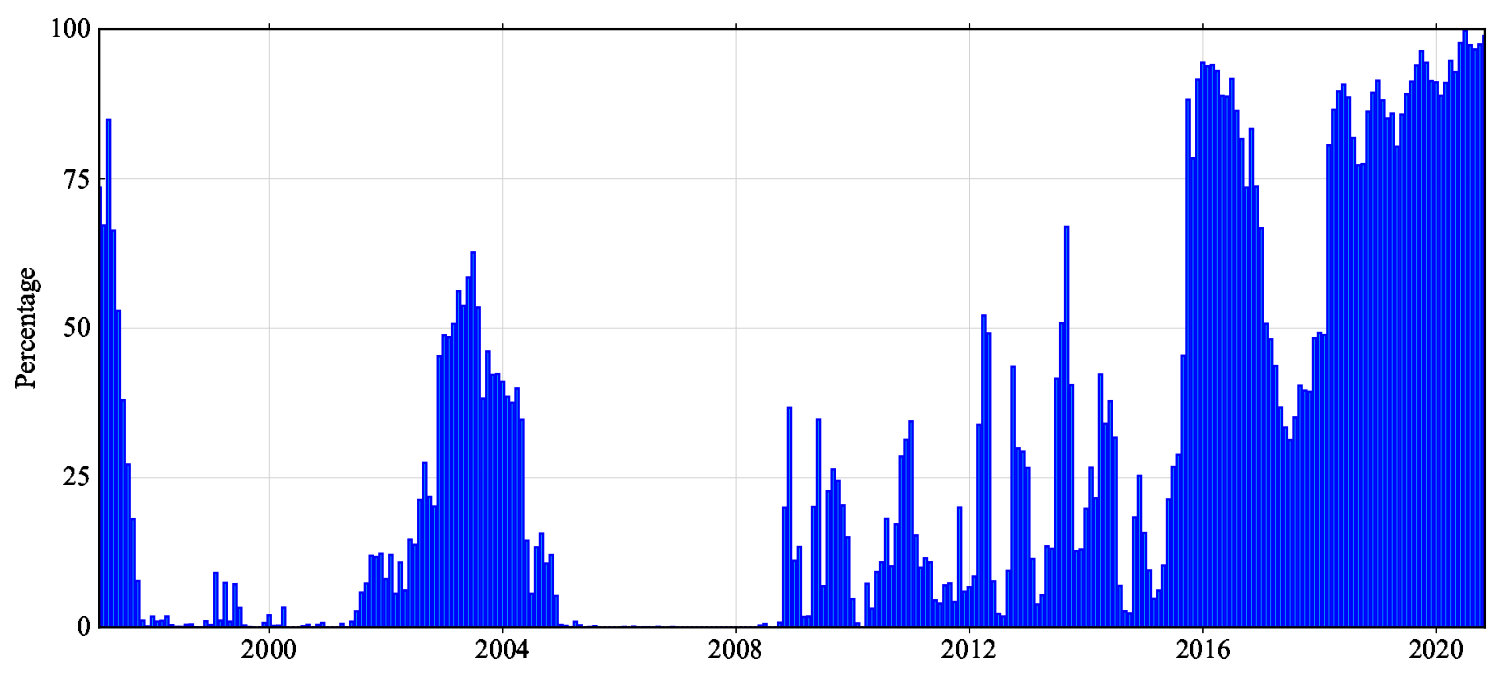

Figure 1. Percentage of Treasury Notes and Bonds Priced Below Their Intrinsic Fair Value. This graph shows the percentage of all Treasury notes and bonds with market values below their intrinsic fair value. 


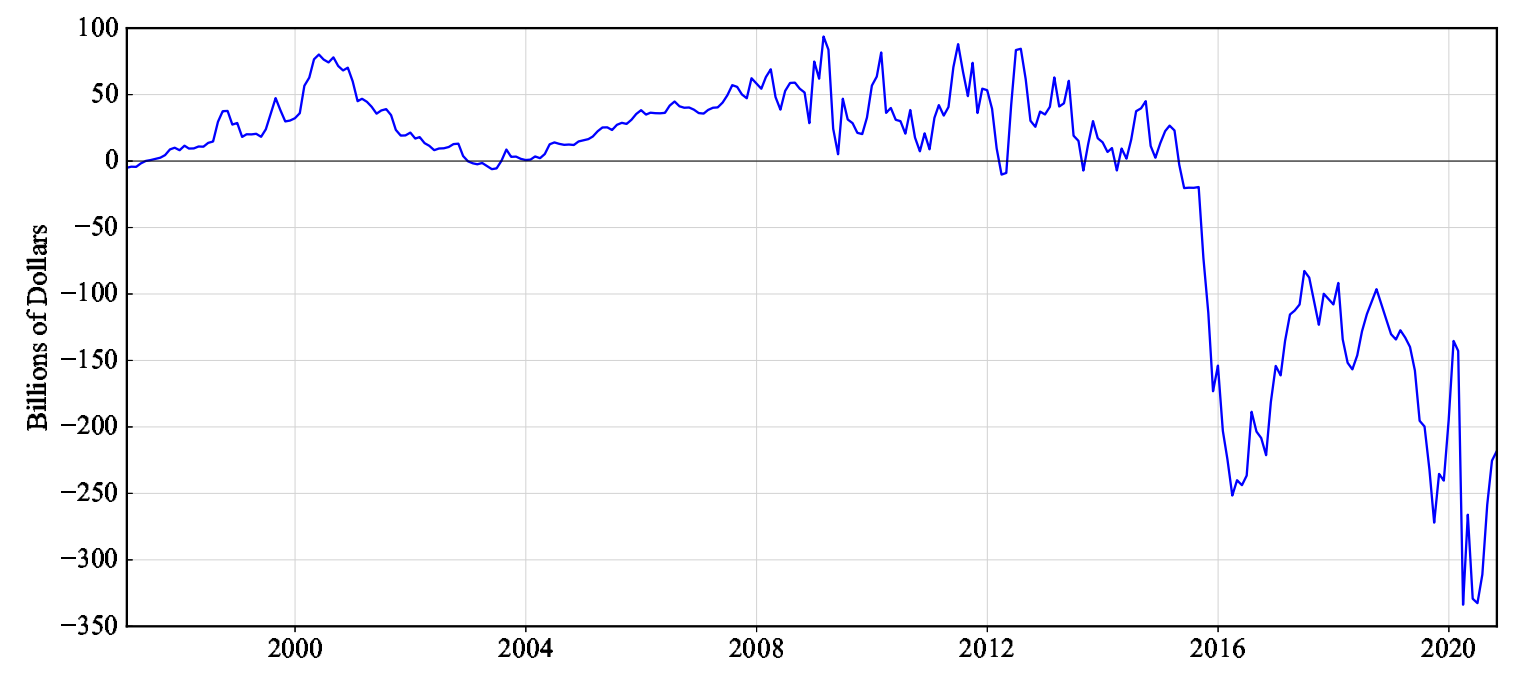

Figure 2. Total Dollar Richness/Cheapness of the Treasury Market. This graph shows the aggregate dollar amount of Treasury richness/cheapness, where the dollar amount for a specific issue is the price premium times the outstanding notional amount of that issue, and the total dollar amount is taken over all Treasury bills, notes, and bonds in the sample each month. 

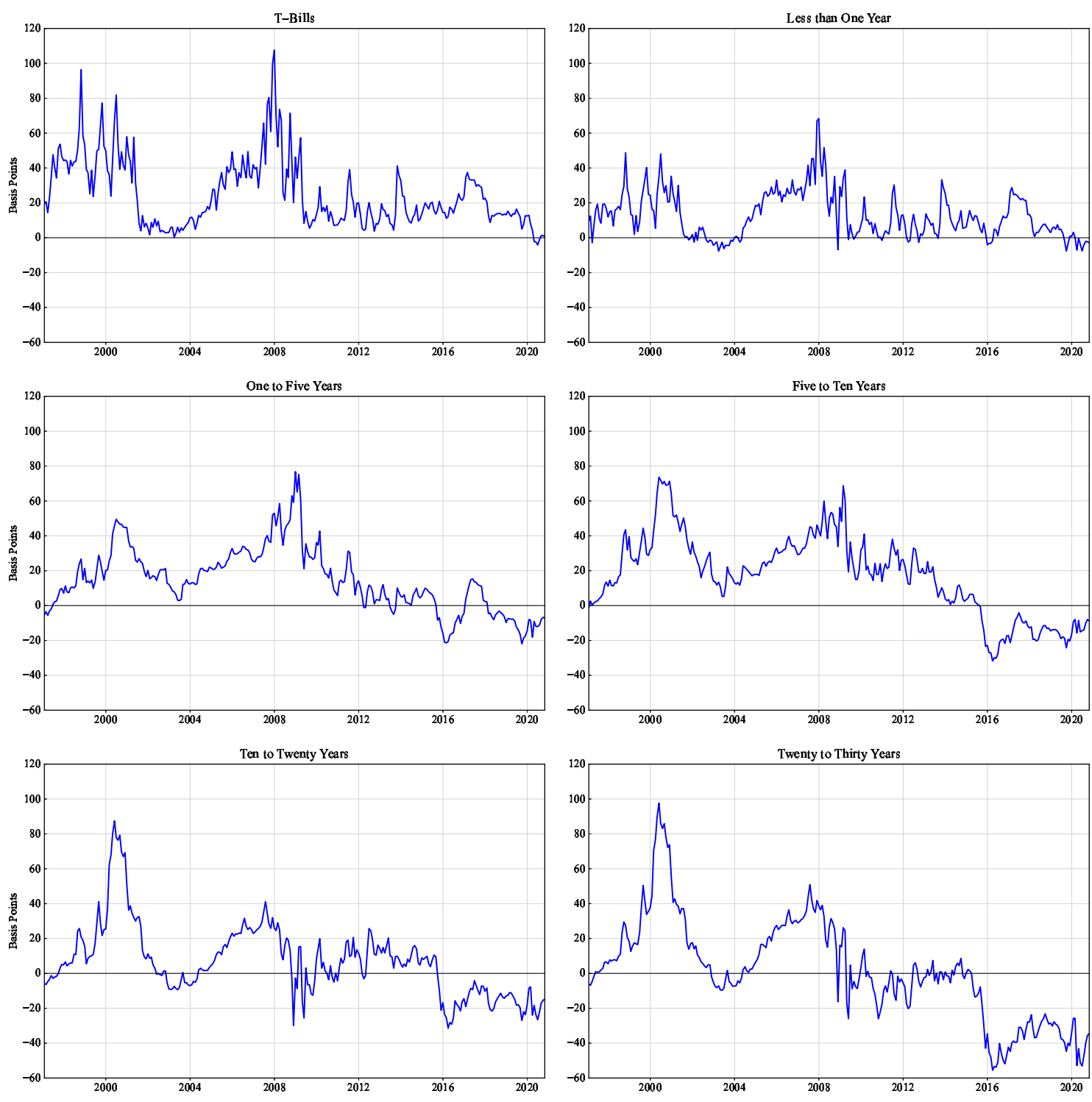

Figure 3. Time Series of Treasury Premia. These graphs show the time series of average premia for Treasury bills and for the individual Treasury note and bond maturity categories. 


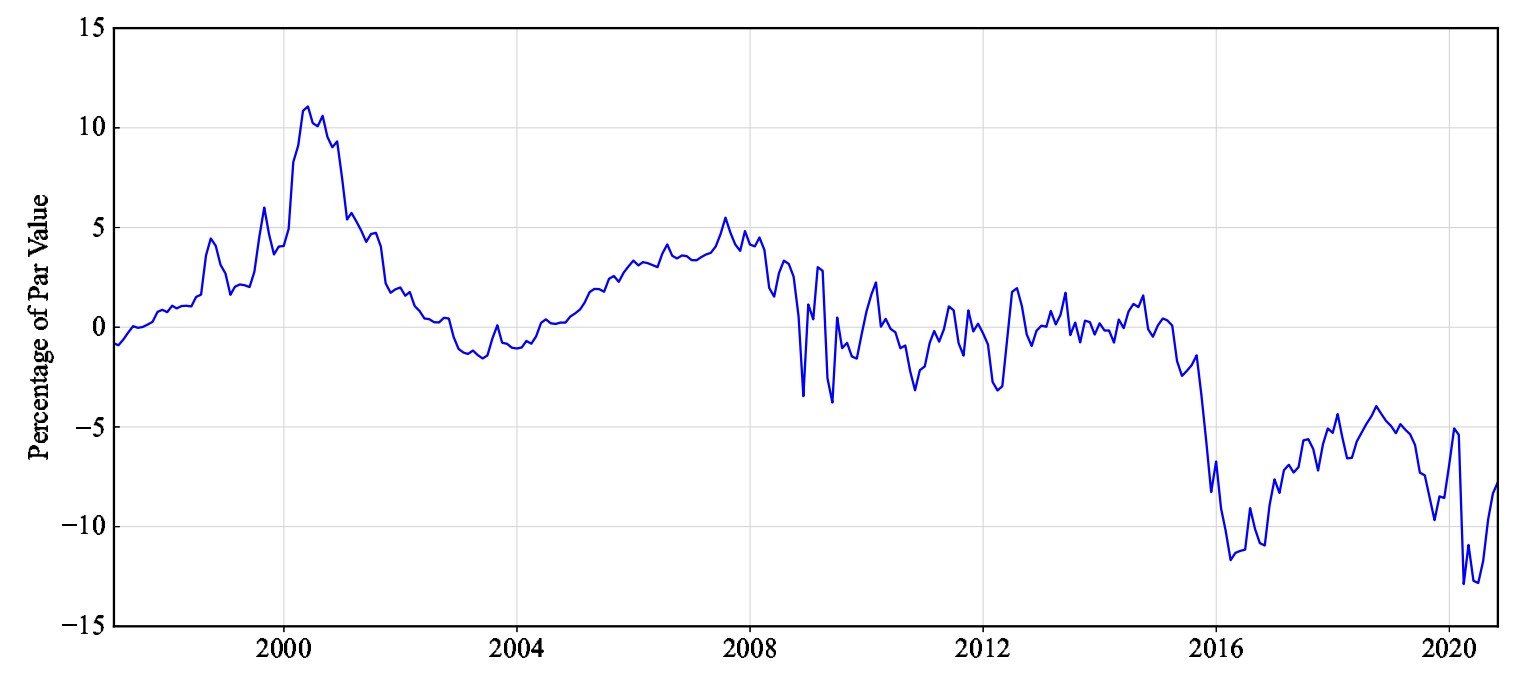

Figure 4. Price Premia for 20- to 30-Year Treasury Bonds This graph shows the average price premia for Treasury bonds with maturities from 20 to 30 years. The average price premia are expressed as a percentage of the par value of the bond. 


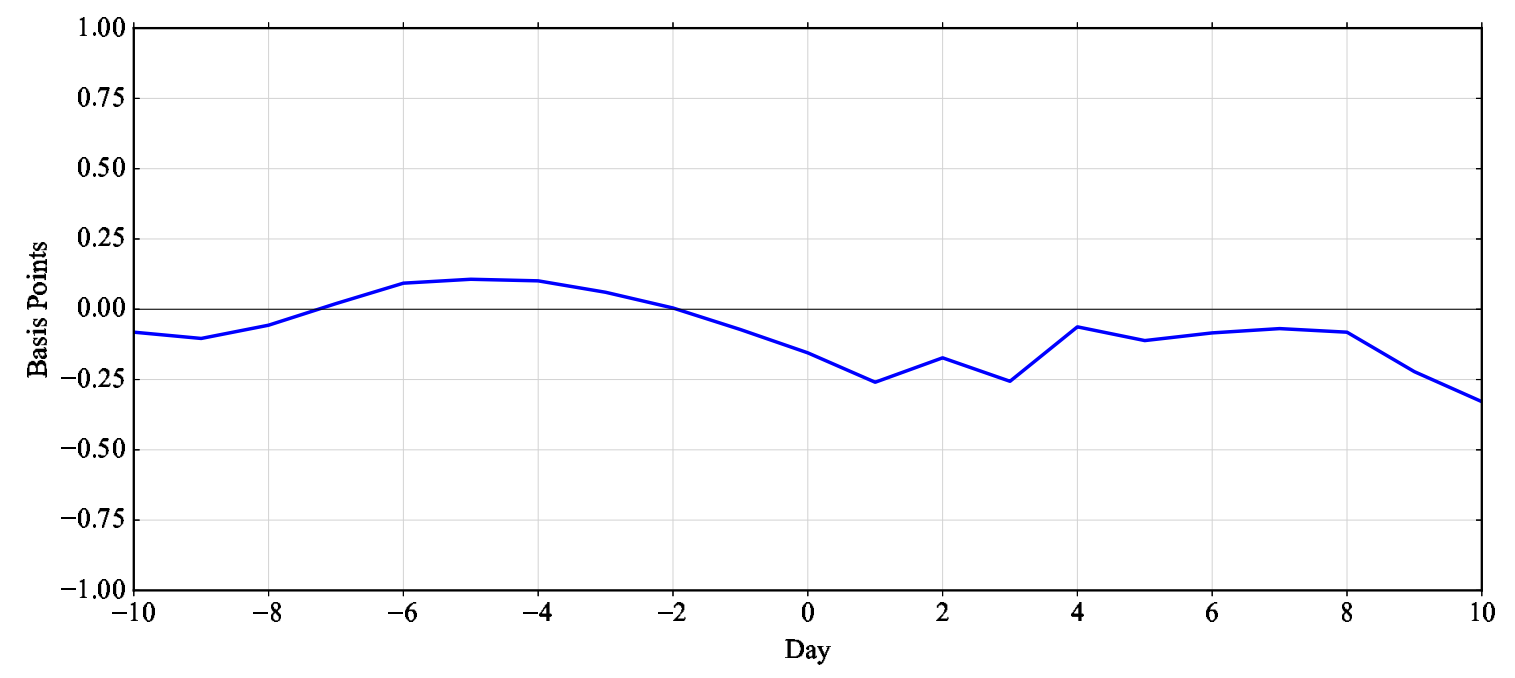

Figure 5. Cumulative Changes in Market-Adjusted Treasury Premia from the 397-Day Money Market Fund Inclusion Event Study. This graph shows the cumulative change in the market-adjusted premia from the 397day money market fund inclusion eligibility event study. The event date (day zero) is defined as the first day when a Treasury security becomes eligible for inclusion in the portfolio of a money market fund because of its maturity being less than or equal to 397 days. 

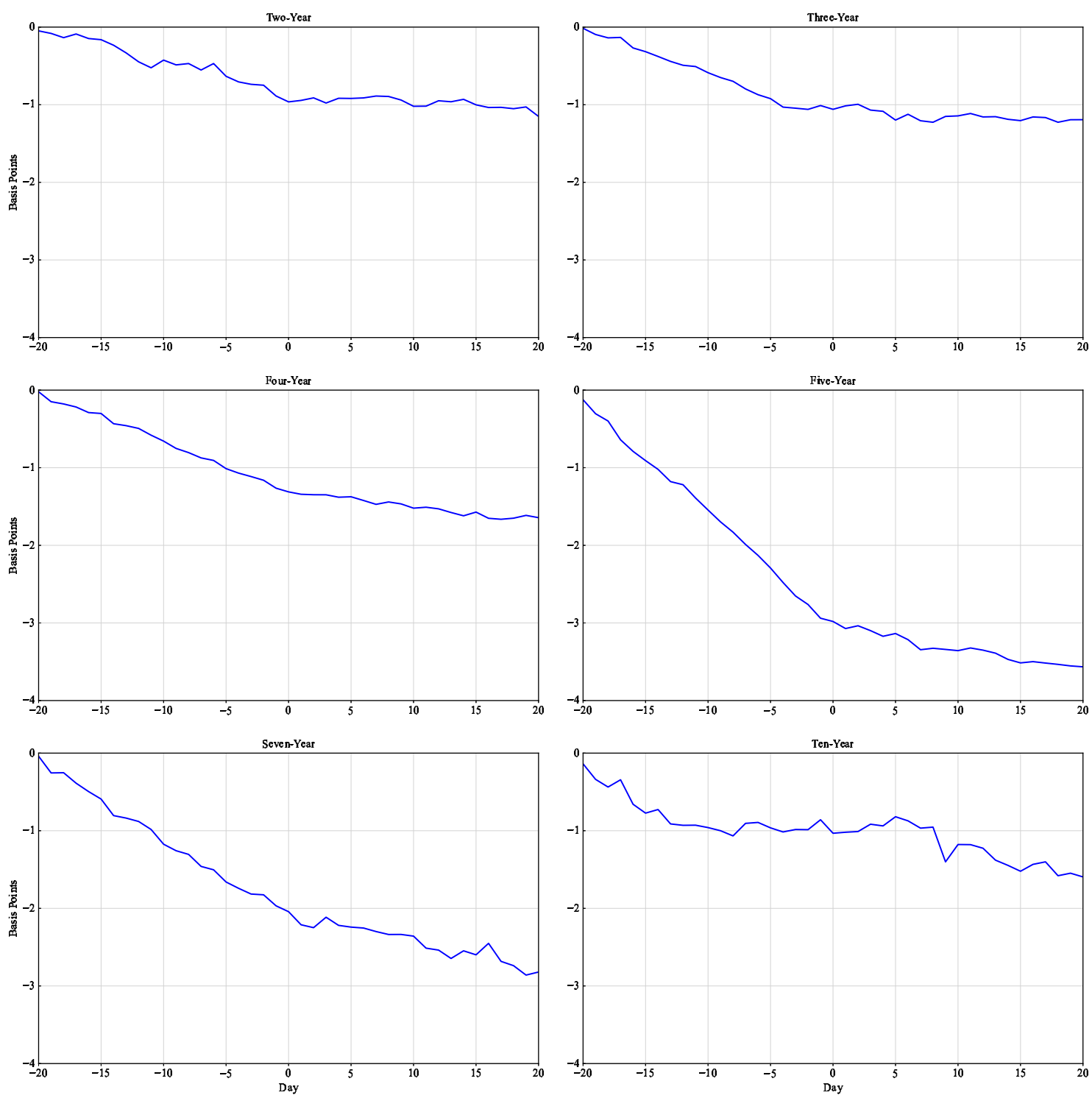

Figure 6. Cumulative Changes in Market-Adjusted Treasury Premia from the Maturity-Crossing Event Study. These graphs show the cumulative change in the market-adjusted premia from the maturity-crossing event study. The event date (day zero) is defined as the first day when a Treasury security's maturity is less than or equal to the indicated number of years. 

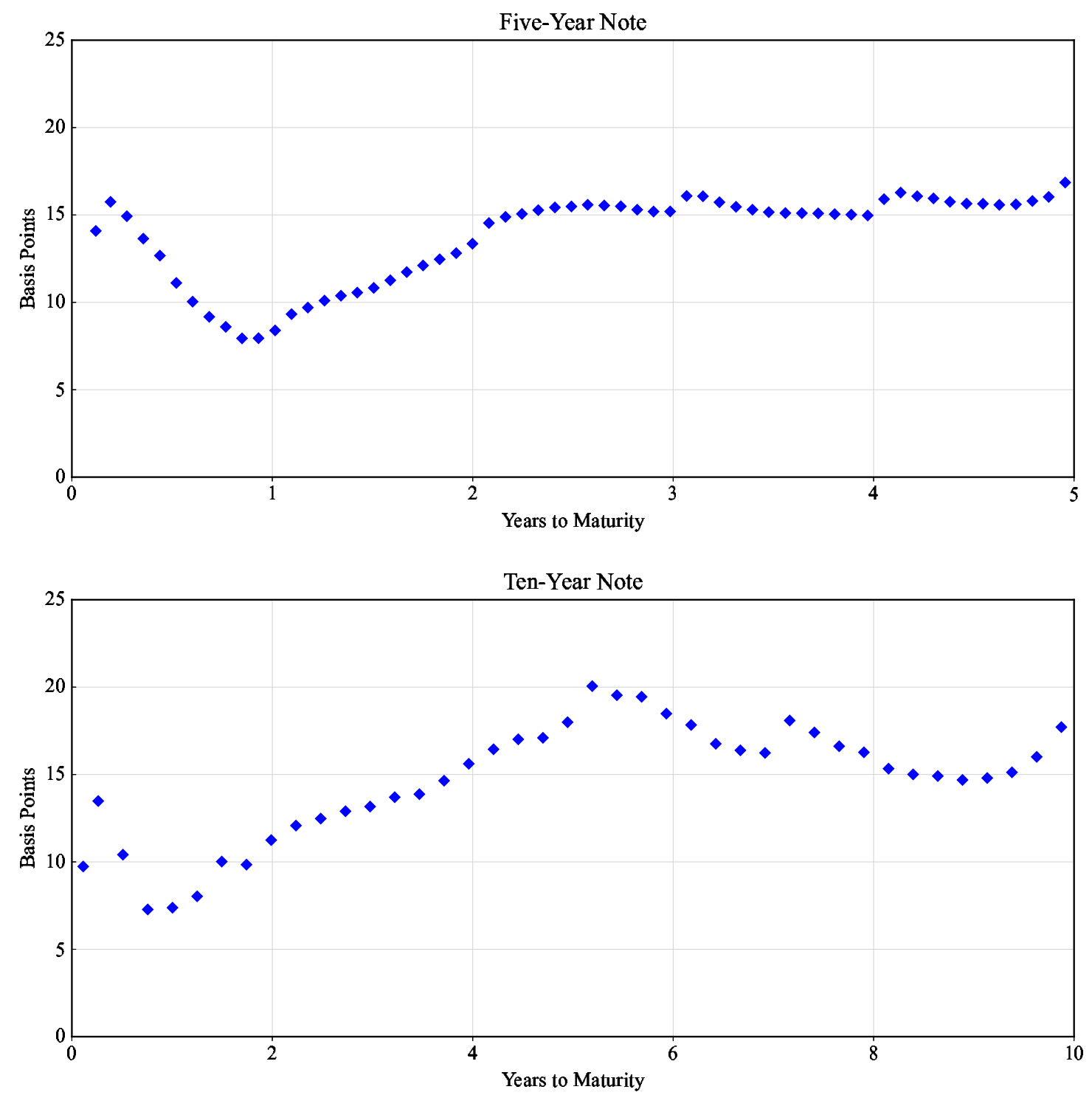

Figure 7. Term Structure of Premia for Five-Year and Ten-Year Treasury Notes. These graphs show the average term structure of premia for Treasury notes originally issued with a five-year maturity (upper panel) or a ten-year maturity (lower panel). 


\section{Table 1}

Cash Flows from a Stylized Portfolio Consisting of a Treasury Bond and CDS Contract. This table presents the cash flows from a stylized portfolio consisting of a long position in a Treasury bond with time-zero price 100, coupon rate $c$, and maturity $T$, and the purchase of default protection via a CDS contract with a spread of $s$ and maturity $T$. If a default occurs at time $\tau$, the Treasury bond is sold at the market price of $c+100-w$ (coupon plus par minus $w$ ) where $w$ denotes the default loss, and the protection leg of the CDS contract pays the protection buyer the default loss $w$. For expositional simplicity, this stylized example assumes that default can only occur on a coupon payment date, and that both the accrued coupon and CDS premium are paid at time $\tau$ if a default occurs.

\begin{tabular}{|c|c|c|c|c|c|c|c|}
\hline & \multicolumn{7}{|c|}{ Timing of Cash Flow } \\
\hline & 0 & 1 & 2 & $\ldots$ & $\tau$ & $\ldots$ & $T$ \\
\hline \multicolumn{8}{|l|}{ Default at Time $\tau$} \\
\hline Bond Cash Flow & -100 & $c$ & $c$ & $c$ & $c+100-w$ & & \\
\hline CDS Cash Flow & 0 & $-s$ & $-s$ & $-s$ & $-s+w$ & & \\
\hline Total Cash Flow & -100 & $c-s$ & $c-s$ & $c-s$ & $c-s+100$ & & \\
\hline \multicolumn{8}{|l|}{ No Default } \\
\hline Bond Cash Flow & -100 & $c$ & $c$ & $c$ & $c$ & $c$ & $c+100$ \\
\hline CDS Cash Flow & 0 & $-s$ & $-s$ & $-s$ & $-s$ & $-s$ & $-s$ \\
\hline Total Cash Flow & -100 & $c-s$ & $c-s$ & $c-s$ & $c-s$ & $c-s$ & $c-s+100$ \\
\hline
\end{tabular}


Table 2

Summary Statistics for Repo Swap Rates. This table presents summary statistics for the repo swap rates for the indicated tenors. Swap rates are expressed as annualized percentages. Mean and Std. Dev. denote the means and standard deviations of swap rates. The columns denoted $25 \%$ $50 \%$, and $75 \%$, represent the respective percentiles of the distribution of swap rates. $N$ denotes the number of observations. The sample period is daily from January 23, 1997 to October 30, 2020.

\begin{tabular}{|c|c|c|c|c|c|c|c|c|}
\hline Repo Swap Tenor & Mean & $\begin{array}{l}\text { Std. } \\
\text { Dev. }\end{array}$ & Min & $25 \%$ & $50 \%$ & $75 \%$ & Max & $N$ \\
\hline 1-Month & 2.148 & 2.145 & 0.000 & 0.128 & 1.493 & 4.532 & 6.678 & 5,984 \\
\hline 3-Month & 2.176 & 2.168 & -0.001 & 0.135 & 1.530 & 4.613 & 6.706 & 5,984 \\
\hline 6-Month & 2.217 & 2.184 & -0.009 & 0.161 & 1.526 & 4.584 & 6.948 & 5,984 \\
\hline 1-Year & 2.325 & 2.203 & -0.035 & 0.297 & 1.539 & 4.618 & 7.346 & 5,984 \\
\hline 2-Year & 2.555 & 2.150 & -0.060 & 0.610 & 1.961 & 4.666 & 7.536 & 5,984 \\
\hline 3-Year & 2.784 & 2.089 & -0.065 & 0.944 & 2.334 & 4.795 & 7.562 & 5,984 \\
\hline 5-Year & 3.163 & 1.975 & -0.010 & 1.454 & 2.737 & 4.945 & 7.633 & 5,984 \\
\hline 7-Year & 3.427 & 1.889 & 0.103 & 1.796 & 3.184 & 5.048 & 7.676 & 5,984 \\
\hline 10-Year & 3.699 & 1.818 & 0.249 & 2.051 & 3.637 & 5.184 & 7.703 & 5,984 \\
\hline 15-Year & 3.961 & 1.777 & 0.389 & 2.329 & 4.040 & 5.400 & 7.716 & 5,984 \\
\hline 20-Year & 4.072 & 1.763 & 0.443 & 2.457 & 4.197 & 5.514 & 7.701 & 5,984 \\
\hline 30-Year & 4.131 & 1.741 & 0.393 & 2.524 & 4.299 & 5.549 & 7.630 & 5,984 \\
\hline
\end{tabular}


Table 3

Summary Statistics for Yield Premia. This table presents summary statistics for the yield premia. Security denotes the type of Treasury security. Maturity denotes the range of maturities included in the respective category, where maturity is expressed in years. The yield premia are expressed in basis points. Mean and Std. Dev. denote the means and standard deviations of the yield premia. The columns denoted $25 \%$, $50 \%$, and $75 \%$ represent basis points. Mean and Std. Dev. denote the means and standard deviations of the yield premia. The columns denoted $25 \%, 50 \%$, and $75 \%$ represent
the respective percentiles of the distribution of yield premia. $N$ denotes the number of observations, where each observation represents the average taken over all Treasury securities within the respective category for that day. The sample period is daily from January 23 , 1997 to October $30,2020$.

\begin{tabular}{|c|c|c|c|c|c|c|c|c|c|}
\hline Security & Maturity & Mean & $\begin{array}{l}\text { Std. } \\
\text { Dev. }\end{array}$ & Min & $25 \%$ & $50 \%$ & $75 \%$ & Max & $N$ \\
\hline T-Bills & $\leq 1$ Year & 25.00 & 20.60 & -10.25 & 10.33 & 18.64 & 35.87 & 143.94 & 5,984 \\
\hline T-Notes & $\begin{array}{l}\leq 1 \text { Year } \\
1-5 \text { Years } \\
5-10 \text { Years } \\
10-20 \text { Years } \\
20-30 \text { Years }\end{array}$ & $\begin{array}{r}12.71 \\
14.60 \\
17.03 \\
6.82 \\
1.75\end{array}$ & $\begin{array}{l}14.10 \\
18.41 \\
23.22 \\
20.88 \\
29.42\end{array}$ & $\begin{array}{l}-28.18 \\
-29.76 \\
-37.41 \\
-43.52 \\
-79.17\end{array}$ & $\begin{array}{r}2.28 \\
2.50 \\
1.61 \\
-7.53 \\
-16.41\end{array}$ & $\begin{array}{r}9.87 \\
13.10 \\
18.08 \\
5.18 \\
0.67\end{array}$ & $\begin{array}{l}21.94 \\
25.73 \\
32.07 \\
17.50 \\
19.17\end{array}$ & $\begin{array}{r}86.75 \\
89.64 \\
83.28 \\
95.56 \\
106.83\end{array}$ & $\begin{array}{l}5,984 \\
5,984 \\
5,984 \\
5,984 \\
5,984\end{array}$ \\
\hline
\end{tabular}




\section{Table 4}

Summary Statistics for Price Premia. This table presents summary statistics for the price premia. Security denotes the type of Treasury security. Maturity denotes the range of maturities included in the respective category, where maturity is expressed in years. The price premia are expressed in dollars per 100 dollar notional amount. Mean and Std. Dev. denote the means and standard deviations of the price premia. The columns denoted $25 \%, 50 \%$, and $75 \%$ represent the respective percentiles of the distribution of price premia. $N$ denotes the number of observations, where each observation represents the average taken over all Treasury securities within the respective category for that day. The sample period is daily from January 23, 1997 to October 30, 2020.

\begin{tabular}{|c|c|c|c|c|c|c|c|c|c|}
\hline Security & Maturity & Mean & $\begin{array}{l}\text { Std. } \\
\text { Dev. }\end{array}$ & Min & $25 \%$ & $50 \%$ & $75 \%$ & $\operatorname{Max}$ & $N$ \\
\hline T-Bills & $\leq 1$ Year & 0.078 & 0.064 & -0.065 & 0.032 & 0.064 & 0.116 & 0.430 & 5,984 \\
\hline T-Notes & $\begin{array}{l}\leq 1 \text { Year } \\
1-5 \text { Years } \\
5-10 \text { Years } \\
10-20 \text { Years } \\
20-30 \text { Years }\end{array}$ & $\begin{array}{r}0.061 \\
0.404 \\
1.121 \\
0.759 \\
-0.415\end{array}$ & $\begin{array}{l}0.071 \\
0.533 \\
1.515 \\
2.815 \\
5.149\end{array}$ & $\begin{array}{r}-0.197 \\
-0.808 \\
-2.571 \\
-7.827 \\
-21.471\end{array}$ & $\begin{array}{r}0.008 \\
0.047 \\
0.132 \\
-1.102 \\
-3.110\end{array}$ & $\begin{array}{l}0.050 \\
0.380 \\
1.223 \\
0.689 \\
0.113\end{array}$ & $\begin{array}{l}0.110 \\
0.718 \\
2.157 \\
2.364 \\
3.000\end{array}$ & $\begin{array}{r}0.444 \\
2.864 \\
5.888 \\
11.168 \\
12.666\end{array}$ & $\begin{array}{l}5,984 \\
5,984 \\
5,984 \\
5,984 \\
5,984\end{array}$ \\
\hline
\end{tabular}




\section{Table 5}

Correlation Matrix for Changes in Premia. This table presents the correlation matrix of monthly changes in the premia for Treasury bills and Treasury notes and bonds for the indicated maturity categories, where maturity is measured in years. The sample is monthly from January 1997 to October 2020.

\begin{tabular}{|c|c|c|c|c|c|c|}
\hline & T-Bills & $\leq 1$ Year & 1-5 Years & 5-10 Years & 10-20 Years & 20-30 Years \\
\hline T-Bills & 1.000 & 0.781 & 0.370 & 0.224 & 0.129 & 0.136 \\
\hline$\leq 1$ Year & 0.781 & 1.000 & 0.533 & 0.350 & 0.268 & 0.235 \\
\hline 1-5 Years & 0.370 & 0.533 & 1.000 & 0.785 & 0.595 & 0.548 \\
\hline 5-10 Years & 0.224 & 0.350 & 0.785 & 1.000 & 0.850 & 0.787 \\
\hline 10-20 Years & 0.129 & 0.268 & 0.595 & 0.850 & 1.000 & 0.935 \\
\hline 20-30 Years & 0.136 & 0.235 & 0.548 & 0.787 & 0.935 & 1.000 \\
\hline
\end{tabular}




\section{Table 6}

Results from Regressions of Monthly Changes in Premia on Changes in Measures of Treasury Debt Supply, Foreign Holdings of Treasury Debt, and Opportunity Cost. This table reports the results from the regressions of monthly changes in the premia for each maturity category on the indicated explanatory variables. Short-Term and Long-Term Debt denote the ratio of short-term and long-term Treasury debt to GDP, respectively. T-Bills Foreign and T-Bonds Foreign denote total foreign holdings of Treasury bills and Treasury notes/bonds, respectively. Fed Funds denotes the change in effective overnight fed funds rate The superscript ${ }^{*}$ denotes significance at the ten-percent level; the superscript ${ }^{* *}$ denotes significance at the five-percent level. Robust standard errors are based on Newey and West (1987). The sample period is monthly from January 2000 to October 2020

\begin{tabular}{|c|c|c|c|c|c|c|c|c|c|c|c|c|}
\hline & \multicolumn{2}{|c|}{ T-Bills } & \multicolumn{2}{|c|}{$\leq 1$ Year } & \multicolumn{2}{|c|}{ 1-5 Years } & \multicolumn{2}{|c|}{ 5-10 Years } & \multicolumn{2}{|c|}{ 10-20 Years } & \multicolumn{2}{|c|}{ 20-30 Years } \\
\hline & Coeff & $t$-Stat & Coeff & $t$-Stat & Coeff & $t$-Stat & Coeff & $t$-Stat & Coeff & $t$-Stat & Coeff & $t$-Stat \\
\hline Intercept & 0.578 & 0.92 & 0.534 & 0.99 & 0.048 & 0.15 & -0.198 & -0.54 & -0.205 & -0.51 & -0.369 & -0.92 \\
\hline$\Delta$ Short-Term Debt & -1.007 & -0.85 & 0.605 & 0.74 & -0.263 & -0.28 & 0.488 & 0.51 & 1.244 & 0.89 & 1.145 & 0.76 \\
\hline$\Delta$ Long-Term Debt & 0.061 & 0.13 & 0.524 & 1.28 & -0.138 & -0.40 & -0.347 & -0.78 & -0.333 & -0.54 & -0.576 & -0.88 \\
\hline$\Delta \mathrm{T}$-Bills Foreign & -0.029 & -0.73 & -0.061 & $-1.81^{*}$ & 0.016 & 0.52 & 0.008 & 0.23 & -0.012 & -0.25 & -0.009 & -0.18 \\
\hline$\Delta \mathrm{T}$-Bonds Foreign & -0.022 & -1.55 & -0.024 & -1.47 & -0.008 & -0.81 & 0.003 & 0.24 & 0.006 & 0.42 & 0.009 & 0.78 \\
\hline$\Delta$ Fed Funds & 10.771 & $1.75^{*}$ & 9.915 & $1.80^{*}$ & 3.417 & $2.28^{* *}$ & 3.315 & 1.41 & 6.745 & $2.32^{* *}$ & 5.071 & $2.08^{* *}$ \\
\hline Adj. $R^{2}$ & & 0.035 & & 0.080 & & 0.003 & & -0.002 & & 0.033 & & 0.016 \\
\hline$N$ & & 249 & & 249 & & 249 & & 249 & & 249 & & 249 \\
\hline
\end{tabular}




\section{Table 7}

Results from Panel Regression of Changes in Premia on the Reopening Ratio. This table reports the results from the regression of the change in premia on the reopening ratio and other control variables. Premia are measured in basis points. The reopening ratio is the ratio of the amount issued in the reopening to the total amount outstanding prior to the reopening. Coupon is expressed as a percentage. $T$ denotes maturity and is expressed in years. The amount outstanding is the total amount outstanding prior to the reopening and is measured in billions of dollars. The superscript ${ }^{*}$ denotes significance at the ten-percent level; the superscript ${ }^{* *}$ denotes significance at the five-percent level. Robust $t$-statistics are based on Newey and West (1987). The sample period is daily from January 23, 1997 to October 30, 2020.

\begin{tabular}{l|rr}
\hline & Coeff & $t$-Stat \\
\hline$T$ & & $-12.49^{* *}$ \\
$T \times T$ & -0.380 & $13.06^{* *}$ \\
$T \times T \times T$ & 0.037 & $-12.73^{* *}$ \\
Coupon & -0.001 & $-9.65^{* *}$ \\
Amount Outstanding & -0.267 & $2.75^{* *}$ \\
Reopening Ratio & 0.008 & $1.71^{*}$ \\
& & \\
Annual Fixed Effects & 0.882 & Yes \\
Adj. $R^{2}$ & & 0.033 \\
$N$ & & 63,334 \\
\hline
\end{tabular}


Table 8

397-Day Money Market Fund Inclusion Eligibility Event Study. This table reports the marketadjusted changes and cumulative changes in the premia for Treasury notes and bonds during the event window, where the event date (day zero) is defined as the first day that the Treasury note or bond satisfies the 397-day requirement for inclusion in the portfolio of a money market fund. Market-adjusted changes are computed by subtracting the average daily change in premia for all Treasury notes and bonds with maturities from 10 to 18 months (event window excluded) from the daily change in the premium for the bond defining the event. Premia are measured in basis points. The superscript ${ }^{*}$ denotes significance at the ten-percent level; the superscript ${ }^{* *}$ denotes significance at the five-percent level. The sample period is daily from January 23, 1997 to October 30, 2020.

\begin{tabular}{r|rrrrr}
\hline & \multicolumn{5}{|c}{ Cumulative } \\
Day & Change & $t$-Stat & Change & $t$-Stat & \\
& & & & \\
\hline & & & & & \\
-10 & -0.081 & -1.53 & -0.081 & -1.53 & 840 \\
-9 & -0.022 & -0.30 & -0.104 & -1.12 & 840 \\
-8 & 0.047 & 0.64 & -0.057 & -0.48 & 840 \\
-7 & 0.077 & 1.64 & 0.020 & 0.16 & 840 \\
-6 & 0.073 & 1.47 & 0.093 & 0.68 & 840 \\
-5 & 0.014 & 0.31 & 0.107 & 0.74 & 840 \\
-4 & -0.006 & -0.12 & 0.101 & 0.67 & 840 \\
-3 & -0.041 & -0.91 & 0.060 & 0.38 & 840 \\
-2 & -0.056 & -1.22 & 0.005 & 0.03 & 840 \\
-1 & -0.077 & -1.44 & -0.072 & -0.42 & 840 \\
& & & & \\
0 & -0.083 & -1.62 & -0.155 & -0.86 & 840 \\
1 & & & & \\
2 & -0.105 & -1.68 & -0.260 & -1.36 & 840 \\
3 & 0.087 & 1.41 & -0.173 & -0.86 & 840 \\
4 & -0.083 & -1.84 & -0.256 & -1.25 & 840 \\
5 & 0.194 & 4.06 & -0.063 & -0.30 & 840 \\
6 & -0.049 & -1.09 & -0.111 & -0.52 & 840 \\
7 & 0.027 & 0.62 & -0.084 & -0.38 & 840 \\
8 & 0.015 & 0.36 & -0.069 & -0.31 & 840 \\
9 & -0.013 & -0.28 & -0.082 & -0.36 & 840 \\
10 & -0.140 & -3.00 & -0.222 & -0.95 & 840 \\
& -0.107 & -2.24 & -0.329 & -1.38 & 840 \\
\hline & & & & & \\
\hline
\end{tabular}




\section{Table 9}

Results from Regressions of Monthly Changes in Premia on Changes in Measures of the Demand for Near-Money Assets. This table reports the results from the regressionsthe effective of monthly changes in the premia for the indicated maturity category on the indicated explanatory variables. Fed Funds denotes the change in overnight fed funds rate. Demand Deposits, Small Time Deposits, and Savings denote the respective components of the M1 and M2 monetary aggregates. Retail, Gov, Agency, and Prime MMFs denote the total assets of retail, government, government/agency, and prime money market funds, respectively. Inflation, Short-Term, Intermediate, Long-Term, State Muni, and National Muni MFs denote the respective total assets of inflation protected, short-term, intermediate-term, long-term, state municipal, and national municipal fixed income mutual funds, respectively. The superscript * denotes significance at the ten-percent level; the superscript ${ }^{* *}$ denotes significance at the five-percent level. Robust standard errors are based on Newey and West (1987). The sample period is monthly from January 2000 to October 2020.

\begin{tabular}{|c|c|c|c|c|c|c|c|c|c|c|c|c|}
\hline & \multicolumn{2}{|c|}{$\mathrm{T}-$ Bills } & \multicolumn{2}{|c|}{$\leq 1$ Year } & \multicolumn{2}{|c|}{$1-5$ Years } & \multicolumn{2}{|c|}{ 5-10 Years } & \multicolumn{2}{|c|}{ 10-20 Years } & \multicolumn{2}{|c|}{ 20-30 Years } \\
\hline & Coeff & $t$-Stat & Coeff & $t$-Stat & Coeff & $t$-Stat & Coeff & $t$-Stat & Coeff & $t$-Stat & Coeff & $t$-Stat \\
\hline Intercept & -0.651 & -0.95 & 0.061 & 0.12 & -0.301 & -0.72 & -0.456 & -0.95 & -0.465 & -0.87 & -0.483 & -0.92 \\
\hline$\Delta$ Fed Funds & 12.568 & $1.91^{*}$ & 12.001 & $2.16^{* *}$ & 4.421 & $2.81^{* *}$ & 4.044 & $1.70^{*}$ & 6.949 & $2.34^{* *}$ & 4.578 & 1.60 \\
\hline$\Delta$ Demand Deposits & -0.058 & $-1.83^{*}$ & -0.008 & -0.31 & -0.011 & -0.70 & -0.007 & -0.32 & 0.017 & 0.62 & 0.034 & 1.08 \\
\hline$\Delta$ Small Time Deposits & -0.043 & -0.70 & -0.061 & -1.12 & 0.035 & 1.49 & 0.004 & 0.14 & -0.026 & -0.52 & -0.002 & -0.04 \\
\hline$\Delta$ Savings & 0.016 & 1.26 & -0.006 & -0.62 & -0.004 & -0.66 & -0.007 & -0.96 & -0.011 & -1.32 & -0.013 & -1.43 \\
\hline$\Delta$ Retail MMFs & -0.015 & -0.23 & -0.001 & -0.02 & -0.048 & $-1.69^{*}$ & -0.041 & -1.13 & -0.056 & -1.24 & -0.052 & -1.16 \\
\hline$\Delta$ Gov MMFs & 0.133 & $2.16^{* *}$ & 0.065 & 1.28 & 0.076 & $3.30^{* *}$ & 0.025 & 0.62 & -0.025 & -0.42 & -0.042 & -0.62 \\
\hline$\Delta$ Agency MMFs & -0.007 & -0.21 & 0.009 & 0.26 & 0.002 & 0.16 & 0.023 & 1.12 & 0.039 & 1.45 & 0.031 & 1.06 \\
\hline$\Delta$ Prime MMFs & -0.017 & -0.67 & -0.006 & -0.32 & 0.007 & 0.77 & 0.012 & 1.07 & 0.018 & 1.35 & 0.016 & 1.17 \\
\hline$\Delta$ Inflation MFs & 0.877 & 1.42 & 1.021 & $2.39^{* *}$ & 0.554 & $2.62^{* *}$ & 0.739 & $2.64^{* *}$ & 1.057 & $2.58^{* *}$ & 0.803 & $1.87^{*}$ \\
\hline$\Delta$ Short-Term MFs & -2.904 & $-2.26^{* *}$ & -1.396 & -1.47 & -0.302 & -0.67 & -0.177 & -0.34 & 0.026 & 0.04 & -0.147 & -0.20 \\
\hline$\Delta$ Intermediate MFs & 0.871 & 0.50 & 1.313 & 0.92 & 0.208 & 0.26 & 0.343 & 0.33 & -0.348 & -0.29 & -0.625 & -0.44 \\
\hline$\Delta$ Long-Term MFs & 0.213 & 0.22 & 0.412 & 0.51 & -0.264 & -0.57 & -0.210 & -0.33 & -0.030 & -0.03 & 0.640 & 0.62 \\
\hline$\Delta$ State Muni MFs & -0.365 & -0.41 & 0.098 & 0.16 & -0.621 & $-2.31^{* *}$ & -0.769 & $-1.84^{*}$ & -1.011 & $-2.17^{* *}$ & -1.210 & $-2.32^{* *}$ \\
\hline$\Delta$ National Muni MFs & 0.073 & 0.28 & -0.199 & -1.10 & 0.166 & 1.41 & 0.162 & 1.06 & 0.140 & 0.85 & 0.203 & 1.16 \\
\hline $\begin{array}{l}\text { Adj. } R^{2} \\
N\end{array}$ & & $\begin{array}{r}0.065 \\
249\end{array}$ & & $\begin{array}{r}0.107 \\
249\end{array}$ & & $\begin{array}{r}0.054 \\
249\end{array}$ & & $\begin{array}{r}0.005 \\
249\end{array}$ & & $\begin{array}{r}0.063 \\
249\end{array}$ & & $\begin{array}{r}0.039 \\
249\end{array}$ \\
\hline
\end{tabular}




\section{Table 10}

Results from Regressions of Monthly Changes in Premia on Inflation-Hedging Asset Returns and Changes in Macroeconomic Inflation, and Tax-Related Variables. This table reports the results from the regressions of monthly changes in the premia for the indicated maturity category on the indicated explanatory variables. Fed Funds denotes the change in the effective overnight fed funds rate. The return indexes and the macroeconomic variables sentiment, unemployment, and CFNFI are described in the Appendix. ST and LT Inflation denote the University of Michigan Indexes of expected short-term and long-term inflation, respectively. Tax rate denotes the U.S. Implied Tax Rate Index reported by Bloomberg. Fiscal Uncertainty and Tax Uncertainty denote the Baker, Bloom, and Davis (2016) indexes of policy uncertainty, respectively. The superscript * denotes significance at the ten-percent level; the superscript ${ }^{* *}$ denotes significance at the five-percent level. Robust standard errors are based on Newey and West (1987). The sample period is monthly from February 1998 to October 2020.

\begin{tabular}{|c|c|c|c|c|c|c|c|c|c|c|c|c|}
\hline & \multicolumn{2}{|c|}{ T-Bills } & \multicolumn{2}{|c|}{$\leq 1$ Year } & \multicolumn{2}{|c|}{$1-5$ Years } & \multicolumn{2}{|c|}{ 5-10 Years } & \multicolumn{2}{|c|}{ 10-20 Years } & \multicolumn{2}{|c|}{ 20-30 Years } \\
\hline & Coeff & $t$-Stat & Coeff & $t$-Stat & Coeff & $t$-Stat & Coeff & $t$-Stat & Coeff & $t$-Stat & Coeff & $t$-Stat \\
\hline Intercept & -1.043 & -1.17 & -0.696 & -1.03 & -0.184 & -0.50 & -0.187 & -0.43 & -0.478 & -0.90 & -0.415 & -0.72 \\
\hline$\Delta$ Fed Funds & 3.385 & 0.91 & 5.707 & $2.30^{* *}$ & 1.243 & 1.13 & 2.451 & $1.92^{*}$ & 5.211 & $3.15^{* *}$ & 4.612 & $2.47^{* *}$ \\
\hline Gold Return & -0.134 & -0.90 & -0.135 & -1.27 & 0.026 & 0.34 & 0.209 & $2.02^{* *}$ & 0.339 & $2.41^{* *}$ & 0.334 & $1.98^{* *}$ \\
\hline Commodity Return & -0.062 & -0.22 & -0.047 & -0.26 & 0.121 & 1.23 & 0.231 & $2.41^{* *}$ & 0.210 & $1.70^{*}$ & 0.239 & $1.79^{*}$ \\
\hline Housing Return & 0.718 & 0.78 & 0.354 & 0.48 & 0.641 & 1.35 & 0.890 & $1.72^{*}$ & 1.204 & $1.90^{*}$ & 1.280 & $1.85^{*}$ \\
\hline TIPS Return & 1.103 & 1.61 & 1.318 & $2.30^{* *}$ & 0.014 & 0.04 & -0.334 & -0.84 & -0.128 & -0.32 & -0.494 & -1.27 \\
\hline S\&P 500 Return & 0.511 & $1.85^{*}$ & 0.206 & 1.12 & -0.177 & -1.34 & -0.308 & $-2.00^{* *}$ & -0.216 & -1.20 & -0.226 & -1.22 \\
\hline$\Delta$ Sentiment & 0.297 & 1.42 & 0.180 & 1.14 & 0.126 & 1.37 & 0.259 & $2.13^{* *}$ & 0.353 & $2.35^{* *}$ & 0.306 & $2.18^{* *}$ \\
\hline$\Delta$ Unemployment & -0.539 & -0.73 & 0.531 & 0.94 & 0.709 & $1.77^{*}$ & 1.183 & $2.27^{* *}$ & 1.904 & $2.95^{* *}$ & 1.639 & $2.77^{* *}$ \\
\hline$\Delta$ CFNFI & 34.916 & $5.29^{* *}$ & 21.199 & $6.82^{* *}$ & 9.593 & $3.75^{* *}$ & 6.496 & $2.51^{* *}$ & 1.155 & 0.33 & -0.436 & -0.14 \\
\hline$\Delta \mathrm{ST}$ Inflation & -2.039 & -0.94 & -3.174 & $-1.81^{*}$ & -2.181 & $-1.84^{*}$ & -1.986 & -1.33 & -1.739 & -0.93 & -2.672 & -1.19 \\
\hline$\Delta \mathrm{LT}$ Inflation & 6.387 & $1.66^{*}$ & 1.233 & 0.43 & 4.327 & $2.16^{* *}$ & 2.838 & 1.12 & 0.310 & 0.11 & -0.037 & -0.01 \\
\hline$\Delta$ Tax Rate & 0.239 & $2.27^{* *}$ & 0.174 & $1.77^{*}$ & 0.060 & 1.24 & 0.120 & $1.74^{*}$ & 0.115 & 1.17 & 0.106 & 0.92 \\
\hline$\Delta$ Fiscal Uncertainty & -0.001 & -0.01 & -0.009 & -0.32 & 0.019 & 0.57 & 0.029 & 0.56 & -0.011 & -0.23 & -0.073 & $-2.49^{* *}$ \\
\hline$\Delta$ Tax Uncertainty & -0.005 & -0.10 & -0.014 & -0.39 & -0.020 & -0.60 & -0.022 & -0.46 & 0.008 & 0.17 & 0.066 & $1.98^{* *}$ \\
\hline Adj. $R^{2}$ & & 0.205 & & 0.241 & & 0.114 & & 0.090 & & 0.097 & & 0.081 \\
\hline & & 273 & & 273 & & 273 & & 273 & & 273 & & 273 \\
\hline
\end{tabular}




\section{Table 11}

Results from Panel Regression of Premia on the Roth Conversion Interaction Variable. This table reports the results from the regression of the premia on the interaction between the coupon rate and Roth IRA conversions. Premia are measured in basis points. $T$ denotes maturity and is measured in years. Coupon is expressed as a percentage. Roth Conversions denotes the year-on-year percentage change in the number of taxpayers converting from an IRA to a Roth IRA. The superscript * denotes significance at the ten-percent level; the superscript ${ }^{* *}$ denotes significance at the five-percent level. Robust $t$-statistics are based on Newey and West (1987). The sample period is monthly from January 1997 to October 2020.

\begin{tabular}{l|rr}
\hline & Coeff & $t$ Stat \\
& & $2.35^{* *}$ \\
$T$ & 0.465 & $-6.68^{* *}$ \\
$T \times T 9^{* *}$ & $1.85^{* *}$ \\
$T \times T \times T$ & -0.124 & $-4.93^{*}$ \\
Coupon & 0.003 & 0.167 \\
Coupon $\times$ Roth Conversions & -3.634 & Yes \\
\hline Annual Fixed Effects & & 0.690 \\
Adj. $R^{2}$ & & 32,960 \\
\hline
\end{tabular}


Table 12

Maturity-Crossing Event Study. This table reports the cumulative changes in market-adjusted premia and $t$-statistics for Treasury notes and bonds during the event window, where the event is defined as the Treasury note or bond crossing the maturity indicated in the column heading. Market-adjusted changes are computed by subtracting the average daily change in premia for all Treasury notes and bonds with maturities straddling the maturity (event window excluded) from the daily change in the premium for the bond defining the event. Premia are measured in basis points. The sample period is daily from January 23 , 1997 to October 30, 2020.

\begin{tabular}{|c|c|c|c|c|c|c|}
\hline \multirow[b]{2}{*}{ Day } & \multicolumn{2}{|c|}{ 2-Year } & \multicolumn{2}{|c|}{ 3-Year } & \multicolumn{2}{|c|}{ 4-Year } \\
\hline & Change & $t$-Stat & Change & $t$-Stat & Change & $t$-Stat \\
\hline-20 & -0.049 & -1.15 & -0.015 & -0.38 & -0.022 & -0.77 \\
\hline-19 & -0.082 & -1.31 & -0.095 & -1.66 & -0.149 & -3.90 \\
\hline-18 & -0.136 & -1.83 & -0.139 & -2.05 & -0.178 & -3.93 \\
\hline-17 & -0.089 & -1.06 & -0.133 & -1.67 & -0.218 & -4.13 \\
\hline-16 & -0.147 & -1.61 & -0.269 & -3.05 & -0.290 & -4.95 \\
\hline-15 & -0.162 & -1.63 & -0.317 & -3.29 & -0.301 & -4.59 \\
\hline-14 & -0.234 & -2.19 & -0.378 & -3.64 & -0.433 & -6.00 \\
\hline-13 & -0.332 & -2.91 & -0.442 & -4.03 & -0.458 & -6.01 \\
\hline-12 & -0.447 & -3.62 & -0.492 & -4.26 & -0.493 & -6.10 \\
\hline-11 & -0.524 & -3.00 & -0.508 & -4.17 & -0.581 & -6.89 \\
\hline-10 & -0.426 & -3.03 & -0.588 & -4.66 & -0.657 & -7.45 \\
\hline-9 & -0.487 & -3.28 & -0.650 & -4.97 & -0.752 & -8.22 \\
\hline-8 & -0.470 & -3.08 & -0.698 & -5.17 & -0.805 & -8.53 \\
\hline-7 & -0.553 & -3.50 & -0.797 & -5.64 & -0.874 & -8.99 \\
\hline-6 & -0.470 & -2.83 & -0.871 & -5.99 & -0.906 & -9.00 \\
\hline-5 & -0.634 & -3.67 & -0.922 & -6.15 & -1.012 & -9.77 \\
\hline-4 & -0.706 & -3.99 & -1.031 & -6.69 & -1.069 & -10.00 \\
\hline-3 & -0.737 & -4.07 & -1.045 & -6.63 & -1.114 & -10.11 \\
\hline-2 & -0.749 & -4.01 & -1.060 & -6.50 & -1.161 & -10.22 \\
\hline-1 & -0.888 & -4.60 & -1.011 & -5.61 & -1.264 & -10.81 \\
\hline 0 & -0.963 & -4.84 & -1.059 & -5.44 & -1.311 & -10.86 \\
\hline 1 & -0.944 & -4.63 & -1.015 & -5.12 & -1.342 & -10.81 \\
\hline 2 & -0.912 & -4.36 & -0.994 & -4.94 & -1.348 & -10.62 \\
\hline 3 & -0.978 & -4.52 & -1.069 & -5.21 & -1.349 & -10.29 \\
\hline 4 & -0.917 & -4.10 & -1.085 & -5.18 & -1.380 & -10.14 \\
\hline 5 & -0.919 & -4.04 & -1.198 & -5.62 & -1.374 & -9.84 \\
\hline 6 & -0.912 & -3.92 & -1.123 & -5.18 & -1.422 & -9.88 \\
\hline 7 & -0.888 & -3.72 & -1.207 & -5.48 & -1.472 & -10.02 \\
\hline 8 & -0.894 & -3.70 & -1.226 & -5.50 & -1.441 & -9.59 \\
\hline 9 & -0.940 & -3.82 & -1.151 & -5.09 & -1.466 & -9.57 \\
\hline 10 & -1.020 & -4.07 & -1.144 & -5.00 & -1.521 & -9.72 \\
\hline 11 & -1.019 & -4.00 & -1.113 & -4.82 & -1.509 & -9.46 \\
\hline 12 & -0.949 & -3.69 & -1.157 & -4.96 & -1.530 & -9.45 \\
\hline 13 & -0.962 & -3.70 & -1.154 & -4.89 & -1.577 & -9.51 \\
\hline 14 & -0.931 & -3.54 & -1.188 & -4.96 & -1.619 & -9.39 \\
\hline 15 & -1.002 & -3.77 & -1.205 & -4.97 & -1.572 & -8.77 \\
\hline 16 & -1.036 & -3.87 & -1.158 & -4.74 & -1.652 & -9.05 \\
\hline 17 & -1.034 & -3.82 & -1.165 & -4.72 & -1.664 & -8.99 \\
\hline 18 & -1.051 & -3.84 & -1.226 & -4.93 & -1.650 & -8.80 \\
\hline 19 & -1.029 & -3.72 & -1.193 & -4.76 & -1.614 & -8.50 \\
\hline 20 & -1.151 & -4.11 & -1.193 & -4.71 & -1.644 & -8.57 \\
\hline
\end{tabular}


Table 12 Continued

\begin{tabular}{|c|c|c|c|c|c|c|}
\hline \multirow[b]{2}{*}{ Day } & \multicolumn{2}{|c|}{ 5-Year } & \multicolumn{2}{|c|}{ 7-Year } & \multicolumn{2}{|c|}{ 10-Year } \\
\hline & Change & $t$-Stat & Change & $t$-Stat & Change & $t$-Stat \\
\hline-20 & -0.124 & -2.78 & -0.040 & -0.54 & -0.138 & -0.90 \\
\hline-19 & -0.304 & -4.23 & -0.255 & -2.55 & -0.338 & -1.87 \\
\hline-18 & -0.398 & -4.90 & -0.253 & -2.01 & -0.437 & -2.08 \\
\hline-17 & -0.640 & -6.20 & -0.388 & -2.58 & -0.344 & -1.55 \\
\hline-16 & -0.789 & -7.00 & -0.496 & -3.08 & -0.659 & -2.40 \\
\hline-15 & -0.908 & -7.35 & -0.592 & -3.54 & -0.773 & -2.57 \\
\hline-14 & -1.021 & -8.00 & -0.805 & -4.64 & -0.727 & -2.34 \\
\hline-13 & -1.179 & -8.98 & -0.837 & -4.61 & -0.912 & -2.75 \\
\hline-12 & -1.219 & -9.02 & -0.881 & -4.66 & -0.930 & -2.76 \\
\hline-11 & -1.390 & -9.84 & -0.984 & -4.97 & -0.929 & -2.71 \\
\hline-10 & -1.545 & -10.61 & -1.174 & -5.83 & -0.960 & -2.77 \\
\hline-9 & -1.698 & -11.45 & -1.258 & -6.06 & -1.000 & -2.78 \\
\hline-8 & -1.830 & -12.10 & -1.305 & -6.13 & -1.067 & -2.70 \\
\hline-7 & -1.989 & -12.83 & -1.460 & -6.64 & -0.905 & -2.17 \\
\hline-6 & -2.130 & -13.44 & -1.503 & -6.65 & -0.893 & -2.13 \\
\hline-5 & -2.293 & -13.97 & -1.661 & -7.23 & -0.963 & -2.27 \\
\hline-4 & -2.479 & -14.83 & -1.742 & -7.43 & -1.016 & -2.37 \\
\hline-3 & -2.653 & -15.55 & -1.816 & -7.42 & -0.984 & -2.26 \\
\hline-2 & -2.762 & -15.84 & -1.826 & -7.28 & -0.986 & -2.25 \\
\hline-1 & -2.939 & -16.52 & -1.968 & -7.61 & -0.859 & -1.92 \\
\hline 0 & -2.981 & -16.34 & -2.403 & -7.76 & -1.033 & -2.25 \\
\hline 1 & -3.072 & -16.55 & -2.212 & -8.19 & -1.019 & -2.17 \\
\hline 2 & -3.036 & -15.89 & -2.249 & -8.13 & -1.010 & -2.12 \\
\hline 3 & -3.099 & -15.92 & -2.114 & -7.27 & -0.916 & -1.91 \\
\hline 4 & -3.172 & -15.88 & -2.219 & -7.35 & -0.938 & -1.94 \\
\hline 5 & -3.136 & -15.28 & -2.242 & -7.27 & -0.820 & -1.66 \\
\hline 6 & -3.215 & -15.45 & -2.254 & -7.17 & -0.873 & -1.75 \\
\hline 7 & -3.345 & -15.85 & -2.299 & -7.19 & -0.967 & -1.93 \\
\hline 8 & -3.326 & -15.51 & -2.337 & -7.15 & -0.954 & -1.85 \\
\hline 9 & -3.341 & -15.34 & -2.336 & -6.98 & -1.401 & -2.32 \\
\hline 10 & -3.357 & -15.28 & -2.358 & -6.83 & -1.178 & -1.79 \\
\hline 11 & -3.322 & -14.81 & -2.513 & -7.02 & -1.179 & -1.78 \\
\hline 12 & -3.350 & -14.79 & -2.538 & -7.00 & -1.226 & -1.84 \\
\hline 13 & -3.389 & -14.69 & -2.646 & -7.17 & -1.379 & -2.06 \\
\hline 14 & -3.470 & -14.82 & -2.547 & -6.78 & -1.447 & -2.16 \\
\hline 15 & -3.515 & -14.83 & -2.599 & -6.74 & -1.522 & -2.25 \\
\hline 16 & -3.498 & -14.52 & -2.451 & -6.21 & -1.433 & -2.10 \\
\hline 17 & -3.517 & -14.42 & -2.683 & -6.64 & -1.401 & -2.04 \\
\hline 18 & -3.534 & -14.38 & -2.739 & -6.66 & -1.580 & -2.28 \\
\hline 19 & -3.553 & -14.36 & -2.860 & -6.86 & -1.547 & -2.23 \\
\hline 20 & -3.565 & -14.27 & -2.821 & -6.68 & -1.595 & -2.30 \\
\hline
\end{tabular}




\section{ONLINE APPENDIX}

\section{TREASURY RICHNESS}

Matthias Fleckenstein

Francis A. Longstaff 


\section{ONLINE APPENDIX}

\section{A.1 Data Sources}

Table A1 provides a description of all the data and variables used in the study along with their definitions and corresponding sources.

\section{A.2 The Riskfree Discounting Curve}

This section shows how the riskfree discounting curve can be inferred from the term structure of fixed-for-floating interest rate swaps in which the floating leg of the swap is based on the overnight repo rate. Since repo swaps may be less familiar than conventional swaps, we begin with a brief description of the overnight repo rate and the repo swap market. We then show how to solve for the riskfree discounting curve from the term structure of overnight repo swaps.

\section{A.2.1 The Overnight Repo Rate}

The key to our approach is the recognition that the interest rate on overnight U.S. Treasury general collateral repurchase transactions (repo rate) can be viewed as a riskfree interest rate in the most basic sense of that term. ${ }^{1}$ There are several reasons for this. First, overnight general collateral (GC) Treasury repo loans are fully secured by the safest and most-liquid collateral in the market-Treasury securities. Specifically, a Treasury repo transaction is structured legally as an agreement between counterparties to engage in a sale of Treasury securities on an initial date with a repurchase of the securities by the initial seller at a later date, typically overnight. ${ }^{2}$ Since the legal title to the Treasury collateral is transferred to the repo buyer, the economic role of a repo transaction is similar to that of a secured loan from the repo buyer's perspective. ${ }^{3}$ In contrast to a se-

\footnotetext{
${ }^{1}$ General collateral is the term used to describe a set of Treasury securities that are equivalent in their use as collateral for repo loans. By contrast, in specific collateral repo transactions the Treasury securities are required to satisfy a number of criteria such as having maturities in specific ranges.

${ }^{2}$ For a discussion of term repos which can have tenors of several months see Fleckenstein and Longstaff (2020a).

${ }^{3}$ U.S. Treasury repo transactions are typically documented with the Securities Industry and Financial Markets Association's (SIFMA) Master Repurchase Agreement and the SIFMA/International Capital Market Association (ICMA) Global Master Repurchase Agreement, but there can also be customized agreements between repo counterparties.
} 
cured loan, a repo transaction provides significant protections to creditors from the normal operation of U.S. bankruptcy laws, such as the automatic stay and avoidance provisions (11 U.S.C. paragraphs 362(b)(7) and 546(f)). Consequently, the counterparty holding the securities (the cash lender) may liquidate the securities held and accelerate or terminate the agreement in the event of insolvency (11 U.S.C. paragraph 559).

Second, repo loans are not only fully secured, but are actually overcollateralized because repo borrowers face haircuts and cannot borrow the full value of the Treasuries they provide as collateral. The median margin (haircut) for Treasury notes in the tri-party repo market is estimated to be about two percent using data from the Federal Reserve Bank of New York. ${ }^{4}$ This implies that the repo borrower can borrow only about 98 cents for each dollar of Treasury collateral. Moreover, Gorton and Metrick (2012) and Baklanova, Caglio, Cipriani and Copeland (2016) find that repo lenders use haircuts to adjust for credit risk and market conditions. For instance, Gorton and Metrick (2012) report that repo lenders tended to adjust the haircuts on repo collateral during the financial crisis of 2007-2008 while leaving repo rates largely unaffected.

Third, since general collateral Treasury repo loans are purely financial contracts rather than securities, overnight repo rates should be less affected by the various liquidity and supply factors that may drive the specialness of cash market instruments such as Treasuries. Moreover, the repo market is a multi-trillion dollar market. Copeland, Duffie, Martin, and McLaughlin (2012) estimate the outstanding value of repo and reverse repo activity in the U.S. at $\$ 3$ trillion and $\$ 2$ trillion, respectively. Comparable or even higher estimates are provided by Aitken and Singh (2010), Gorton and Metrick (2012), Krishnamurthy, Nagel, and Orlov (2014), and Baklanova, Copeland, and McCaughrin (2015). Baklanova, Caglio, Cipriani and Copeland (2016) report that transactions involving U.S. Treasuries represented 61 percent of the value for securities in (transactions in which a dealer bank receives securities in exchange for lending cash) and 81 percent for securities out (transactions in which a dealer bank delivers securities

\footnotetext{
${ }^{4}$ The U.S. repo market is comprised of three segments based on differences in settlement: the tri-party, the General Collateral Finance (GCF), and the bilateral repo markets. A triparty/ GCF repo involves a clearing bank as a third party which provides settlement and collateral management services. In the bilateral market, lenders and borrowers usually interact directly to negotiate the terms and settle the trade (Baklanova, Copeland and McCaughrin (2015)). A bilateral repo is an inter-dealer transaction in which the cash borrower and cash lender directly negotiate a rate and duration for the repo, and specify a class of assets which can be pledged as collateral (e.g., Treasuries with fewer than five years to maturity, all mortgage-backed securities, etc.).
} 
in exchange for borrowing cash).

\section{A.2.2 Repo Swaps}

Our approach to identify the riskless discounting curve is to use the term structure of fixed-for-floating interest rate swap rates in which the rate on the floating leg is the overnight repo rate. We designate this type of interest rate swap a repo swap. ${ }^{5}$ A repo swap is a specific case of the set of interest rate swaps commonly referred to as overnight index (OIS) swaps. ${ }^{6}$ In a standard fixed-for-floating OIS swap the counterparties agree to exchange the difference between the fixed rate set at inception of the swap (referred to as the OIS rate) and interest accrued from the geometric average of the floating overnight index rate on the agreed notional amount at regular intervals over the life of the swap. ${ }^{7}$ For OIS swaps with maturities of one year or less, cash flows are only exchanged once at maturity of the swap. By contrast, cash flows are exchanged at the end of every twelvemonth period in OIS swaps with maturities of more than one year. To illustrate, consider a one-year OIS swap with a notional amount of $\$ 100$ and a quoted swap rate of 1.200 percent. In one year (365 days), the fixed rate payer pays $1.200 \times 365 / 360=1.21667$ and receives the geometrically compounded overnight index rate for 365 days. $^{8}$

This approach has several advantages. First, repo swaps are traded for maturities of several months up to 30 years which allows us to construct a discounting

\footnotetext{
${ }^{5}$ Repo swaps exist as plain-vanilla fixed-for-floating interest rate swaps and as basis swaps in which an overnight repo rate is exchanged against the effective overnight fed funds rate or the London Interbank Offered Rate (LIBOR). For additional details on contract specifications, clearing, and margining see CME Group (2018) and Srinivasan et al. (2020).

${ }^{6}$ In the U.S., the most-common type of OIS swap references the effective overnight federal funds rate which is published daily by the Federal Reserve in its H.15 release. We designate this type of OIS swap as a fed funds OIS swap.

${ }^{7}$ The accrual on the floating leg of an OIS swap mirrors a strategy which borrows the swap's notional amount, invests it in the overnight index rate and rolls over principal plus interest on an overnight basis between the swap's designated regular cash flow dates. The fixed leg accrual is a straightforward interest calculation using the swap's fixed rate and the actual/360 money market convention.

${ }^{8}$ In a standard OIS swap, the overnight rate for the last day of the compounding period is not known prior to the morning of the expiration day. Hence, the market convention is that OIS swaps have a fixing lag of one day and the final payment occurs with a lag of two days.
} 
curve for the entire maturity spectrum of Treasury bills, notes and bonds. Second, repo swaps have zero initial cash flows and there is no exchange of notional amounts between the counterparties. Third, repo swaps are collateralized, and the cash flows over the life of the swap are settled on a net basis. Thus, counterparty risk issues and the various liquidity and supply factors that may drive the specialness of cash market instruments should also be minuscule in repo swaps. ${ }^{9}$

At the start of our sample on January 23, 1997, market rates for repo swaps are not available. However, data for swaps based on the effective overnight fed funds rate exist, and it is straightforward to adjust the fed funds OIS rates for the difference between the overnight repo and the effective overnight fed funds rate, thus creating synthetic repo swaps. ${ }^{10}$ First, as discussed, repo swaps and fed funds OIS swaps are essentially the same type of contract, except that the former uses the overnight repo rate and the latter uses the effective overnight fed funds rate to calculate the cash flows on the swap's floating leg. ${ }^{11}$ Second, fed funds OIS swaps have become widely-used liquid derivatives since their introduction in the 1990s. ${ }^{12}$ Third, discounting factors calculated from fed funds OIS swaps have become the industry standard used to mark-to-market cash-collateralized swap trades (LCH Group (2010)). Since term structures of fed funds OIS swap rates are available from 1997, we can use the adjusted fed funds OIS swaps data to proxy for repo swap rates over a significantly longer period which allows us to study the patterns of Treasury richness/cheapness across the entire range of maturities for all types of Treasury securities over a period spanning nearly 25 years.

${ }^{9}$ See Wheatley (2012) and Tabb and Grundfest (2013).

${ }^{10}$ The Chicago Mercantile Exchange (CME) provides historical term structures of SOFR swap rates for tenors out to 30 years going back to 2008 using an approach that has parallels to ours. Specifically, the CME obtains their data from SOFR fixings published by the New York Fed and existing term structures and fixings for three-month LIBOR and the OIS swaps curve (see https://www.cmegroup.co $\mathrm{m} /$ market-data/faq-sofr-third-party-data.html).

${ }^{11}$ Both fed funds and repo swaps use the actual/360 day-count convention and have the same settlement date rules.

${ }^{12}$ On March 15, 2013, total daily and year-to-date volumes cleared in OIS derivatives exceeded those of standard plain-vanilla interest rate swaps for the first time (see LCH SwapClear, SwapClear Daily Volumes, March 15, 2013, at https://ww w.lch.com/services/swapclear/volumes). Moreover, in 2019, the total annual dollar notional amount of OIS swaps cleared on LCH SwapClear and the CME exceeded $\$ 120$ trillion. In 2020 , around $\$ 400$ billion in OIS swaps was cleared at $\mathrm{LCH}$ and the CME each day (see Clarus Financial Technology, CCP Volumes and Market Shares 2019 and 2020 at https://www.clarusft.com). 
For fed funds OIS swaps over the period from January 1997 to February 2002, our approach is to create a fixed-for-floating fed funds OIS swap by simultaneously entering into a fed funds/three-month LIBOR basis swap and a plain-vanilla fixed-for-floating interest rate swap based on three-month LIBOR. ${ }^{13}$ Specifically, we collect end-of-day fed funds/three-month LIBOR basis swap rates for tenors of 1, 3, and 6 months, and 1, 2, 3, 5, 7, 10, 15, 20, and 30 years from the Bloomberg system for the period starting on January 23, 1997. Fed funds/threemonth LIBOR swaps exchange quarterly floating rate cash flows for the tenor of the basis swap based on the daily compounded effective overnight fed funds rate over the quarter plus a spread for floating cash flows based on the three-month LIBOR rate set at the beginning of the quarter. Next, we also collect end-of-day fixed-for-floating three-month LIBOR interest rate swap rates for tenors of 1,3 , and 6 months, and 1, 2, 3, 5, 7, 10, 15, 20, and 30 years from the Bloomberg system for the period starting on January 23, 1997. Fixed-for-floating three-month LIBOR interest rate swaps exchange quarterly floating cash flows based on the three-month LIBOR rate set at the beginning of the quarter for semiannual cash flows based on the fixed swap rate which is set at inception of the swap.

To illustrate how we obtain a fed funds OIS swap with maturity in $T$ years by simultaneously executing a fed funds/three-month LIBOR basis swap and a standard fixed-for-floating three-month LIBOR interest rate swap with identical tenor $T$, suppose the basis swap has quarterly cash flows based on the daily-compounded fed funds rate over the quarter plus a constant spread $F_{B}$, in exchange for quarterly cash flows based on the three-month LIBOR rate set at the beginning of the quarter. Furthermore, suppose that the fixed-for-floating three-month LIBOR swap has quarterly cash flows based on the three-month LIBOR rate set at the beginning of the quarter in exchange for fixed quarterly cash flows based on the fixed swap rate $F_{L}$ set at the initiation of the swap. ${ }^{14}$ The net effect of executing the two swaps are fixed quarterly cash flows based on the fixed rate $F_{L}-F_{B}$ in exchange for quarterly cash flows based on the daily-compounded effective overnight fed funds rate over the quarter. Thus, the cash flows of a combined fed funds basis swap and a plain-vanilla interest rate

\footnotetext{
${ }^{13}$ For a discussion of the basis swap market see Fleckenstein and Longstaff (2020b).

${ }^{14}$ Since the fixed leg of a standard LIBOR interest swap pays cash flows on a semiannual basis, we reannuitize the rate on the fixed leg of the swap to correspond to quarterly cash flows. Moreover, the day-count convention used for fed funds/LIBOR basis swaps is actual/360 whereas it is 30/360 for the fixed leg of the LIBOR interest rate swap. To correctly account for day-count differences, we convert all swap rates to the 30/360 day-count convention.
} 
swap mirror the cash flows of a fed funds OIS swap. ${ }^{15}$

There are instances where we lack data for specific tenors of fed funds/threemonth LIBOR basis swaps and for standard three-month LIBOR interest rate swaps at the beginning of our sample. Specifically, data on 1-, 3-, and 6-month basis swaps are not available between January 1997 and December 2001. Instead, we use the one-year basis swap rate. Furthermore, we do not observe basis swap data for the 15-, 20-, and 30-year tenors from January 1997 to July 2008. During this period we estimate the missing 15-, 20-, and 30-year tenors by regressing these longer-term tenors on the 1-, 2-, 3-, 5-, 7-, and 10-year basis swap rates. ${ }^{16}$ Between January 1998 and November 2003, we have no data for 1-, 3-, and 6month LIBOR interest rate swaps. During this period we use 1-, 3-, and 6-month LIBOR cash rates for the corresponding 1-, 3-, and 6-month swap rates.

Starting in February 2002, we have actual fixed-for-floating fed funds OIS swaps for the same tenors. Specifically, we collect fed funds OIS swap rates for tenors of 1,3 , and 6 months, and 1, 2, 3, 5, 7, 10, 15, 20, and 30 years for the period from February 13, 2002 to January 1, 2017 from the Bloomberg system. Between December 2001 and July 2008, only fed funds OIS swaps with tenors of 1,3 , and 6 months and 1,2,3, and 5 years are quoted in the Bloomberg system. For the 7-, 10-, 15-, 20-, and 30-year tenors, we obtain fed funds OIS by simultaneously executing a fed funds/three-month LIBOR basis swap and a standard fixed-for-floating three-month LIBOR interest rate swap with the same tenor.

From January 2017 through the end of our sample in October 2020, we use actual repo swap rates which use a specific construction of the overnight repo rate known as the Secured Overnight Financing Rate (SOFR) to calculate cash flows on the floating leg of the repo swap. ${ }^{17}$ SOFR is designed to be a riskfree benchmark interest rate. ${ }^{18}$ It measures the cost of borrowing cash in the repo market via overnight loans collateralized by U.S. Treasury securities.

${ }^{15}$ Since OIS swaps have annual cash flows for tenors of one year or longer, we also reannuitize the fixed leg of the combined basis/interest rate swap to correspond to annual cash flows.

${ }^{16}$ This regression methodology allows us to match the upward sloping term structure of basis swap rates in the data.

${ }^{17} \mathrm{SOFR}$ has been designated by the Alternative Reference Rates Committee (ARRC) to become the new benchmark riskfree interest rate at the end of December 2021 in the U.S. The ARRC is a group of private-market participants convened by the Federal Reserve Board and the New York Fed (see https://www.newyorkfed.org/arrc).

${ }^{18}$ The Treasury repo market "reflects the best available measure of the private 
Specifically, SOFR is calculated using a broad basket of transactions from the three segments of the over $\$ 800$ billion overnight U.S. Treasury repo market. First, in the General Collateral Finance (GCF) repo market, member banks of the Fixed Income Clearing Corporation (FICC) trade general U.S. Treasury collateral repos which are cleared through the FICC's GCF repo service. ${ }^{19}$ Second, in the FICC Delivery-versus-Payment (DvP) repo market, FICC members trade repos for specific Treasury securities. Third, in the tri-party repo market, security dealers trade repos with the Bank of New York Mellon acting as the third party. Each day, SOFR is calculated as the volume-weighted median of overnight repo rates on transactions in the GCF, FICC DvP, and tri-party repo markets. ${ }^{20}$ While SOFR has only been officially published since 2018 by the New York Fed in cooperation with the Office of Financial Research (OFR), indicative SOFR rates are available going back to August 2014. ${ }^{21}$ The New York Fed also provides a time series of the volume-weighted average rate of primary dealers' overnight Treasury general collateral repo borrowing activity which it collects through its primary dealer survey going back to February 1998. The New York Fed considers primary dealer repo rates a good measure of riskfree reference rates over a significantly longer time horizon. ${ }^{22}$ We collect daily data on repo swaps based on SOFR for tenors of 1,3, and 6 months, and 1, 2, 3, 5, 7, 10, 15, 20, and 30 years from the Bloomberg system for the period from January 1, 2017 to October 30, 2020. ${ }^{23}$

sector's near risk-free rate of borrowing relevant to a wide segment of market participants." SOFR is "a fully-transaction based, nearly risk-free reference rate." See https://www.newyorkfed.org/medialibrary/Microsites/arrc/files/ARRC-fa q.pdf.

${ }^{19}$ In general collateral repo transactions, the specific Treasury securities provided as collateral are not specified at the point of trade execution. Rather, the repo transaction is collateralized by a broad set of U.S. Treasury securities (see https://www.dtcc.com/clearing-services/ficc-gov/gcf-repo).

${ }^{20}$ The repo rates from all three segments of the repo market are used to calculate SOFR, except for FICC DvP trades that have rates falling below the 25th percentile of the whole FICC DvP data each day. The reason for this is that these repos are considered to be "special" and are hence excluded from the calculation.

${ }^{21}$ See https://apps.newyorkfed.org/markets/autorates/sofr.

22 "[T] he survey rate can play an important role in providing insight into how a broad measure of repo market activity would have behaved over a significantly longer time horizon." See https://www.newyorkfed.org/markets/opolicy/opera ting_policy_180309.

${ }^{23}$ Trading of centrally-cleared SOFR swaps started in July 2017. Specifically, the first cleared SOFR swaps were traded in July 2017 for a cumulative monthly total of $\$ 375$ million gross notional, of which $\$ 300$ million were in one-year swaps and 
The resulting dataset consists of fed funds OIS swaps for the period starting in January 1997 to January 2017, and repo swaps based on SOFR from January 2017 to the end of October 2020. As the final step, we adjust the fed funds OIS swap rates for the difference between the overnight fed funds rate and the overnight repo rate to turn them into synthetic repo swaps. In doing so, we first calculate the difference between repo swap rates and fed funds OIS swap rates of the same maturity for the period starting in January 2017 during which we observe market rates on both types of OIS swaps. The average repo/fed funds OIS swap spread for 30 -year swaps is 4.5 basis points. In addition, we also calculate the average difference between the effective overnight fed funds rate and the overnight repo rate, and the average difference between the overnight primary dealer survey repo rate provided by the New York Fed and SOFR. Over the 2017-2020 period, the differences are 2.00 basis points and 2.67 basis points, respectively. We note that the sum of these two estimates is close to 4.5 basis points within a fraction of a basis point. We thus subtract 4.5 basis points from the fed funds OIS swap rates for all tenors to calculate the equivalent repo swap rates. Our final dataset consists of repo swap rates for tenors of 1, 3, and 6 months, and $1,2,3,5,7,10,15,20$, and 30 years the period starting on January 23, 1997 to October 30, 2020. We use this data to solve for the riskfree discounting curve as described below.

\section{A.2.3 Solving for the Riskfree Discounting Curve}

To illustrate how we solve for the riskfree discounting curve using the term structure of repo swaps, we begin with the case of a one-year repo swap. Let $r_{t}$ denote the overnight repo rate, and let $D(t)$ denote the present value of a riskfree cash flow of one dollar to be received at time $t$. Assuming continuous cash flows, the floating leg of the repo swap pays a single cash flow of $\exp \left(\int_{0}^{1} r_{t} d t\right)$ in one year. Using the risk-neutral measure, the present value of this floating cash flow is

$$
E\left[\exp \left(-\int_{0}^{1} r_{t} d t\right) \exp \left(\int_{0}^{1} r_{t} d t\right)\right]=1
$$

The fixed leg of the repo swap pays a single cash flow of $\left(1+F_{1}\right)$ in one year, where $F_{1}$ is the current one-year repo swap rate observed in the market. Since $F_{1}$ is fixed at time zero, the present value of the fixed leg is just $\left(1+F_{1}\right) D(1)$. Because the initial value of the repo swap is zero, the present value of the fixed

$\$ 75$ million in two-year swaps (see https://www.clarusft.com/more-sofr-swapsare-trading). By June 2020, there were over $\$ 600$ billion in outstanding notional in SOFR swaps and over $\$ 700$ billion in SOFR basis swaps (Bowman (2020)). 
leg of the repo swap equals the present value of the floating leg, which gives

$$
D(1)=\frac{1}{1+F_{1}} .
$$

This approach is easily extended to longer maturities. Let $i$ denote the time of the $i$-th cash flow of an $N$-year maturity repo swap, where $i=1, \ldots, N$. Table A2 shows the cash flows from a fixed-for-floating repo swap with maturity in $N$ years and annual cash flows at $i=1,2, \ldots, N-1, N$. The cash flows on the fixed leg of the repo swap are denoted by $F_{N}$. As shown, setting the present value of the fixed leg of an $N$-year repo swap equal to the present value of the floating leg gives the relation

$$
F_{N} \sum_{i=1}^{N} D(i)+D(N)=1 .
$$

Thus, given a term structure of repo swap rates $F_{N}, N=2,3, \ldots, 30$, Equation (A3) can be solved recursively for the riskfree discount factors $D(i), i=$ $2,3, \ldots, 30$.

In calculating riskfree discount factors using Equation (A3) using the dataset of repo swaps from January 1997 to October 2020 described in the previous section, we first solve for the riskfree discount factors for tenors of $1,3,6$, and 12 months. Since repo swaps with maturities with one year or less have a single cash flow at maturity of the swap, the riskfree discount factor is given by

$$
D(T)=\frac{1}{1+\Delta_{T} F(T)},
$$

for $T=0.25,0.50$, and 1.00, where $\Delta_{T}$ denotes the number of days between the inception and the maturity of the swap, expressed as a fraction of one year. ${ }^{24}$ To calculate discount factors for tenors greater than one year using Equation (A3), we first interpolate the term structure of repo swap rates at annual intervals using a standard cubic spline. Then, we recursively solve Equation (A3) for the riskfree discounting function $D(N), N=\{1,2,3,4,5, \ldots, 30\}$ at annual intervals. ${ }^{25}$ In the last step, we calculate discount factors $D(t)$ for any given maturity $t$ by

${ }^{24}$ We convert all swap rates used in bootstrapping the riskfree discounting curve to the $30 / 360$ day-count convention.

${ }^{25}$ For more details on this algorithm see Longstaff, Mithal, and Neis (2005). 
interpolating the continuously-compounded yields from the discounting function linearly at monthly intervals.

\section{A.3 Estimating Treasury Richness}

Given the riskfree discounting curve, we can estimate the richness/cheapness of individual Treasury bills, notes, and bonds directly. As shown in Section 3 of the paper, the present value of a riskless bond with maturity $T$ is straightforward to calculate given the set of riskfree discounting factors $D(t)$, the CDS spread $s$, and the default intensity $\lambda$ for the time to maturity $T$ of the bond by using Equation (2).

To estimate the default intensity $\lambda$ for any maturity $T$, we collect daily endof-day CDS mid-spreads $s$ of dollar-denominated contracts for tenors of $T=0.5$, $1,2,3,5,7,10,15,20$, and 30 years from Markit for the period from December 1, 2003 to October 30, 2020. ${ }^{26}$ Next, we follow the widely-used approach and model hazard rates as a piecewise constant function of time to maturity, and then bootstrap a term-structure of hazard rates from the CDS spreads market data. For details on this approach see Hull and White (2000), Schönbucher (2003), Brigo and Mercurio (2006), O'Kane (2008), and Beumee, Brigo, Schiemert and Stoyle (2009). The result of this algorithm is a daily term structure of CDS spreads $s$ and hazard rates $\lambda$ for any maturity $T$.

We identify Treasury richness directly as the difference between the market price of the actual Treasury security and the present value of the Treasury/CDS portfolio. Analogously, we define Treasury richness in yield space as the difference in yields between the actual Treasury security and the Treasury/CDS portfolio.

\section{A.4 Treasury Reopenings}

While the Treasury regularly sells Treasury bills, notes, and bonds to investors via public auctions, it often offers additional amounts of outstanding securities via so-called reopenings. The reopened Treasury security has the same maturity date and coupon interest rate as the original security, and the reopened and the previously-auctioned Treasury are identical securities with the same CUSIP number.

\footnotetext{
${ }^{26}$ We also collect CDS mid-spreads of euro-denominated contracts for the same maturities from the same source. In robustness tests, we confirm that using dollar- or euro-denominated CDS has no effect on our Treasury premia estimates prior to the 2008 financial crisis, and after the crisis the estimates are qualitatively very similar.
} 
Specifically, the U.S. Treasury sells Treasury bills, notes, and bonds to investors via public auctions which occur on a regular and pre-announced schedule. Treasury bills with 4-week, 8-week, 13-week, and 26-week to maturity are auctioned weekly (4- and 8-week bills on Thursdays, and 13- and 26-week bills on Mondays). 52-week bills are typically auctioned every four weeks on Tuesdays. ${ }^{27}$ The U.S. Treasury announces all auctions ahead of time via a public announcement. ${ }^{28}$ The U.S. Treasury currently issues notes with 2-, 3-, 5-, 7-, and 10-year maturities. Treasury notes with maturities of $2,3,5$, and 7 years are auctioned on a monthly basis, 10-year notes are auctioned quarterly in February, May, August, and November, and 20-year and 30-year bonds are auctioned at quarterly frequency in February, May, August, and November.

The U.S. Treasury offers additional amounts of outstanding securities via reopenings which also occur on a pre-determined schedule. Specifically, 10-year notes are reopened one month after original issuance and reopened a second time two months after original issuance. Thus, reopenings of 10-year notes are in January, March, April, June, July, September, October, and December. Treasury bonds with original maturities of 20 and 30 years are reopened one month after original issuance and are reopened a second time two months after original issuance. Thus, reopenings of 20- and 30-year Treasury bonds are in January, March, April, June, July, September, October, and December.

We use Treasury reopenings as an instrument for increases in supply of specific Treasury securities. To illustrate that the exclusion restriction is likely satisfied for Treasury reopenings, consider the case of Treasury bonds. Clearly, the auction schedule of 20-year and 30-year bonds is known ahead of time and the two reopenings after the initial issuance are fully-anticipated exogenous events unrelated to the richness of the bond. The same line of reasoning holds for Treasury bills and notes. Thus, increases in the supply of Treasury securities via reopenings provide us with a valid instrument with which we can directly test whether changes in Treasury richness are related to exogenous changes in the supply of debt at a more fundamental causal level.

\section{A.5 The 397-Day Money Market Fund Inclusion Criterion}

Money market funds (MMFs) are subject to requirements on the maturity of the

${ }^{27}$ The U.S. Treasury also auctions so-called cash management bills (CMBs) on an as-needed basis basis to meet temporary financing needs. CMBs have original maturities ranging from a single day to several months and may be new securities or reopenings of previously issued bills (Fleming (2002)).

${ }^{28}$ The U.S. Treasury publishes a list of upcoming auctions at https://www.treasu rydirect.gov/instit/instit.htm?upcoming. 
assets in their investment portfolios. Specifically, SEC Rule 2a-7(c)(2) requires that MMFs not acquire any security with a remaining maturity greater than 397 days, that the dollar-weighted average maturity of the securities owned by the MMF may not exceed 60 days, and that the MMF's dollar-weighted average life to maturity may not exceed 120 days.

In response to disruptions in the money markets during the 2008 financial crisis when the Reserve Primary Fund "broke the buck," the SEC announced amendments to Rule 2a-7 of the Investment Company Act of 1940 on July 12, 2014 which were set to take effect on October 14, 2016 after a two-year transition period. ${ }^{29}$ The money market fund reform essentially created two broad classes of MMFs - government and non-government funds. One important dimension in which these two types differ is their price stability. Government funds are stable value investments because they trade at a constant one dollar net asset value (NAV) per share, but they are required to invest at least 99.50 percent of their total assets in cash and U.S. government securities. By contrast, non-government funds are subject to floating NAV requirements, gating restrictions and liquidity fees, but they can invest in non-government securities such as commercial paper. ${ }^{30}$ As a result, investors in non-government MMFs might not be able redeem their shares at a moment's notice. ${ }^{31}$ Many investors also face institutional constraints that prevent them from holding shares in non-government MMFs. ${ }^{32}$ The

${ }^{29}$ Money Market Fund Reform; Amendments to Form PF: Final Rule, Securities and Exchange Commission, 79 Fed. Reg at 47,736 (14 August 2014), Section III.N.

${ }^{30}$ Non-government MMFs are no longer allowed to report a stable $\$ 1.00$ per share NAV, but are now required to sell and redeem shares based on the current markto-market value of the securities in their underlying portfolios. As a result, the NAV can fluctuate, or float.

${ }^{31}$ For example, the SEC recognizes that since it may take several hours to strike a market-based NAV price, floating NAV MMFs may no longer be able to offer trading times for same day settlement late in the day, i.e., after 4 p.m. (see Money Market Fund Reform; Amendments to Form PF, Investment Company Act Release No. 31166 (July 23, 2014), pp. 192-193).

${ }^{32}$ As one example, public agencies may be required by their investment policy to only hold MMFs that maintain a stable $\$ 1.00$ NAV per share. "... If the policy authorizes an investment in mutual funds, it shall indicate whether the authorization is limited to securities whose intention is to maintain a net asset value of $\$ 1.00$ per share or also includes securities whose net asset value per share may fluctuate on a periodic basis" (Michigan Department of Treasury, Public Act 196 of 1997, Amendments to Public Act 20 of 1943, Basic Investment Policy, March 1998). 
MMF Reform also introduced new requirements for daily and weekly liquid assets and concentration limits on portfolio holdings. ${ }^{33}$ In response to the MMF Reform, investors withdrew over $\$ 404$ billion in assets from non-government MMFs, and moved $\$ 432.8$ billion into government MMFs between October 2015 and May $2016 .^{34}$

Since MMFs designated as government funds are required to invest at least 99.50 percent of their total assets in cash and U.S. government securities, we use the threshold of 397 days when a Treasury becomes eligible to be held by government MMFs as a vehicle to test whether Treasury richness/cheapness is related to exogenous changes of the elasticity of substitution of Treasury securities. ${ }^{35}$ The reason for this is that Treasury securities that are eligible for inclusion in a MMF should have higher elasticities of substitution with respect to money than ineligible Treasury securities, consistent with the model in Nagel (2016). Since crossing the 397-day-to-maturity threshold is a purely mechanical event for inclusion in a MMF portfolio, it allows us to identify an exogenous change in the elasticity of substitution for individual Treasury securities.

\section{A.6 Tax Effects and Roth IRA Conversions}

Individual Retirement Accounts (IRAs) and Roth IRAs are designed to provide retirement income on a tax-advantaged basis. ${ }^{36}$ The IRA was first introduced by Congress in the 1974 Employee Retirement Income Security Act (ERISA) legislation. ${ }^{37}$ The Tax Reform Act of 1986 introduced income limitations restricting higher-income households from participating in tax-deductible IRAs which were subsequently eased by the Taxpayer Relief Act of 1997. The Taxpayer Relief Act of 1997 also introduced so-called Roth IRA accounts on January 1, 1998. ${ }^{38}$

${ }^{33}$ See Fleckenstein and Longstaff (2020b) for details on MMF stress testing and disclosure requirements.

${ }^{34}$ Crane Data, Money Market Funds News, 08/02/2016, www.cranedata.com.

${ }^{35}$ A government security is defined as a security backed by the full faith and credit of the U.S. government (Rule 2a-7(a)(17); section 2(a)(16)).

${ }^{36}$ The U.S. Internal Revenue Service (IRS) provides detailed information on retirement savings options at https://www.irs.gov/retirement-plans.

${ }^{37}$ See Employee Retirement Income Security Act of 1974, Pub. L. No. 93-406, 88 Stat. 829, 958-66.

${ }^{38}$ See Taxpayer Relief Act, P.L. 105-34, 302(a). The Roth IRA is named for Senator Roth who introduced it (Congressional Record Vol. 143, No. 111, July 31, 1997). 
Traditional IRA and Roth IRA accounts differ in important ways. Amounts deposited into a traditional IRA are typically on a pre-tax basis, and accumulated interest, dividends, and capital gains are tax-deferred until withdrawn and then taxed as ordinary income. IRA participants can take distributions at any time. However, these distributions then become taxable income and are typically subject to a $10 \%$ additional tax if the plan participant is under the age of 59.5 years. ${ }^{39}$ Moreover, participants in traditional IRAs are required to start taking distributions by April $1^{\text {st }}$ following the year in which they turn $72 .{ }^{40}$ These mandatory distributions are specified by the Internal Revenue Service's Required Minimum Distribution (RMD). ${ }^{41}$ By contrast, amounts deposited in a Roth IRA are on an after-tax basis, and investment gains are tax-free upon withdrawal if certain requirements are met (so-called qualified distributions). ${ }^{42}$ Furthermore, Roth IRAs are not subject to RMD requirements, and participants can make contributions to Roth IRAs after reaching age 70.5 and leave amounts in Roth IRAs as long as they live. ${ }^{43}$ In 2006 , legislation was passed that extended the concept of Roth IRA savings to employer-provided retirement plans, such as the Roth 401(k) or 403(b).

The main difference between traditional and Roth IRAs is the timing of the tax benefit to the plan participants. In a traditional IRA, the individual receives the benefit up-front with a tax deduction for the contribution, accumulates income tax-free, and pays taxes on the distributions when taken at retirement. By contrast, in a Roth IRA, the individual does not receive a tax deduction when the contribution is made, but still accumulates tax-free income, and does not pay taxes when distributions are taken. In addition, Roth IRAs allow participants to

${ }^{39}$ Contributions can also be withdrawn without restrictions and penalty fee for higher education expenses, disability, qualified medical expenses, death, and qualified payments of health insurance premiums.

${ }^{40}$ Prior to January 1, 2020, required distribution started after reaching 70.5 years of age.

${ }^{41}$ The RMD is designed to distribute the IRA evenly over retirement and enable the IRS to collect taxes on those distributions. The RMD is recomputed annually as a function of the IRA balance on December 31 and the estimate of the life expectancy of the retiree made by the IRS.

${ }^{42} \mathrm{~A}$ qualified distribution is any payment or distribution from a Roth IRA that is made after the 5-year period beginning with the first tax year after the first Roth IRA contribution, and the participant has reached age 59.5, or an exception such as disability, death, or a first-time home purchase applies.

${ }^{43}$ Prior to January 1, 2020, participants were unable to contribute to traditional IRAs after reaching age 70.5. 
withdraw distributions without incurring fees and penalty charges if it is a qualified distribution. Another difference is that participants can generally shift from a traditional IRA to a Roth IRA. The shifted amounts are included in taxable income ratably over 4 years (assuming they would be taxed if they were normal distributions), and the $10 \%$ penalty tax on early withdrawals will not apply. Prior to 2010, this conversion feature was subject to a $\$ 100,000$ income ceiling. However, in 2010, income limitations on Roth IRA conversions were removed. ${ }^{44}$

Under what conditions might a retirement plan participant prefer a traditional IRA relative to a Roth IRA or vice versa? Basically, a traditional IRA accumulates greater wealth if the tax rate applied to contributions is higher than the withdrawal tax rate. By contrast, the Roth IRA is relatively more attractive if the contribution tax rate is lower than the withdrawal tax rate. Thus, when participants expect tax rates to increase in the future, then converting a traditional IRA into a Roth IRA becomes attractive since contributions are taxed at current tax rates, whereas in a traditional IRA, withdrawals would be subject to higher future tax rates. Thus, when participants expect tax rates to increase in the future, they have incentives to convert a traditional IRA into a Roth IRA. Hence, the number of conversions from traditional IRAs to Roth IRAs can be viewed as a exogenous measure of the perceived risk of higher tax rates in the future.

In addition, since the semiannual coupon interest on Treasury notes and bonds is exempt from state and local income taxes, but not from federal income taxes, an investor expecting future tax rates to increase might prefer to convert a portfolio of Treasury notes/bonds from a traditional IRA to a Roth IRA. ${ }^{45}$ This is because earned coupon interest would be taxed at current tax rates, whereas in a traditional IRA, coupon interest would be subject to higher future tax rates upon withdrawal. All things being equal, the incentive to convert a traditional IRA to a Roth IRA should be stronger the higher the coupon rate on a Treasury security. Thus, we use an interaction term between coupon rates and the annual percentage changes in the number of Roth IRA conversions as the primary explanatory variable in the empirical analysis in Section 8.2 of the paper.

We collect data on Roth IRA conversions from the webpage of the U.S.

\footnotetext{
${ }^{44}$ See Internal Revenue Service, Publication 590, Cat. No. 15160X, February 3, 2011.

${ }^{45}$ If interest on a Treasury note or bond is scheduled to be paid on December 31 and that date falls on a non-business day, the Treasury reports the income as earned on the first federal banking day of the following year (https://www.treasu rydirect.gov/indiv/research/indepth/tnotes/res_tnote_tax.htm).
} 
Internal Revenue Service. Specifically, we collect the annual percentage changes in the number of Roth IRA conversions for all years starting in 2001 through yearend 2018 from the IRS's Accumulation and Distribution of Individual Retirement Arrangements reports. ${ }^{46}$ Since the removal of the income limit on Roth IRA conversions in 2010 could affect Roth IRA conversions for reasons unrelated to future tax rates, we exclude the annual percentage changes for the years 2010 and 2011 from the analysis.

\section{A.7 Maturity-Related Investment Policies of Treasury Mutual Funds}

Bond mutual funds face implicit and explicit requirements on the maturities of the securities that they can hold in their portfolios. ${ }^{47}$ First, regulations by the SEC impose explicit restrictions on the investment portfolios of bond mutual funds. Specifically, Rule 35-d (17 CFR 270.35d-1) under the Investment Company Act of 1940 (15 U.S.C. 80a-1 et seq.), requires bond funds that include the words "short-term," "intermediate-term," or "long-term" in their names to have a dollar-weighted average maturity of, respectively, no more than 3 years, more than 3 years but less than 10 years, or more than 10 years. In addition, the name and maturity requirements jointly imply that bond funds face the implicit requirement to match the average maturity and duration of their respective benchmark indices. ${ }^{48}$

Second, bond funds disclose in their prospectuses targets for the average maturity of their investment portfolios, as well as lower and upper bounds for maturity ranges of the securities they hold in their portfolios. We manually collect data from the Bloomberg system and from prospectuses of bond mutual funds about the range of maturities that their investment policies allow them to hold in their portfolios. We identify the set of active closed-end and open-end mutual funds in the U.S. that are designated short-term, intermediate-term, and long-term U.S. government bond funds and filtering out funds that are not U.S. Treasury-only funds. For these remaining funds, we obtain their fund prospectuses and search for information related to the maturity of their investments. If

${ }^{46}$ Data are available at https://www.irs.gov/statistics/soi-tax-stats-accumulati on-and-distribution-of-individual-retirement-arrangements.

${ }^{47}$ Bond funds have become increasingly important players in the U.S. government bond market. The total net asset value held by mutual funds has grown from roughly $\$ 100$ billion at year-end 1999 to $\$ 1.28$ trillion at year-end 2020 (see Z.1 Financial Accounts of the United States).

${ }^{48}$ DeCosta, Leng, and Noronha (2013) find that bond funds actively buy and sell bonds in their portfolios as a result of the implicit maturity rules of their benchmark indices. 
the prospectus does not contain specific maturity-related information, we identify the benchmark index that the fund tracks and use the minimum and the maximum maturity of the fund's benchmark index, respectively.

Table A3 summarizes this data. As shown, the eligible range of maturities is almost always expressed in terms of an integer number of years. For example, the Vanguard Short-Term Treasury Index Fund has a maturity range of 1-3 years, the T. Rowe Price U.S. Treasury Intermediate Index Fund has a maturity range of 4-10 years, and the Fidelity Long-Term Treasury Bond Index Fund has a maturity range of 10-30 years. Typical maturity ranges for short-term bond funds are 1-3 years or 1-5 years. Common maturity ranges for intermediate-term bond funds include 3-5 years, 3-7 years, 5-7 years, 5-10 years, and 7-10 years. 


\section{ONLINE APPENDIX REFERENCES}

Aitken, James, and Manmohan Singh, 2010, The (Sizable) Role of Rehypothecation in the Shadow Banking System, IMF Working Paper No. 10/172.

Bliss, Robert R. and Ehud I. Ronn, 1998, Callable U.S. Treasury Bonds: Optimal Calls, Anomalies, and Implied Volatilities, The Journal of Business 71(2), 211252.

Baklanova, Viktoria, Adam M. Copeland, and Rebecca McCaughrin, 2015, Reference Guide to U.S. Repo and Securities Lending Markets, Office of Financial Research Working Paper No. 15-17.

Baklanova, Viktoria, Cecilia Caglio, Marco Cipriani, and Adam Copeland, 2016, The U.S. Bilateral Repo Market: Lessons from a New Survey, Office of Financial Research Brief Series No. 16-01.

Beumee, Johan, Damiano Brigo, Daniel Schiemert, and Gareth Stoyle, 2009, Charting a Course Through the CDS Big Bang, Fitch Solutions Quantitative Research Global Special Report.

Bowman, David, SOFR Explained, Presentation at the Alternative Reference Rates Committee (AARC) Summer Series, New York, NY, July 13, 2020, Accessed December 6, 2020, available at https://newyorkfed.org/medialibrary/ Microsites/arrc/files/2020/ARRC_SOFR_Summer_Series_Event_SOFR_Explain ed.pdf

Brigo, Damiano and Fabio Mercurio, 2006, Interest Rate Models: Theory and Practice, 2nd ed., Springer, New York, NY.

Cheng, Michael, Sonam Leki Dorji, and Carl Lantz, 2010, A Guide to the FrontEnd and Basis Swap Markets, Basis points, Credit Suisse Fixed Income Research.

CME Group, 2018, OTC SOFR Swaps Clearing Q4 2018, Accessed December 6, 2020, available at https://www.cmegroup.com/education/files/otc-sofr-swapsproduct-overview-10-18.pdf.

Copeland, Adam, Darrell Duffie, Antoine Martin, and Susan McLaughlin, 2012, Key Mechanics of the U.S. Tri-Party Repo Market, FRBNY Economic Policy Review November, 17-28.

DeCosta, Darrin, Fei Leng, and Gregory Noronha, 2013, Minimum Maturity Rules: The Cost of Selling Bonds before Their Time, Financial Analysts Journal $69(3), 45-56$. 
Du, Wenxin, Joanne Im, and Jesse Schreger, 2018, The U.S. Treasury Premium, Journal of International Economics 112, 167-181.

Fleckenstein, Matthias, and Francis A. Longstaff, 2020a, Renting Balance Sheet Space: Intermediary Balance Sheet Rental Costs and the Valuation of Derivatives, Review of Financial Studies 33, 5051-5091.

Fleckenstein, Matthias and Francis A. Longstaff, 2020b, The Treasury Floating Rate Note Puzzle: Is there a premium for mark-to-market stability?, Journal of Financial Economics, 137(3), 637-658.

Fleming, Michael J., 2002, Are Larger Treasury Issues More Liquid? Evidence from Bill Reopenings, Journal of Money, Credit, and Banking 34(3), 707-35.

Gorton, Gary, and Andrew Metrick, 2012, Securitized Banking and the Run on Repo, Journal of Financial Economics 104, 425-451.

Hull, John C., and Alan White, 2000, Valuing Credit Default Swaps I: No Counterparty Default Risk, Journal of Derivatives 8, 29-40.

Krishnamurthy, Arvind, Stefan Nagel, and Dmitri Orlov, 2014, Sizing Up Repo, Journal of Finance 69, 2381-2417.

Nagel, Stefan, 2016, The Liquidity Premium of Near-Money Assets, Quarterly Journal of Economics 131, 1927-1971.

LCH Group, 2010. LCH.Clearnet adopts OIS discounting for $\$ 218$ trillion IRS portfolio, Press Release, June 17, 2010, available at: http://195.246.229.12 /Images/2010_06_17\%20LCH.Clearnet\%20adopts\%20OIS\%20discounting\%20for $\% 20 \$ 218 \% 20$ IRS\%20portfoilio_tcm6-54555.pdf).

O'Kane, Dominic, 2008, Modelling Single-name and Multi-name Credit Derivatives, John Wiley \& Sons, Hoboken, NJ.

O'Kane, Dominic and Stuart Turnbull, 2003, Valuation of Credit Default Swaps, Lehman Brothers, Fixed Income Quantitative Credit Research, April 2003.

Longstaff, Francis A., Sanjay Mithal, and Eric Neis, 2005, Corporate Yield Spreads: Default Risk or Liquidity? New Evidence from the Credit Default Swap Market, Journal of Finance 60, 2213-2253.

Srinivasan, Sayee, Steven J. Dayon, Philip Whitehurst, Richard Chambers, and Ann Battle, Preparing to move from LIBOR Derivatives, Presentation at the Alternative Reference Rates Committee (AARC) Summer Series, New York, N.Y., July 15, 2020, Accessed December 6, 2020, available at https://www.newyorkfed. org/medialibrary/Microsites/arrc/files/2020/Preparing-to-Move-From-LIBOR- 
Derivatives.pdf

Ranasinghe, Dhara, 2020, Unilever, JP Morgan entered into $\$ 500$ million corporate swap linked to new SOFR benchmark, Reuters.com, October 13, 2020. Accessed December 6, 2020, available at https://www.reuters.com/article/us-jpmorgan-libor/unilever-jp-morgan-entered-into-500-million-corporate-swap-lin ked-to-new-sofr-benchmark-idUSKBN26Y2DD

Schönbucher, Philipp J., 2003, Credit Derivatives Pricing Models: Models, Pricing and Implementation, John Wiley \& Sons, Hoboken, NJ.

Tabb, Rebecca and Joseph Grundfest, 2013, Alternatives to Libor, Capital Markets Law Journal 8(3), 229-260.

Whitley, Martin, 2012, The Whitley Review of LIBOR Final Report, Financial Conduct Authority (FCA), available at: https://assets.publishing.service.gov.uk /government/uploads/system/uploads/attachment_data/file/191762/wheatley_r eview_libor_finalreport_280912.pdf 


\section{Table A1}

Data Definitions and Sources. This table summarizes the datasets used in this study. Frequency shows at what intervals the data are available Description and Source show the data source and its definition. All data are for the period from January 1997 to October 2020 unless indicated otherwise.

Data

Frequency

Description and Source

$1 \quad$ Treasury Note and Bond Prices

Fed Funds Rate

Daily

LIBOR Rates

Daily

Daily

Daily

SOFR Interest Rate Swaps
U.S. Treasury note and bond end-of-day closing mid, bid, and ask prices, coupon rates, issue and maturity dates from the Bloomberg system and the U.S. Treasury auction tables. Data consist of Treasury notes with $2,3,5,7$, and 10 years to maturity and Treasury bonds with 20 and 30 years to maturity for all individual Treasury note/bond CUSIPs with maturity dates between January 1, 1997 and October 30, 2020.

U.S. Treasury bill end-of-day mid, bid, and ask prices, and issue and maturity dates from the Bloomberg system and the U.S. Treasury auction tables. Data consist of Treasury bills with tenors of $4,13,26$, and 52 weeks to maturity for all individual Treasury CUSIPs with maturity dates between January 1, 1997 and Octo

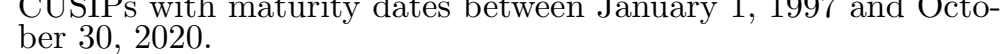

Treasury note, bond, and Treasury bill auction results from the website of the U.S. Treasury at https://www.treasurydirect.gov /instit/annceresult/press/press.htm for all individual Treasury CUSIPs with maturity dates between January 1, 1997 and October 30,2020. For Treasury notes and bonds, data are the coupon rate, the auction high yield, and the auction price, and for 4-, 1326- and 52-week Treasury bills the auction data are high yield and the auction price. In addition, the auction results include prices and accrued interest at auction, auction announcement and auction dates, dated dates, issue dates, and maturity dates, amounts bid by competitive and non-competitive bidders, amounts issued, and bid-to-cover ratios, and reopening dates and amounts.

End-of-day credit default swap mid spreads for 6-month, 1-year, 2-year, 3-year, 5-year, 7-year, 10-year, 15-year, 20-year and 30year contracts written on U.S. Treasury debt for the period from December 1, 2003 to October 30, 2020. Data from Markit.

End-of-day overnight general-collateral (GC) repo rate from the Bloomberg system.

End-of-day effective federal funds rate from the Bloomberg system.

End-of-day LIBOR rates for tenors of $1,3,6$, and 12 months from the Bloomberg system.

SOFR interest rate swap rates for tenors of $1,3,6,9,12$ months, and $1,2,3,5,7,10,15,20$, and 30 years for the period from January 1, 2017 to October 30, 2020. SOFR swaps exchange fixed for floating SOFR cash flows based on the daily compounded SOFR rate annually for maturities over one year and have a single cash flow at maturity for tenors up to one year. Data from the Bloomberg system. 


\section{Table A1 - Continued}

Data

$9 \quad$ OIS Interest Rate Swaps

Small Time Deposits

Description and Source

Daily

Daily

Daily

Monthly

Monthly

Monthly

Monthly

Quarterly

Monthly

Monthly
Overnight Index Swap (OIS) rates for tenors of 1, 3, 6, 9, 12 months, and $1,2,3,5,7,10,15,20,30$ years for the period from February 13, 2002 to October 30, 2020. OIS swaps exchange fixed for floating cash flows based on the daily compounded overnight Fed funds rate annually for maturities over one year, and have a single cash flow at maturity for tenors up to one year. Data from single cash flow at mat
the Bloomberg system.

End-of-day federal funds/LIBOR basis swap rates for tenors of $3,6,9,12$ months, and 2, 3, 5, 7, 10, 15, 20, 30 years from the Bloomberg system for the period from January 1, 1997 to July 31, 2008. Fed funds/LIBOR swaps exchange quarterly floating cash flows for the tenor of the basis swap based on the daily compounded effective overnight federal funds rate over the quarter plus a spread for floating cash flows based on the three month LIBOR rate set at the beginning of the quarter.

End-of-day LIBOR interest rate swap rates for tenors of 3, 6, 9, 12 months, and $2,3,5,7,10,15,20,30$ years from the Bloombers system for the period from January 1, 1997 to July 31,2008. system for the period from January 1, 1997 to July 31, 2008. LIBOR interest rate swaps exchange quarterly floating cash flows for the tenor of the interest rate swap based on the three month LIBOR rate set at the beginning of the quarter for fixed semiannual cash flows

Total Treasury bills outstanding from the Monthly Statement of the Public Debt (MSPD) by the U.S. Treasury available at https://fiscaldata.treasury.gov.

Total Treasury notes and bonds outstanding from the Monthly Statement of the Public Debt (MSPD) by the U.S. Treasury available at https://fiscaldata.treasury.gov.

Total holdings of Treasury bills by Foreigners from the Major Foreign Holders of U.S. Treasury Securities (MFH) table in the Treasury International Capital (TIC) System at https://home.treasury .gov/data/treasury-international-capital-tic-system.

Total holdings of Treasury notes and bonds by Foreigners from the Major Foreign Holders of U.S. Treasury Securities (MFH) table in the Treasury International Capital (TIC) System at https://home. treasury.gov/data/treasury-international-capital-tic-system.

The U.S. gross domestic product (GDP) reported by Bureau of Economic Analysis, retrieved from FRED, Federal Reserve Bank of St. Louis.

Total Demand Deposits from Table H.6 (Money Stock Measures) reported by the Board of Governors of the Federal Reserve System. Data retrieved from FRED, Federal Reserve Bank of St. Louis.

Total Small Time Deposits from Table H.6 (Money Stock Measures) reported by the Board of Governors of the Federal Reserve System. Data from the Federal Reserve Bank of St. Louis. 


\section{Table A1 - Continued}

Data
Agency MMF Total Net Assets

Prime MMF Total Net Assets

Inflation Mutual Funds Total Net Assets

Short-Term Mutual Funds Total Net Assets

Intermediate Mutual Funds Total Net Assets

Monthly

Monthly

State Municipal Mutual Funds Total Net Assets Monthly
Description and Source

Total Savings Deposits from Table H.6 (Money Stock Measures) reported by the Board of Governors of the Federal Reserve System. Data retrieved from FRED, Federal Reserve Bank of St. Louis.

The Retail Money Funds component of M2 from Table H.6 (Money Stock Measures) reported by the Board of Governors of the Federal Reserve System. Data retrieved from FRED, Federal Reserve Bank of St. Louis.

Monthly End-of-month total net assets of money market funds investing in U.S. government securities reported by the Investment Company Institute (ICI). Data retrieved from the Bloomberg system.

End-of-month total net assets of money market funds investing in U.S. government and federal agency securities reported by the Investment Company Institute (ICI). Data retrieved from the Bloomberg system.

Monthly End-of-month total net assets of prime money market funds investing reported by the Investment Company Institute (ICI). Fund classifications are available at http://www.ici.org/iob_update. Data retrieved from the Bloomberg system.

Monthly End-of-month total net assets of Inflation Protected funds reported by ICI. Data retrieved from the Bloomberg system.

End-of-month total net assets of Short-term Government Bond funds reported by ICI. Short-term bond funds invest a minimum of $80 \%$ of their portfolios in short-term U.S. government securities and maintain a portfolio duration of between 1.5 and 3.5 years. Data retrieved from the Bloomberg system.

End-of-month total net assets of Intermediate-term Government Bond funds reported by ICI. Intermediate bond funds invest a minimum of $80 \%$ of their portfolios in U.S. Treasury notes and maintain a portfolio duration of between 3.5 and 6 years. Data retrieved from the Bloomberg system.

End-of-month total net assets of Longterm Government Bond funds reported by ICI. Longterm bond funds invest a minimum of $80 \%$ in longterm U.S. government bonds and maintain a portfolio duration of more than 6 years. Data from the Bloomberg system. End-of-month total net assets of state municipal bond funds reported by ICI. State Municipal bond funds invest a minimum of $80 \%$ in bonds issued by state and local governments and maintain a portfolio duration of more than 7 years (or average maturities of more than 12 years). The income from such bonds is generally free from federal taxes and from state taxes in the issuing state. Data retrieved from the Bloomberg system. 


\section{Table A1 - Continued}

Data Total Net Assets

\section{Gold Return}

Commodity Return

Housing Return

TIPS Return

\section{S\&P500 Return}

Sentiment

Unemployment

NFCI

ST Inflation

LT Inflation

Tax Rate
Monthly
Monthly

Monthly

Monthly

Monthly

Monthly

Monthly

Monthly

Monthly

Monthly

Monthly

Monthly

Monthly

Monthly
End-of-month total net assets of national municipal bond funds reported by ICI. National Municipal bond funds invest a minimum of $80 \%$ in bonds issued by state and local governments and maintain a portfolio duration of more than 7 years (or average maturities of more than 12 years). The income from these bonds is generally free from federal taxes. Data retrieved from the Bloomberg system.

The monthly return on gold calculated as the monthly percentage price change of the gold spot price in USD. Data retrieved from the Bloomberg system.

The monthly arithmetic return of the Bloomberg Commodity Index (BCOM Index). Data retrieved from the Bloomberg system. The monthly percent change of the S\&P CoreLogic Case-Shiller U.S. National Home Price Index. Data retrieved from the Bloomberg system.

The monthly return of the Bloomberg Barclays U.S. Government Inflation-Linked Total Return Index (all maturities). Data retrieved from the Bloomberg system.

The monthly return on the S\&P 500 index. Data retrieved from the Bloomberg system.

The University of Michigan Consumer Sentiment Index. Data retrieved from the Bloomberg system.

The U.S. unemployment rate from the U.S. Bureau of Labor Statistics. Data retrieved from the Bloomberg system.

The Chicago Fed (adjusted) National Financial Conditions Index from the Federal Reserve Bank of Chicago. Data retrieved from the Bloomberg system.

The University of Michigan index of the average expected change in prices during the next year. Data retrieved from the Bloomberg system.

The University of Michigan index of the average expected change in prices over the next 5-10 years. Data retrieved from the Bloomberg system.

The implied tax rate is the inverse of the Municipal SIFMA Swap/ LIBOR Ratio. The index represents the tax rate implied by the current pricing of the SIFMA Swap rate and LIBOR Ratio. The index is equal to 1 minus the average of the quarterly weighted average of the weekly SIFMA resets divided by the 3-month LIBOR erage of the weekly SIFMA resets divided by the 3-month LIBOR
fixing from 2 business days prior to the beginning of the quarterly period. Data retrieved from the Bloomberg system.

The Baker, Bloom \& Davis U.S. Fiscal Policy Uncertainty Index. Data retrieved from the Bloomberg system.

The Baker, Bloom \& Davis U.S. Tax Policy Uncertainty Index. Data retrieved from the Bloomberg system. 


\section{Table A2}

Cash Flows from a Fixed-for-Floating Interest Rate Swap based on the Overnight Repo Rate. This table presents the cash flows from a fixed-for-floating interest rate swap in which the floating leg of the swap is based on the overnight repo rate, denoted by $r_{t}$. The interest rate swap has a tenor of $N$ years and annual cash flows at $t=1,2, \ldots, N-1, N$. The cash flows on the fixed leg of the interest rate swap are denoted by $F_{N}$, and the present value of a riskfree cash flow of one dollar to be received at time $t$ is denoted by $D(t)$.

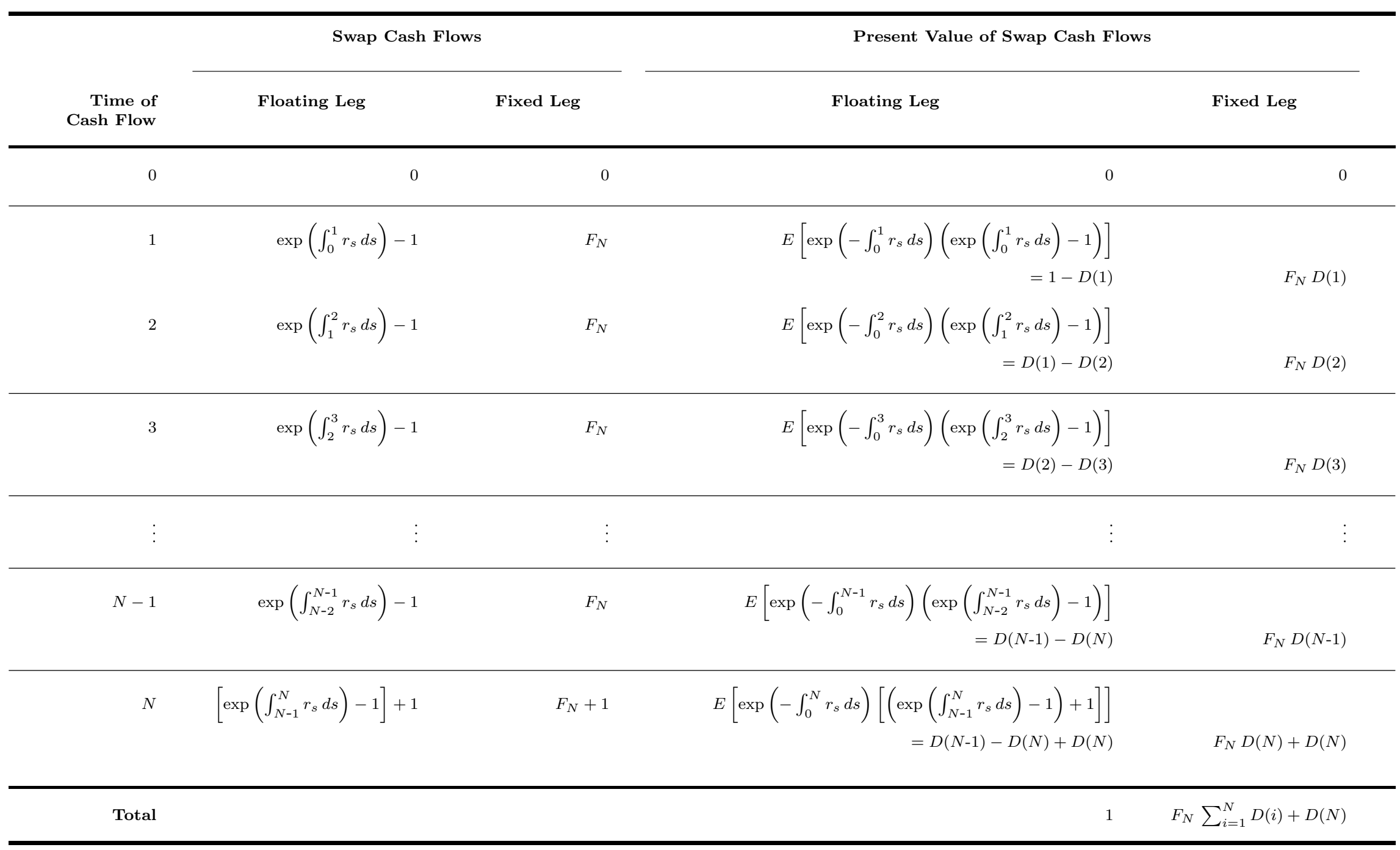




\section{Table A3}

This table shows open-end mutual bond funds listed in the U.S. that invest in short-term, intermediate-term, and long-term U.S. Government Securities. Panels A, B, and C show the fund maturity designations from SEC Rule 35-d (17 CFR 270.35d-1). The column Fund Name shows the name of the fund. The columns Min and Max show the minimum and the maximum maturities measured in years, respectively, of the securities that the fund invests in, as disclosed in the fund's prospectus. If not specified, the columns Min and Max show the minimum and the maximum maturity of the fund's benchmark index measured in years, respectively, as disclosed in the fund's prospectus. All data from the Bloomberg system and from fund prospectuses.

\section{Fund Name}

Min

\section{Panel A) Short-Term}

AB Short Duration Income Portfolio American Century Short-Term Government Fund

American Short Term Bond Fund of America

BNY Mellon Short-Term U.S. Government Securities Fund

Commerce Short-Term Government Fund

Davis Government Bond Fund

DFA One-Year Fixed Income Portfolio

DFA Short-Term Government Portfolio

DFA Two-Year Government Portfolio

Eaton Vance Short Duration Government Income Fund

Federated Hermes Short-Term Government Fund

Federated Hermes Ultrashort Bond Fund

Fidelity Limited Term Government Fund

Goldman Sachs Short Duration Government Fund

Goldman Sachs Short-Term Conservative Income Fund

Homestead Short-Term Government Securities Fund

Integrity Short Term Government Fund

John Hancock Trust Short Term Government Income

Permanent Short-Term Treasury Portfolio

Fidelity Short Term Treasury Bond Index Fund

SDIT Short Duration Government Fund

Transamerica High Quality Bond

TransWestern Institutional Short Duration Government Bond Fund

Vanguard Short-Term Federal Fund

Vanguard Short-Term Treasury Fund

Vanguard Short-Term Treasury Index Fund

Victory INCORE Fund for Income
$\operatorname{Max}$

5

3

3

3

5

3

3

5

3

1

3

1.5

5

3

1

3

3

3

3

5

3

3

5

5

3

5

Panel B) Intermediate-Term

BlackRock U.S. Government Bond Portfolio

City National Rochdale Government Bond Fund

DFA Intermediate Government Fixed Income Portfolio

Dupree Intermediate Government Bond Series

Federated Hermes Short-Intermediate Government Fund

Fidelity Government Income Fund

Fidelity Intermediate Government Income Fund

Fidelity Intermediate Treasury Bond Index Fund

Goldman Sachs Government Income Fund

JPMorgan Government Bond Fund

Manor Investment Funds Inc. - Bond Fund
10

10

10

10

5

10

10

10

10 
Table A3 - continued

\section{Panel B) Intermediate-Term}

Direxion Monthly 7-10 Year Treasury Bull 2X Fund

Northern Short-Intermediate U.S. Government Fund

Northern U.S. Government Fund

Northern U.S. Treasury Index Fund

Rydex Series Funds - Government Long Bond 1.2x Strategy Fund

Sit US Government Securities Fund

Sterling Capital Intermediate U.S. Government Fund

T. Rowe Price U.S. Treasury Intermediate Index Fund

The Payden Rygel Investment Group U.S. Government Fund

Thornburg Limited Term U.S. Government Fund

Thrivent Government Bond Fund

Vanguard Intermediate-Term Treasury Fund

Vanguard Intermediate-Term Treasury Index Fund

10
10
10
10
10
10
10
10
5
10
10
10
10

\section{Panel C) Long-Term}

Direxion Monthly 25+ Year Treasury Bear 1.35X Fund 25

Direxion Monthly 25+ Year Treasury Bull 1.35X Fund 25

DoubleLine Long Duration Total Return Bond Fund

Fidelity Long-Term Treasury Bond Index Fund

Fidelity SAI Long-Term Treasury Bond Index Fund

MassMutual Select T. Rowe Price U.S. Treasury Long-Term Fund

PIMCO Long-Term U.S. Government Fund

Profunds Rising Rates Opportunity ProFund

Profunds U.S. Government Plus ProFund

Rydex Series Funds - Inverse Government Long Bond Strategy Fund

T. Rowe Price U.S. Treasury Long-Term Index Fund

10 10 10 10 10 10 10 5 10 10 10 10

Vanguard Long-Term Treasury Index Fund 